University of Rhode Island

DigitalCommons@URI

Open Access Master's Theses

1987

\title{
Investigation of Dynamic Fracture Using Strain Gages and Photoelastic Coatings
}

Rakesh K. Agarwal

University of Rhode Island

Follow this and additional works at: https://digitalcommons.uri.edu/theses

\section{Recommended Citation}

Agarwal, Rakesh K., "Investigation of Dynamic Fracture Using Strain Gages and Photoelastic Coatings" (1987). Open Access Master's Theses. Paper 926.

https://digitalcommons.uri.edu/theses/926

This Thesis is brought to you for free and open access by DigitalCommons@URI. It has been accepted for inclusion in Open Access Master's Theses by an authorized administrator of DigitalCommons@URI. For more information, please contact digitalcommons-group@uri.edu. 


\section{IKVESTIGATION OF DYMAHIC FRACTURE USING STRAIN GAGES AND PHOTOELASTIC COATINGS}

BY

RARESH K. AGARWAL

A THESIS SUBMITTED IN PARTIAL FULFILLMENT OF THE REQUIREMENTS FOR THE DEGREE OF MASTER OF SCIENCE IX MECHANICAL ENGINEER ING 
MASTER OF SCIENCE THESIS

OF

RAKESH K. AGARWAL

APPROVED :

Thesis Committee

Major Professor

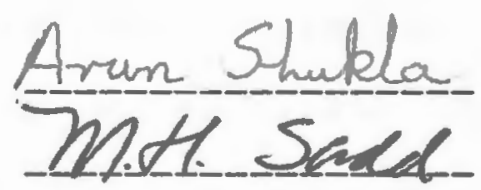

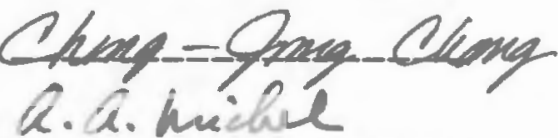

DEAN OF GRADUATE SCHOOL

UNIVERSITY OF RHODE ISLAND

1987 


\section{ABSTRACT}

This study is divided into two parts namely, the use of strain gages and photoelastic coatings to investigate dynamic fracture.

In the first part use of electrical resistance strain gages to determine instantaneous stress intensity factors for running crack is presented. Dynamic strain field equations are developed using the Westergaard's stress function approach. These equations are then analyzed to study the effect of various parameters like crack velocity, distance from the crack tip, etc. on the dynamic strain profile. Finally, a series of experiments was conducted with two different geometries on brittle birefringent polyester, Homalite 100 to determine dynamic stress intensity factors with strain gages. The $\mathbf{K}$-values thus determined were compared with similar results obtained from the method of photoelasticity in transmission mode.

In the second part of this thesis, mirror like reflective photoelastic coatings were used to study dynamic fracture in brittle structural metals. Dynamic fracture experiments are conducted on heat-treated 4340 steel and 7075-T6 Aluminum with face grooved SEN specimen geometry. The mirror like reflective coating used in conjunction with 
focused light is the key to obtaining clear isochromatic fringe patterns. Instantaneous stress intensity factors, $\mathbf{K}_{\mathrm{Id}}$, as a function of crack length are obtained independently from the method of photoelasticity and the method of strain gages and compared. 


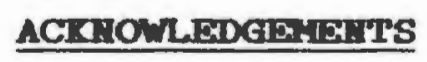

I would like to express my thanks and appreciation to Prof.A. Shukla for his guidance and encouragement throughout the course of this investigation. I would also like to thank Prof. M. H. Sadd for many valuable discussions over the past year.

I would like to thank Jimmy of the filtration lab. for assistance in building the experimental apparatus. I would also like to thank the members of the Machine Shop and The Instrument Shop for their assistance in the specimen preparation. The assistance of my colleagues H. Migam, V. Prakash and $X u Y i$ in carrying out the experiments, is also appreciated.

This research effort was funded by the National Science Foundation under Grant Ko. 532593. 


\section{ABSTRACT}

11

ACRHOWLEDGEMENTS

iii

1. O INTRODUCTION 1

2. 0 DYNAMIC CRACK-TIP STRESS FIELD AKALYSIS 3 Chapter-3 : USE OF STRAIN GAGES IN DYMAMIC FRACTURE 3. 1 DYMAHIC CRACK-TIP STRAIN FIELD REPRESENTATION

3. 2 EVALUATION OF CRACK TIP STRAIN FIELD EQUATIONS 15

3. 3 AVERAGING EFFECTS DUE TO FINITE SIZE OF 18 THE STRAIN GAGE

3. 4 VALIDITY OF THE NEAR FIELD ASSUMPTION 20

3. 5 EXPERIMENTAL PROCEDURE, RESULTS AND DISCUSSION 21

3. 6 SUMMARY

Chapter-4 : INVESTIGATION OF DYNAMIC FRACTURE USING PHOTOELASTIC COATINGS

4. 1 REVIEW OF RELATED RESEARCH

4. 2 AKALYSIS PROCEDURE

4. 3 EXPERIMENTAL PROCEDURE, RESULTS AND DISCUSSION

4. 4 SUMMARY

42

5. 0 CONCLUSION

44

FUTURE WORK

46

REFEREKCES

48

APPENDIX

52

BIBL IOGRAPHY

60 


\section{LIST OF FIGURES}

FIGURE

PAGE

$\begin{array}{ll}\text { FIG. 1. Coordinate System. } & 67\end{array}$

FId. 2 Relationship of the Radii of Complex 67

Variables of the Stress Function.

FIG. 3 Coordinate System $G_{X G Y G}$ and LXLYL for 68 strain gage analyses

FId. 4. Strain gage Orientation, $\alpha$, for which the 69 contribution of the first nonsingular term drops out, as a function of Poisson's ratio, $v$

FIG. 5. Theoretical strain, $\epsilon_{\mathrm{G}} \mathrm{T}$ as a function of 70 crack tip position, $x_{L}$, for various strain gage orientation, $\alpha$, at a distance of $6 \mathrm{~mm}$ from the crack propagation path.

Fig. 6. Theoretical strain, $\epsilon_{G}{ }^{T}$, as a function of 71 crack tip position, $x_{L}$, for various strain gage distance, $H$, above the crack propagation path.

Fig. 7. Theoretical strain, $\epsilon_{G}{ }^{T}$, as a function of 72 crack tip position, $x_{L}$, for various crack velocities.

Fi8. 8. Error in evaluating peak $s$ train, $\left(\epsilon_{G}\right)^{P}$, 73 at the strain gage grid center as a function of strain gage grid length, 1.

Fig. 9. Theoretical and experimental strain for 74 strain gage orientation, $\alpha=90$ and 120.6 . on Homalite 100 .

Fig. 10. Single Edge Kotch specimen geometry. 75

Fig. 11. Double Cantilever Beam specimen geometry. 76

Fig. 12. Schematic for the Strain aage circuit. $\quad 77$

Fig. 13. Typical strain profiles as a function of 78 time from four strain gages mounted on the SEN mode 1 . 
Fig. 14. Stress intensity factor, $K$ as a function of crack length to width ratio, a/w for SEN model at $4.21 \mathrm{kN}$.

Fig. 15. Stress intensity factor, $K$ as a function 80 of crack length to width ratio, a/w for SEN model at $6.88 \mathrm{kN}$.

Fig. 16. Stress intensity factor, $K$ as a function 81 of crack length to width ratio, a/w for the DCB model.

Fig. 17. SEN geometry with face grooves and 50 strain gages

Fig. 18 a Experimental and theoretical strain per pound load in vicinity of the face grooves as a function of the height of the strain gage above the crack line, $H$, for crack length to width ratio, $a / w=0.25$.

Fig. $18 \mathrm{~b}$ Experimental and theoretical strain per pound load in vicinity of the face grooves as a function of the height of the strain gage above the crack $l$ ine, $H$, for crack length to width $\operatorname{rat} 10, a / w=0.30$.

Fig. 18c Experimental and theoretical strain per 85 pound load in vicinity of the face grooves as a function of the height of the strain gage above the crack line, $H$, for crack length to width ratio, $a / w=0.325$.

Fig. 19. Theoretical strain for steel, $\epsilon_{G} S$, and for 86 aluminum, $\epsilon_{G} A$, as a function of crack tip position, $\mathbf{x}_{L}$.

Fig. 20. Photoelastic Coating on SEN 4340 steel 87 specimen.

Fig. 21. Photoelastic Coating on SER 7075-T6 88 aluminum specimen.

Fig. 22. Diagram showing optical arrangement and synchronization circuit.

Fig. 23. Diagram showing various stages of 1 ight 90 filtering to obtain isochromatic fringes.

F1g. 24. Isochromatic fringe loops obtained with the photoelastic coatings on 4340 steel specimen. 
Fif. 25. Isochromatic fringe loops obtained with the 92 photoelastic coatings on 7075-T6 aluminum specimen.

Fig. 26. Crack length, a/w, as a function of time, 93 $t$, for 4340 steel specimen.

Fig. 27. Stress intensity factor $\mathbf{K}_{1 d}$ as a function. 94 of crack length to width ratio, $a / w$ and time, $t$ for 4340 steel specimen.

Fig. 28. Crack length, $a / w$, as a function of time, $t$, for 7075-T6 aluminum specimen.

Fig. 29. Stress intensity factor $\mathrm{K}_{I d}$ as a function of crack length to width ratio, $a / w$ and time, $t$ for 7075-T6 aluminum specimen.

Fig. 30. Strain Gages on SEN 4340 steel specimen.

Fig. 31. Strain Gages on SEN 7075-T6 aluminum specimen.

Fig. 32. Typical strain profiles obtained from the strain gages mounted on the aluminum specimen. 


\section{LIST OF TABLES}

TABLE

PAGE

TABLE 1.

Orientation, $\alpha$, as a function of

64

Poisson's ratio, $v$.

TABLE 2

Properties of Homalite 100,4340

65

Steel and 7075-T6 Aluminum.

TABLE 3. Properties of Photoelastic Coating

66 (PS-1) 


\section{MOHIF:CLATURE}
a
crack length
$2, c$
crack velocity
$\alpha$
angle of orientation of a strain gage
B
thickness of the model
$\mathrm{B}_{\mathbf{N}}$
Net thickness at the face grooves
$c_{1}$
dilatational wave velocity
$c_{2}$
shear wave velocity
$\mathrm{C}_{\mathbf{r}}$
Rayleigh wave velocity
E
Young's modulus
$\epsilon$
strain
fo
stress fringe value
$f \epsilon$
strain fringe value
$f(a / w)$
back surface correction factor
F
face groove correction factor
$\lambda$
modulus associated with dilation
$\mathbf{K}, \mathrm{K}_{\text {Id }}$ instantaneous stress intensity factor
$K_{I s}$ stress intensity factor (static)
$p$ density of material
$\sigma_{X}, \sigma_{Y}, T_{X Y} \quad$ stress components
h thickness of the coating
H shear modulus
N fringe order
$v \quad$ Poisson's ratio
width of the specimen 
Chapter - 1

\section{IIMPRODUCTIOI}

Experimental studies of dynamic fracture are mostly performed using optical methods. Dally [1] and Kobayashi [2] have extensively used the method of photoelasticity. Theocaris [3], Kalthoff [4], Ravichander and Knauss [5], Rosakis [6] have employed the method of caustics in the studies of dynamic fracture. These techniques usually require an expensive and elaborate high speed photographic system to photograph the stress flelds associated with the running cracks. The method of photoelasticity cannot be used directly in the study of opaque materials though indirect use of photoelasticity can be made by applying photoelastic coatings[7]. The method of caustics can be used with opaque materials but it requires a highly polished reflecting surface on the model being studied. This quality of reflecting surface cannot be easily obtained with some opaque materials like ceramics and rocks. In this study, a new method of strain gages has been developed and its application demonstrated. The method uses electrical resistance strain gages to record the dynamic strain profile associated with running cracks. From this strain data, the fracture parameter $\mathbf{K}_{I d}$ is evaluated. 
The second part of this study photoelastic coatings have been used to investigate dynamic fracture in structural metals. Previously, Robayashi and Dally[7] have used photoelastic coatings on structural steel. They have used the coatings under diffused light and employed Cordin Model 330 simultaneous streak and framing recording device. However, the images are small and the fringe patterns recorded fringe patterns recorded are not of good quality. In the present study Cranz Schardin camera has been used in reflection mode under focused 1 ight. Due to use of focused light use of high speed recording device has been elminated. Static image film has been employed as shown in Fig. 22 to record the isochromatic fringe pattern associated with the dynamic fracture event.

Dynamic fracture in structural matals was also studied using method of strain gages. Series of experiments were performed using both the methods under similar condition. Instantaneous stress intensity factors were evaluated from both the techniques and compared. Results obtained from the two techniques show good agreement. 


\section{Chapter - 2}

\section{CRACX TIP STRESS FIELD ARALYSIS}

The objective of the derivation of the stress field equations is to understand the assumptions under which the stress field equations hold for proper interpretation of the results obtained using them.

\section{Derivation of the Dynamic Stress Field Equations}

The analysis shall make use of Irwin's crack tip stress function [8] and shall assume plane $\operatorname{strain}\left(\varepsilon_{z}=0\right)$. The leading edge of the crack will be taken as the positive $x$ axis and the crack tip as the origin of the coordinate system, as shown in Fig. 1.

For crack propagation in the $x$-direction and assuming that the stress field does not change with time with respect to the moving coordinate system, the following equations apply:

$$
\begin{aligned}
& \frac{\partial^{2} u}{\partial^{2} t}=c^{2} \frac{\partial^{2} u}{\partial x^{2}} \\
& \frac{\partial^{2} v}{\partial^{2} t}=c^{2 \frac{\partial^{2} v}{\partial x^{2}}}
\end{aligned}
$$

where $u$ and $v$ are the displacements in the $x$ and $y$ directions and $c$ the crack velocity.

Dynamic equilibrium conditions in the $x$ and $y$ directions 
lead to the following results:

$$
\begin{aligned}
& \frac{\partial \sigma_{X}}{\partial X}+\frac{\partial \tau_{X Y}}{\partial y}=\rho \frac{\partial^{2} u}{\partial t^{2}}=\rho C^{2} \frac{\partial^{2} u}{\partial x^{2}} \\
& \frac{\partial \tau_{X Y}}{\partial X}+\frac{\partial \sigma_{Y}}{\partial Y}=\rho \frac{\partial^{2} v}{\partial t^{2}}=\rho c^{2} \frac{\partial^{2} v}{\partial x^{2}}
\end{aligned}
$$

where $\sigma_{X}, \sigma_{Y}$ and $\tau_{X Y}$ are the stress components and $\rho$ the density of the body.

Using Hooke's law in the form

$$
\begin{aligned}
& \sigma_{X}=\lambda \Delta+2 \mu \epsilon_{X} \\
& \sigma_{Y}=\lambda \Delta+2 \mu \epsilon_{Y} \\
& \tau_{X Y}=\mu \gamma_{X Y}
\end{aligned}
$$

where $\mu$ is the shear modulus and $\lambda$ the Lame's constant.

We can rewrite the equations (2.3) and (2.4) in terms of dilatation $\Delta$ and rotation $\omega$, where
$\Delta=\frac{\partial u}{\partial x}+\frac{\partial v}{\partial y}$
$\omega=\frac{\partial v}{\partial x}-\frac{\partial u}{\partial Y}$

Equations (2.3) and (2.4) then take the following form,

$$
\begin{gathered}
(\lambda+2 \mu) \frac{\partial \Delta}{\partial x}-\mu \frac{\partial \omega}{\partial y}=\rho c^{2} \frac{\partial^{2} u}{\partial x^{2}} \\
\mu \frac{\partial \omega}{\partial x}+(\lambda+2 \mu) \frac{\partial \Delta}{\partial y}=\rho c^{2} \frac{\partial^{2} v}{\partial x^{2}}
\end{gathered}
$$

Noting that 


$$
\frac{\partial}{\partial x}\left(\frac{\partial^{2}}{\partial x^{2}}\right)^{2}+\frac{\partial}{\partial y}\left(\frac{\partial^{2}}{\partial x^{2}} Y=\frac{\partial^{2}}{\partial x^{2}} \Delta\right.
$$

and

$$
\frac{\partial}{\partial x}\left(\frac{\partial^{2} v}{\partial x^{2}}\right)+\frac{\partial}{\partial y}\left(\frac{\partial^{2} u}{\partial x^{2}}\right)=\frac{\partial^{2} \omega}{\partial x^{2}}
$$

we can derive the equations

$$
\begin{aligned}
& (\lambda+2 \mu) \nabla^{2}(\Delta)=\rho c^{2} \frac{\partial^{2} \Delta}{\partial x^{2}} \\
& \mu \nabla^{2} \omega=\rho c^{2} \frac{\partial^{2} \omega}{\partial x^{2}}
\end{aligned}
$$

Equations (2.14) and (2.15) can be simplified in appearance in the following ways. In equation (2.14), we substitute $Y_{1}=\lambda_{1} Y$ where

$$
\begin{aligned}
& \lambda_{1}{ }^{2}=1-\left(\frac{c}{c_{1}}\right)^{2}=1-\frac{\rho c^{2}}{\lambda+2 \mu} \\
& \lambda_{2}{ }^{2}=1-\left(\frac{c}{c_{2}}\right)^{2}=1-\frac{\rho c^{2}}{\mu}
\end{aligned}
$$

The resulting pair of equations is

$$
\begin{aligned}
& \frac{\partial^{2} \Delta}{\partial x^{2}}+\frac{\partial^{2} \Delta}{\partial y_{1}^{2}}=0 \\
& \frac{\partial^{2} \omega}{\partial x^{2}}+\frac{\partial^{2} \omega}{\partial y_{2}^{2}}=0
\end{aligned}
$$

Clearly $\Delta$ is a narmonic function of $x$ and $\lambda_{1} Y$ while $\omega$ is a harmonic function of $x$ and $\lambda_{2} Y$.

It can be shown there is no loss of generality for the 
proposed problem [9] if we assume

$$
\begin{aligned}
& \Delta=\left(1-\lambda_{1}^{2}\right) A \operatorname{Re} \Gamma_{1} \\
& \omega=\left(1-\lambda_{2}{ }^{2}\right) B \operatorname{Im} \Gamma 2
\end{aligned}
$$

where $\Gamma_{1}=f^{\prime}\left(z_{1}\right), \Gamma_{2}=f^{\prime}\left(z_{2}\right), z_{1}=x+i y_{1}$ and $z_{2}=x+i y_{2}$.

In addition it is helpful to recognize that the displacements can be divided into non rotational $\left(u_{1}, v_{1}\right)$ and nondilatational $\left(u_{2}, v_{2}\right)$ components. Thus $u=u_{1}+u_{2}, v$ $=v_{1}+v_{2}$ where

$$
\begin{array}{ll}
\Delta=\frac{\partial u_{1}}{\partial x}+\lambda_{1} \frac{\partial v_{1}}{\partial y_{1}}=\left(1-\lambda_{1} 2\right) A \operatorname{Re} \Gamma_{1} & --(2.22) \\
\frac{\partial v_{1}}{\partial x}-\lambda_{1} \frac{\partial u_{1}}{\partial y_{1}}=0 & --(2.23)
\end{array}
$$

Also

$$
\begin{aligned}
& \omega=\frac{\partial v_{2}}{\partial x}+\lambda_{2} \frac{\partial u_{2}}{\partial y_{2}}=\left(1-\lambda_{2}{ }^{2}\right) B \operatorname{Im} \Gamma_{2} \\
& \frac{\partial u_{2}}{\partial x}-\lambda_{2} \frac{\partial v_{2}}{\partial y_{2}}=0
\end{aligned}
$$

Comparing equations (2.22) and (2.23), we get

$$
\begin{aligned}
& u_{1}=A \operatorname{Re}\left[f\left(z_{1}\right)\right] \\
& v_{1}=-\lambda_{1} \text { A Im }\left[f\left(z_{1}\right)\right]
\end{aligned}
$$

Similarly from equations (2.24) and (2.25),

$$
\begin{aligned}
& u_{2}=-\lambda_{2} B \operatorname{Re}\left[f\left(z_{2}\right)\right] \\
& v_{2}=B \operatorname{Im}\left[f\left(z_{2}\right)\right]
\end{aligned}
$$

Since the shear stress on the crack faces is zero; $T_{X Y}=0$ 
on $y=0$ for $x<0$. Along this line $f^{\prime}\left(z_{1}\right)=f^{\prime}\left(z_{2}\right)=f^{\prime}(x)$. one finds that on $y=0$

$$
\frac{1}{\mu} \tau_{X Y}=y_{X Y}=\left[-2 \lambda_{1} A+\left(1+\lambda_{2}{ }^{2}\right) B\right] \operatorname{Im}\left[f^{\prime}(x)\right] \quad--(2.28)
$$

since $\operatorname{Im}\left[f^{\prime}(x)\right]$ on $Y=0$ is not zero along the entire $x$ axis, we must assume

$$
B=\frac{2 \lambda_{1}}{1+\lambda_{2}{ }^{2}} A
$$

In order to determine $A$, consider next that

$$
f^{\prime}(z)=\sum_{n}^{\infty} A_{n} z^{n-x}
$$

1.e. $\Gamma_{1}=\sum_{n=0}^{M} A_{n} z_{1}^{n-k} \quad \Gamma_{2}=\sum_{n=0}^{M} A_{n} z_{2}^{n-K}$

Since $\partial u / \partial x$ and $\partial v / \partial y$ are proportional to $\operatorname{Re}\left[f^{\prime}(x)\right]$ along $y=0$, equation (2.30) ensures $\sigma_{x}$ and $\sigma_{y}=0$ when $x$ is negative. When $x$ is positive, $\sigma_{y}$ is not zero.

The constant $A$ can be determined from the defining equation for the stress intensity factor, $K$. That is, for $x$ very small and positive and $y=0$

$$
\sigma_{y}=\frac{Z}{\sqrt{2 \pi x}}=\lambda \Delta+2 \mu \frac{\partial v}{\partial y}
$$

From previous expressions

$$
\begin{aligned}
& \lambda \Delta=\lambda\left(1-\lambda_{1}{ }^{2}\right) A A_{0} / \sqrt{x} \\
& 2 \mu \frac{\partial v_{1}}{\partial Y}=2 \mu \lambda_{1} \frac{\partial v_{1}}{\partial Y_{1}}=-2 \mu \lambda_{1}{ }^{2} A A_{0} / \sqrt{x} \\
& 2 \mu \frac{\partial v_{2}}{\partial Y}=2 \mu \lambda_{2} \frac{\partial v_{2}}{\partial Y_{2}}=-2 \mu \frac{2 \lambda_{1} \lambda_{2}}{1+\lambda_{2}{ }^{2}} A_{O} / \sqrt{x}
\end{aligned}
$$


When the above relation are inserted into equation (2. 30 ), it is convenient to replace $\lambda$ using the equation

$$
(\lambda+2 \mu)=\frac{\left(1-\lambda_{2}^{2}\right)}{\left(1-\lambda_{1}{ }^{2}\right)} \mu
$$

It is also convenient to assume $K=A_{0} \sqrt{2 \pi}$. This can be done because all of the constant coefficients in equation (2.30) must be adjusted to fit the boundary conditions.

$$
\text { Thus } A=\frac{1}{\mu} \frac{1}{\left[\frac{4 \lambda_{1} \lambda_{2}}{1+\lambda_{2}{ }^{2}}-\left(1+\lambda_{2}{ }^{2}\right)\right]}
$$

The expression for $\sigma_{X}, \sigma_{Y}$ and $\tau_{X Y}$ are derived as follows:

$$
\begin{aligned}
\sigma_{x} & =\lambda \Delta+2 \mu \frac{\partial u}{\partial x} \\
& \left.=\lambda\left(1-\lambda_{1}{ }^{2}\right) A \operatorname{Re} \Gamma_{1}+2 \mu\left(A \operatorname{Re} \Gamma_{1}-\lambda_{2} B \operatorname{Re} \Gamma_{2}\right)-\ldots \text { (2. } 34\right)
\end{aligned}
$$

We know from equation (2.29) that

$$
B=\frac{2 \lambda_{1}}{1+\lambda_{2}{ }^{2}} A
$$

and from equation (2.32) that

$$
\lambda=\mu\left[\frac{1-\lambda_{2}^{2}}{1-\lambda_{1}^{2}}-2\right]
$$

Substituting these in equation (2. 34)

$$
\begin{aligned}
& \sigma_{\mathbf{X}}=\mu\left(2 \lambda_{1}{ }^{2}-\lambda_{2}{ }^{2}-1\right) A \operatorname{Re} \Gamma_{1} \\
&+2 \mu\left[A \operatorname{Re} \Gamma_{1}-\lambda_{2} \frac{4 \lambda_{1}}{1+\lambda_{2}{ }^{2}} A \operatorname{Re} \Gamma_{2}\right] \\
&= A \mu\left[\left(1+2 \lambda_{1}{ }^{2}-\lambda_{2}{ }^{2}\right) \operatorname{Re} \Gamma_{1}-\frac{4 \lambda_{1} \lambda_{2}}{1+\lambda_{2} 2^{2}} \operatorname{Re} \Gamma_{2}\right] \ldots(2.35)
\end{aligned}
$$


Similarly we can obtain

$$
\sigma_{y}=A \mu\left[-\left(1+\lambda_{2}{ }^{2}\right) \operatorname{Re} \Gamma_{1}+\frac{4 \lambda_{1} \lambda_{2}}{1+\lambda_{2}{ }^{2}} \operatorname{Re} \Gamma_{2}\right]
$$

and $T_{X Y}=A \mu .2 \lambda 1\left[\operatorname{Im} \Gamma_{2}-\operatorname{Im} \Gamma_{1}\right]$

where

$$
A \mu=\frac{1}{\left[\frac{4 \lambda_{1} \lambda_{2}}{1+\lambda_{2}{ }^{2}}-\left(1+\lambda_{2}{ }^{2}\right)\right]} \text { from equation (2.33) }
$$

and

$$
\frac{1-\lambda_{1}{ }^{2}}{1-\lambda_{2}{ }^{2}}=\frac{c_{2}^{2}}{c_{1}^{2}}
$$

A second choice for the function $\Gamma$ an be made in the form

$$
Y_{1}=\sum_{m=0}^{m} B_{m} z_{1}^{m} \quad Y_{2}=\sum_{m=0}^{m} B_{m} z_{2}
$$

One can observe that on $y=0$ and for any value of $x, Y 1$ and Y2 have zero imaginary parts. Thus $T_{X Y}=0$ on $y=0$. In order to have $\sigma_{y}=0$ on the 1 ine segment occupied by the crack, it is necessary to require

$$
B=\frac{1+\lambda_{2}^{2}}{2 \lambda_{2}} A
$$

The resulting stress equations are

$$
\begin{aligned}
& \sigma_{X}=A \mu\left[\left(1+2 \lambda_{1}{ }^{2}-\lambda_{2}^{2}\right) \operatorname{ReY}_{1}-\left(1+\lambda_{2}^{2}\right) \operatorname{Re} Y_{2}\right] \\
& \sigma_{Y}=A \mu\left(1+\lambda_{2}{ }^{2}\right)\left(\operatorname{ReY}_{2}-\operatorname{ReY}_{1}\right]
\end{aligned}
$$

Af in equations (2.40-2.42) can be obtained by using the boundary condition $\sigma_{x}=\sigma_{0 x}=2 B_{0}$ as $x$ on the positive 
$x$-axis. So from equation (2.40), we get $\sigma_{x}$ as $x$ equal to $A \mu\left[\left(1+2 \lambda_{1}{ }^{2}-\lambda_{2}{ }^{2}\right) \operatorname{ReY}_{1}-\left(1+\lambda_{2}{ }^{2}\right) \operatorname{Re} Y_{2}\right]$ where $\operatorname{Re} Y_{1}=\operatorname{Re} Y_{2}=B_{0}$ from equation (2.38) i.e. $\sigma_{0 x}=2 A \mu\left[\lambda_{1}{ }^{2}-\lambda_{2}^{2}\right] B_{0}$. Assuming that $\sigma_{x}$ as $r$ and $\theta$ is a constant value of $\sigma_{o x}=B_{0}$, we get

$$
A \mu=\frac{1}{\left[\lambda_{1}{ }^{2}-\lambda_{2}{ }^{2}\right]}
$$

since the above two series functions satisfy the boundary conditions of the problem, the sum of the two should also satisfy the boundary conditions.

so $\sigma_{\mathbf{x}}=\frac{1}{\left[\Omega-\left(1+\lambda_{2}{ }^{2}\right)\right]}\left[\left(1+2 \lambda_{1}{ }^{2}-\lambda_{2}{ }^{2}\right) \operatorname{Re} \Gamma_{1}-\Omega \operatorname{Re} \Gamma_{2}\right]$

$$
+\frac{1}{\left(\lambda_{1}{ }^{2}-\lambda_{2}{ }^{2}\right)}\left[\left(1+2 \lambda_{1}{ }^{2}-\lambda_{2}{ }^{2}\right) \operatorname{ReY}_{1}-\left(1+\lambda_{2}{ }^{2}\right) \operatorname{Re} Y_{2}\right]--(2.43)
$$

$$
\sigma_{Y}=\frac{1}{\left[\Omega-\left(1+\lambda_{2}^{2}\right)\right]}\left[-\left(1+\lambda_{2}^{2}\right) \operatorname{Re} \Gamma_{1}-\Omega \operatorname{Re} \Gamma 2\right]
$$

$$
+\frac{\left(1+\lambda_{2}^{2}\right)}{\left(\lambda_{1}{ }^{2}-\lambda_{2}^{2}\right)}\left[\operatorname{Re} Y_{2}-\operatorname{ReY}_{1}\right]
$$

$$
\begin{aligned}
T_{X Y} & =\frac{1}{\left[\Omega-\left(1+\lambda_{2}^{2}\right)\right]} 2 \lambda_{1}\left(\operatorname{Im} \Gamma_{2}-\operatorname{Im} \Gamma_{1}\right) \\
& +\frac{1}{\left(\lambda_{1}{ }^{2}-\lambda_{2}{ }^{2}\right)}\left[\frac{\left(1+\lambda_{2}^{2}\right)^{2}}{2 \lambda_{2}} \operatorname{Im} Y_{2}-2 \lambda_{1} \operatorname{ImY_{1}]}\right.
\end{aligned}
$$

where $\Omega=4 \lambda_{1} \lambda_{2} /\left(1+\lambda_{2}{ }^{2}\right)$

From equations $(2.43)$ and (2.44), we obtain

$$
\begin{aligned}
\frac{\sigma_{y}-\sigma_{x}}{2} & =\frac{1}{\left[\Omega-\left(1+\lambda_{2}{ }^{2}\right)\right]}\left[\Omega \operatorname{Re} \Gamma_{2}-\left(1+\lambda_{1}{ }^{2}\right) \operatorname{Re} \Gamma_{1}\right] \\
& +\frac{1}{\left(\lambda_{1}{ }^{2}-\lambda_{2}{ }^{2}\right)}\left[\left(1+\lambda_{2}{ }^{2}\right) \operatorname{ReY}_{2}-\left(1+\lambda_{1}{ }^{2}\right) \operatorname{Re} Y_{1}\right] \ldots(2.46)
\end{aligned}
$$


The first three terms in each of the series $Z$ and $Y$ are as follows:

$$
\begin{aligned}
& \Gamma_{1}=A_{0} z_{1}-x+A_{1} z_{1} x+A_{2} z_{1} 1.5 \text { and } \\
& \Gamma_{2}=A_{0} z_{2}-x+A_{1} z_{2}{ }^{x}+A_{2} z_{2}{ }^{1.5}
\end{aligned}
$$

$Y_{1}$ and $Y_{2}$ can be expressed as

$$
\begin{aligned}
& \mathbf{Y}_{1}=\mathbf{B}_{0}+\mathbf{B}_{1} \mathbf{Z}_{1}+\mathbf{B}_{2} \mathbf{z}_{1}{ }^{2} \\
& \mathbf{Y}_{2}=\mathbf{B}_{0}+\mathbf{B}_{1} \mathbf{z}_{2}+\mathbf{B}_{2} \mathbf{z}_{2}{ }^{2}
\end{aligned}
$$$$
--(2.49)
$$

where $A_{0} \sqrt{2 \pi}=\mathbf{K}$, the stress intensity factor and remote stress $\sigma_{O X}=2 B_{0}$

$$
z_{1}=\rho_{1} e^{i \delta_{1}} \text { and } \quad z_{2}=\rho_{2} e^{i \delta_{2}}
$$

where $p_{1}, P_{2}, \bar{\phi}_{1}$ and $\bar{\phi}_{2}$ are shown in Fig. 2. Substituting for $z_{1}$ and $z_{2}$ in equations (2.47 to 2.50) and separating the real and imaginary parts, we get

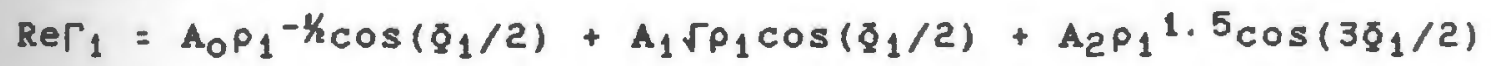
$\operatorname{Im} \Gamma_{1}=-A_{0} p_{1}-K \sin \left(\delta_{1} / 2\right)+A_{1} \sqrt{ } \rho_{1} \sin \left(\delta_{1} / 2\right)+A_{2} \rho_{1} 1 \cdot 5 \sin \left(3 \delta_{1} / 2\right)$

Replacing $z_{1}$ by $z_{2}$ in the above equations

$\operatorname{Re} \Gamma_{2}=A_{0} P_{2}-K \cos \left(\delta_{2} / 2\right)+A_{1} \sqrt{ } \rho_{2} \cos \left(\delta_{2} / 2\right)+A_{2} \rho_{2}{ }^{1 \cdot 5} \cos \left(3 \delta_{2} / 2\right)$ $\operatorname{Im} \Gamma_{2}=-A_{0} P_{2}-K_{\sin }\left(\phi_{2} / 2\right)+A_{1} r \rho_{2} \sin \left(\phi_{2} / 2\right)+A_{2} P_{2}{ }^{1} \cdot{ }^{5} \sin \left(3 \phi_{2} / 2\right)$ Simil ar $1 Y$,

$$
\begin{aligned}
& \operatorname{Re} Y_{1}=B_{0}+B_{1} \rho_{1} \cos \phi_{1}+B_{2} \rho_{1}{ }^{2} \cos 2 \phi_{1} \\
& I m Y_{1}=B_{1} \rho_{1} \sin \phi_{1}+B_{2} \rho_{1}{ }^{2} \sin 2 \phi_{1} \\
& \operatorname{ReY}_{2}=B_{0}+B_{1} P_{2} \cos \phi_{2}+B_{2} P_{2}{ }^{2} \cos 2 \phi_{2} \\
& \operatorname{Im} Y_{2}=B_{1} \rho_{2} \sin \dot{\phi}_{2}+B_{2} \rho_{2}{ }^{2} \sin 2 \phi_{2}
\end{aligned}
$$


From Fig. 2, it is evident that

$$
\begin{aligned}
& \Phi_{1}=\operatorname{Arctan}\left[\lambda_{1} \tan \theta\right] \\
& \Phi_{2}=\operatorname{ArcTan}\left[\lambda_{2} \tan \theta\right] \\
& \rho_{1}=r\left[1-\left(1-\lambda_{1}{ }^{2}\right) \sin ^{2} \theta\right]^{K} \\
& \rho_{2}=r\left[1-\left(1-\lambda_{2}{ }^{2}\right) \sin ^{2} \theta\right] k
\end{aligned}
$$

where $\lambda_{1}=\left[1-\left(c / c_{1}\right)^{2}\right]^{k}$ and $\lambda_{2}=\left[1-\left(c / c_{2}\right)^{2}\right]^{k}$

Sustituting the expressions (2.52 to 2.59) in eq. (2.45) and (2.46) and making use of equations (2.60-2.63), we can obtain expression for $\left(\sigma_{y}-\sigma_{z}\right) / 2$ and $\tau_{x y}$ in terms of the series constants and the polar coordinates $r$ and $\theta$. 


\section{Chapter - 3 \\ USE OF STRAII GAGES II DYMAIC FRACTURE}

Although, Irwin [10] first suggested the use of strain gages to determine the stress intensity factor near the tip of the crack in 1957, little progress has been made in implementing this suggestion. The primary reason for the delay in the development of a suitable method involves the finite size of the strain gage. Questions arise regarding the effects of the strain gradients on the gage output, the magnitude of the strains to be measured if the gage is placed in close proximity to the crack tip and the relative size of the strain gage compared to the size of the near field region.

Recently, Dally and Sanford [11] have demonstrated the use of strain gages in static fracture mechanics. To extend the use of strain gages to dynamic fracture firstly, dymamic strain field representation was needed, secondly, a relation was required to identify the instantaneous location of the running crack tip with respect to the strain gage so as to be able to compute the stress intensity factor from the strain field representation. The objective of this work is to extend the use of strain gages to dymamic fracture studies.

Dynamic strain field equations were developed using 
Westergaard's stress function approach. These equations were then analyzed to look at the effect of atrain gage position and orientation with respect to the crack tip on the dynamic strain profile. The effect of material properties, such as crack velocity, and the finite size of the strain gage on the strain profile is also investigated. Finally, a series of experiments was conducted where strain gages were bonded at a predetermined distance and orientation from the crack propagation path and the strain profiles recorded. These strain profiles were used to compute the dynamic stress intensity factor as a function of the crack propagation distance. The results thus obtained were compared with similar results obtained using the method of photoelasticity [12].

3. 1

\section{DYNAMIC CRACK TIP STRAIN FIELD REPRESENTATION}

The dynamic stress field representation equations (2. 43 to 2.45) can be converted to strain field representation in a rotated coordinate system using Hooke's law and appropriate transformation 1 aws.

The rotated coordinate system associated with the strain gage is shown in Fig. 3. The strain field in the coordinate system, $\mathbf{G}_{\mathbf{X} G \mathbf{Y}}$, located at an arbitrary point, $G(x, y)$, which is coincident with the strain gage grid center, and rotated at an angle $\alpha$ with respect to coordinate system, $X_{\mathbf{I} Y}$, can be determined from the complex 
strain transformation equation

$$
\left(\epsilon_{Y G}-\epsilon_{X G}\right)+\gamma_{X G Y G}=\left(\varepsilon_{Y Y}-\varepsilon_{X X}+\dot{1}_{Y X Y}\right) e^{2 i \alpha}
$$

and the first strain invariant

$$
\epsilon_{X G}+\varepsilon_{Y G}=\varepsilon_{X}+\varepsilon_{Y}
$$

Using Hooke's law along with eq. (3.1) and eq. (3.2), we get

$$
\begin{aligned}
2 \epsilon_{X G}=\frac{1}{E}\left[(1-v)\left(\sigma_{Y}+\sigma_{X}\right)-(1+\nu)\left(\sigma_{Y}-\sigma_{X}\right) \cos 2 \alpha\right. \\
\left.+2(1+v) \tau_{X Y} \sin 2 \alpha\right]
\end{aligned}
$$

Substituting $\sigma_{X}, \sigma_{Y}$, and $r_{X Y}$ from eq. (2.43), eq. (2. 44) and eq. (2. 45) into eq. (3.3) leads to

$$
\begin{aligned}
& \epsilon_{X G}=\frac{A \mu *(1+v)}{B}\left[\left(\frac{1}{1}=\frac{v}{v}\right)\left(\lambda_{1}{ }^{2}-\lambda_{22}\right)\left(\operatorname{Re} \Gamma_{1}\left(z_{1}\right)+\operatorname{Re} Y_{1}\left(z_{1}\right)\right)\right. \\
& +\left(1+\lambda_{1}^{2}\right)\left(\operatorname{Re} \Gamma_{1}\left(z_{1}\right)+\operatorname{Re} Y_{1}\left(z_{1}\right) / \cos 2 \alpha\right. \\
& -\frac{4 \lambda_{1} \lambda_{2}}{1+\lambda_{2}{ }^{2}} \operatorname{Re} \Gamma_{2}\left(z_{2}\right) \cos 2 \alpha-\left(1+\lambda_{2}{ }^{2}\right) \operatorname{ReY}_{2}\left(z_{2}\right) \cos 2 \alpha \\
& -\left(1+\lambda_{2}{ }^{2}\right) \operatorname{Re} Y_{2}\left(z_{2}\right) \cos 2 \alpha \\
& +2 \lambda_{1}\left(\operatorname{Im} \Gamma_{2}\left(z_{2}\right)-\operatorname{Im} \Gamma_{1}\left(z_{1}\right)-\operatorname{Im} Y_{1}\left(z_{1}\right)\right) \sin 2 \alpha \\
& \left.+\frac{\left(1+\lambda_{2}{ }^{2}\right)^{2}}{2 \lambda_{2}{ }^{2}} \operatorname{ImY} Y_{2}\left(z_{2}\right) \sin 2 \alpha\right]
\end{aligned}
$$

where $\quad A \mu=\frac{1+\lambda_{2}{ }^{2}}{4 \lambda_{1} \lambda_{2}-\left(1+\lambda_{2}{ }^{2}\right)^{2}}$

Also the strain in the $Y_{G}$ direction is given by

$$
\epsilon_{Y G}=\epsilon_{\mathbf{X G}}(\alpha+90 \cdot)
$$

Setting $n=0$ and $m=0$ in eq. (2.30) and eq. (2. 38) and sustituting them in eq. (3.4) yields a two parameter representation of the strain field 


$$
\begin{aligned}
& \epsilon_{x G}=\frac{A_{\mu}(1+v)}{E}\left(A _ { 0 } \left[\left(\frac{1-v}{1+v}\right)\left(\lambda_{1}^{2}-\lambda_{2}^{2}\right) p_{1}-K \cos \left(\delta_{1} / 2\right)\right.\right. \\
& +\left(1+\lambda_{1}^{2}\right) \rho_{1}-K \cos \left(\phi_{1} / 2\right) \cos 2 \alpha \\
& -\frac{4 \lambda_{1} \lambda_{2}}{\left(1+\lambda_{2}^{2}\right)} \rho_{2}-x \cos \left(\phi_{2} / 2\right) \cos 2 \alpha \\
& \left.+2 \lambda_{1} \sin 2 \alpha\left(\rho_{1}-K_{\sin }\left(\delta_{1} / 2\right)-\rho_{2}-K_{\sin }\left(\delta_{2} / 2\right)\right)\right] \\
& \left.+B_{0}\left[\left(\lambda_{1}^{2}-\lambda_{2}^{2}\right)\left(\frac{1-v}{1+v}+\cos 2 \alpha\right)\right]\right\}
\end{aligned}
$$

Inspection of eq. (3.6) suggests that the contribution of $B_{0}$ term can be set to zero if

$$
\cos 2 \alpha=-\left(\frac{1-v}{1+v}\right)
$$

For a range of values of Poisson's ratio, $v$, the angles, a, which removes the contribution of $B_{0}$ term are shown in Table 1.

3. 2 EVALUATION OF CRACK TIP STRAIH FIELD EQUATIONS

\section{2(a) Effect of Strain Gage Orientation on the Strain}

Theoretical strain $\epsilon_{G} T$ is plotted in Fig. 5 as a function of crack tip position $x_{L}$ for several different strain gage orientations. Material properties of Homalite 100, Table 2, a value of $\mathbf{K}=1 \mathrm{MPa} \sqrt{\mathrm{m}}$, and $\mathrm{ACr}=0.33$ are used in the generation of these plots. The strain profiles are plotted for fixed height of $6 \mathrm{~mm}$ from the crack propagation path. In this plot, curves 2 and 8 correspond to $\alpha=59.4$ deg. and $\alpha=120.6$ deg. respectively, for which 
the contribution of the second term $B_{0}$ is zero. The plots show that the peak value of the strain profile becomes sharper as the gage orientation angle $\alpha$ increases from 59.4 deg. to $130 \mathrm{deg}$. Interestingly, the peak strain for $\alpha=$ 120.6 deg. occurs at $x_{L}=0$ i.e. when the crack tip is directly below the strain gage. Also, the peak strain for $\alpha$ $=120.6$ deg. is 40 percent higher than the peak strain for $\alpha=59.4$ deg. Thus in all the dynamic experiments the strain gages have been placed at $\alpha=120.6$ deg.

Using peak strain, $\left(\epsilon_{x G}\right)^{P}$, from the dynamic strain profile leads to $\left(\theta=\Phi_{1}=\delta_{2}=90\right.$ and $\left.p_{1}=p_{2}=Y=H\right)$, where $H$ is the height of the strain gage above the crack propagation path. Substituting these values in eq. (3.6) and using the relation between the instantaneos stress intensity factor $X$ and coefficient of the first nonsingular term $A_{0}$ given by, $\mathbf{K}_{I d}=\Lambda_{0} \sqrt{2 \pi}$ yields

$$
\begin{aligned}
\left(\varepsilon_{X G}\right)^{P}=K * & \frac{(A H)(1+v) H^{-K}}{2 E}\left\{\frac{(1-v)}{(1+v)}\left(\lambda_{12}-\lambda_{2}{ }^{2}\right)\right. \\
& \left.+\cos 2 a\left[\left(1+\lambda_{1}{ }^{2}\right)-\frac{4 \lambda_{1} \lambda_{2}}{1+\lambda_{22}}\right]\right\}
\end{aligned}
$$

Knowing peak strain from the strain profile, $\left(\varepsilon^{X_{G}}\right)^{P}$, the crack velocity, $c$, and measuring the gage orlentation, $\alpha$, and the gage height, H, provides necessary data to evaluate $\mathbf{K}$.

3. 2 (b) Effect of the Height of Strain Gage on the Strain 
using equation (3.6) and $\alpha=120.6$ deg., theoretical strain $\epsilon_{G}{ }^{T}$ is plotted in Fig. 6 as a function of the crack tip position, $x_{L}$, for various heights above the crack propagation path. The plot shows that the strain increases in magnitude and its peak becomes well defined and sharper as the gage position is moved closer to the crack propagation path. However, in actual practice as one comes closer to the crack tip the strain field becomes nonlinear [14]. Thus in all the experiments the strain gages have been bonded at a distance equal to half the plate thickness plus half the gage grid length away from the crack propagation path.

3. 2(c) Effect of Crack Speed on Strain Profile

Again, using equation $(3.6)$, theoretical strain $\epsilon_{G}{ }^{T}$ is plotted in Fig. 7 as a function of the crack tip position, $x_{L}$, for different values of crack velocity. The figure shows the strain magnitude increases with increasing velocity. This effect is more pronounced as the velocity approaches the Raleigh wave velocity.

3. 3 AVERAGING EFFECTS DUE TO FIMITE SIZE OF THE STRAIN GAGE 
since the strain gage has a finite slze it averages the strain over 1 ts grid size area. This average strain is not equal to the strain at the grid geometric center. The error due to this averaging effect is calculated by considering a strain gage with grid size (1Xb) positioned at height, $H$, above the crack propagation path and oriented at an angle $\alpha=120.6$ deg. Now the peak strain at the geometric center of the gage, $\left(\epsilon_{G} C\right) P$, is calculated using equation (3.6) with $x_{L}=0$. To evaluate the average strain the strain gage grid is divided into a matrix of $100 \times 100$ points and strain at each point is evaluated using equation (3.6). From this the average peak $\operatorname{strain}\left(\epsilon_{G}^{A V}\right) P$ is computed. This strain is infact the peak strain recorded by the strain gage in an experiment. since $\left(\epsilon_{G}{ }^{A V}\right) P$, instead of $\left(\epsilon_{G}\right)^{P}$ is used for the evaluation of $\mathbf{K}$-value, the error in peak strain is $\left(\left(\epsilon_{G}\right)^{P}-\left(\epsilon_{G} A V\right) P\right) /\left(\epsilon_{G} C\right) P$. The results are presented in Fig. 8 which shows the percentage error due to averaging effect as a function of gage grid length for the gage grid aspect ratio, $1 / b=1$. The results are plotted for two different heights of the strain gage. The error is higher for strain gages closer to the crack propagation path because of steep strain gradients. Also, the error increases as the gage size increases. For the size of strain gages used in this study this error is less than 0.5 percent. 
3. 4

Validity of Near Field Assumption - Comparison of Ioperimentally Obtained Strain Profiles with the Theoretically Generated Strain Profiles

Since, single parameter dynamic strain field representation is being used, question arise wheather the strain gage is placed inside the singular term dominated zone or not. To verify this experiment was conducted with two strain gages on a SEN model cut out from Homalite 100 sheet, one at orientation, $\alpha=90$ deg and the other at $\alpha=120.6$ deg. The strain gages were placed at a distance $H$ equal to half the plate thickness away from the crack propagation path. The position $(r, \theta)$ of the two strain gages was kept the same. The strain profiles obtained show strain as a function of time. The time axis was converted to crack tip position axis using the average crack velocity. Strain profiles thus obtained as a function of crack tip position are shown in Fig.9. From the peak strain recorded by strain gage oriented at $\alpha=120.6$ deg, Instantaneous stress intensity factor, $K$, was computed using eq. (3.8). For this value of $\mathbf{x}$, theoretical strain profiles where plotted for $\alpha=90$ def and $\alpha=120.6$ deg using eq. (3.6). The theoretical strain profiles thus obtained are also shown in Fig.9. Comparing experimentally obtained strain profiles with the theoretically obtained profiles shows that the singular solution gives good match in a 
region of $\pm 5 \mathrm{~mm}$ from the crack tip along the crack propagation direction.

3. 5

\section{EXPERIMENTAL PROCEDURE, RESULTS AND DISCUSSION}

The fracture specimen geometries used in this study are shown in F1g.10 and 11. These model geometries were selected so as to collect data over a wide range of crack relocities. The SEN specimen, when tested with Benter-pin-loading, has an increasing stress intensity factor and can be used to study strain gage behavior with accelerating and high speed cracks. The DCB on the other hand is tested with constant displacement with crack-line-loading and it exhibits decreasing crack speed. The specimens were cut out of a $12.7 \mathrm{~mm}$ thick sheet of brittle polyester birefringent material Homalite 100. Properties of Homalite 100 are tabulated in Table 2. A notch was saw-cut into the specimen and the tip of this starter notch blunted so that the model could be loaded to the desired value of load before fallure. Four strain gages were bonded on the model at predetermined angle of orientation $\alpha=120.6$ deg and at a distance $H=7$ mm. Strain gages used were EA-13-031DE-350 ( acquired from Masurements Group ), which have a frid size $0.79 \times 0.81 \mathrm{~mm}$ and electrical resistance 350 ohms. High resistance strain gages were chosen such heat generated at the gage grid is 
less. The strain gage circuit schematic is show in Fig. 12. The strain gages were connected to dynamic amplifiers with frequency response of $200 \mathrm{KHz}$, and there output was recorded on digital oscilloscopes every 500 ns. The oscilloscopes were set to trigger simultaneously at 50 percent of the maximum expected strain value from the first strain gage, refer Fig. 10 with a pretrigger setting of 40 micro seconds. The specimen is then loaded to desired load value and the crack initiated by pulling a sharp knife across the tip of the blunted starter notch.

Two experiments were performed with the SEN models. In the first experiment the crack was initiated at an initial load of $4.21 \mathrm{kN}$ whereas in the second experiment a higher load of $6.88 \mathrm{kN}$ was used. These loads were selected because photoelastic results from them were available from prior experiments [12]. Typical strain profiles as obtained from the first experiment are shown in Fig.13. Since the peak of the strain profiles is directly proportional to the stress intensity factor, an increasing trend in $\mathrm{K}$-value is anticipated, knowing the gages were exactly at the same height above the crack propagation path. This is typical of the SEK geometry. Results from the strain gage experiments are compared with the photoelastic results in Fig.14 and 16. Strain gage values match well within experimental errors with photoelastic values.

A series of two experiments was also performed with 
the DCB model geometry. One experiment was done with four strain gages bonded along the crack propagation path whereas the other was performed using the method of photoelasticity. In both the experiments the crack opening displacement was kept the same. The results for the two experiments are shown in Fig. 16. Both the experiments show a decreasing trend in the $\mathrm{K}$-values a property of the wedge loaded DCB geometry. Again the match between the two results is good. .

\section{6 SUMMARY}

This study illustrates the successful use of strain gages in the study of dynamic fracture. The results indicate that a strain gage with proper orientation could be used to provide strain data necessary for the computation of instantaneous stress intensity factor from the two parameter dynamic strain field equations. In this study only the peak value of strain profile was used in the computation of $\mathbf{K}$-value. However, it should be mentioned that the strain profile from a single gage could be used to get $K$ values for several crack tip positions provided the strain gage for all these positions stays in the singularity dominated zone. It must also be mentioned that the velocity of the crack in the computations of $\mathrm{r}$, from the strain gage data, were previously obtained from 
photoelastic results. If strain gages themselves have to be used for velocity determination also, then several strain gages must be used in the experiments. With four gages in the present experiments only average velocities could be determined. The results from strain gages and photoelastic experiments showed good agreement. 


\section{Chapter - 4 \\ IEVESTICATIOI OP DTAAIC FRACTURE USIEG}

\section{PHOTOELASTIC COATIRGS}

Fracture study of metals in the laboratory is important in predicting and preventing failure of machines and structures. In the domain of linear elastic fracture mechanics the behavior of a crack is primarily governed by the stress intensity factor defining the stress field near the crack tip. It is currently believed that an existing crack becomes unstable and propagates when the existing stress intensity factor exceeds the $\mathrm{K}_{\mathrm{I}} \mathrm{y}$ value. Also a dynamically growing crack will be arrested if the instantaneous dynamic stress intensity factor $\mathbf{K}$ Id is less than the dynamic crack arrest stress intensity factor $\mathrm{K}_{\mathrm{I}}$. If the fracture initiation resistance of the material were always to increase with loading rate and if crack propagation resistance were independent of crack tip speed, then quasi-static tests could be used to establish complete design criteria. This is not the case, however, for most structural materials and it is thus necessary to perform dynamic fracture experiments for proper characterization of the materials. In finite bodies the problem becomes analytically more difficult because of the boundary reflected stress waves transmitting information about the 
changing boundary conditions to the crack tip, and direct experimental observations are necessary for complete understanding of the dynamic fracture process.

There are many methods now avallable to an experimentalist for evaluating the stress intensity factor for a dynamically moving crack. These methods include both optical and non-optical techniques. Among the optical methods are method of caustics and the method of photoelasticity. The method of caustics, developed by Manogg[15] is in current use by many researchers $[16,17,18]$. This technique gives the first term of the series representing the stress field which is related to the stress intensity factor. The great advantage of the method over other experimental techniques is that it provides a direct measure of the crack tip field and the corresponding crack speed without concern of the geometry of the specimen, the boundry conditions, or the complex stress wave pattern in the bulk of the specimen.

The method of photoelasticity has been used for almost 20 years by many investigators[19, 20, 21] and over the years many improvements have been incorporated in the analysis technique to allow full field evaluation of the stresses around the crack tip[8]. Kobayashl and Dally[7] have demonstrated the successful use of photoelastic coatings on steel. However, the coatings employed by them are applicable only under diffused light and the resolution 
of the photographs obtained is not very good.

4. 1

REVIEW OF RELATED RESEARCH ON PHOTOELASTIC COATIMGS

The concept of birefringent coatings was first introduced by Mesnager [25] in France in 1930. The method was examined by Oppel [26] in Germany in 1937. Early efforts were not successful due to lack of suitable adhesives, the low sensitivity of available polymers, and the reinforcing effects. When epoxy became avilable, in the early 1950s, the bonding and sensitivity problems were alleviated. Significant development of the method in the area of materials and technique were made by Fleury and Zandman [27] in France in 1954 and later by D'Agostino, Drucker, Liu, and Mylonas [28] in the United States and by Rawata [29] in Japan.

In previous investigations $[30,31]$ a continuous sheet of birefringent coating material was used over the specimen surface and this procedure caused uncertainnity as to whether the observed response in the coating is dominated by the fracture of the base material or by the fracture of the coating itself [32]. A split birefringent coating fechnique - a separate sheet of birefringent coating on either side of the anticipated crack path - was developed by Kobayashi and Dally [7] which alleviates problems encountered by previous researchers. They used diffused 
11 ht and rotating drum type camera to determine stress intensity factors. However, the resolution of the photographs obtained from using diffused 1 ight was not very good.

In this study the method of split birefringent coatings has been used to study drnamic fracture of structural metals 4340 steel and 7075-T6 aluminum Face grooves are made on the specimens to guide the crack and to ensure failure in tension mode. Previously researchers [7, 32] have used diffused 1 ight to record the fringe pattern in the coatings. These coatings have a reflective paint on their back surface, which when used in focused light, due to front surface reflection being more intense than the reflection from the back surface, do not yield sharp fringe pattern. This problem was faced in this study and was also reported by Kawatta et al[33]. Therefore, in the present study vacuum deposited aluminum coating on the back surface of the polycarbonate sheet (PS-1) have been used as photoelastic coatings under focused light. Fringe patterns associated with the running crack have been obtained using Cranz Schardin camera in reflection mode. Instantaneous stress intensity factors have been obtained by the the methods of strain gages and photoelastic coatings and compared. K-values obtained from the two methods compare well within experimental error. 
PHOTOELASTIC ANALYSIS : The method of photoelasticity is based on the stress-optic law[19] which relates the birefringent material properties and isochromatic fringe order to the stress field components as:

$$
2 \tau_{m}=\sigma_{1}-\sigma_{2}=N f_{\sigma} / h
$$

where :

$$
\begin{aligned}
& \sigma_{1} \& \sigma_{2} \text { are the inplane principal stresses } \\
& \tau_{m} \text { is the maximum inplane shear stress } \\
& N \text { is the fringe order } \\
& f_{\sigma} \text { is the material fringe value } \\
& h \text { is the length of the optical path through } \\
& \text { the birefringent material. }
\end{aligned}
$$

Stress optic law can be combined with the dynamic stress field equations (2.43-2.45) to relate the fringe order, $\mathbf{n}$, at any point in an isochromatic field with the unknown real coeficicients, $A_{n}$ and $B_{m}$ through the equation

$$
\left(N f_{\sigma} / 2 h\right)^{2}=T_{m}^{2}=\left(\sigma_{Y Y}-\sigma_{X X}\right)^{2} / 4+\tau_{X Y^{2}}-\cdots(4.2)
$$

The equation is then solved using the multiple point overdeterministic method suggested by Sanford and Dally 
[22].

The number of coefficients in the series of eq. $s$ (2.30) and (2.38) necessary for an adequate representation of the stress fleld over the data acquisition region is decided by examining the average fringe order error, the values of leading coefficients and the reconstructed fringe patterns corresponding to a given set of coefficients [34]. The leading coefficient, Ao, in eq. (2. 30) is related to the stress intensity factor in the birefringent coating, $\mathrm{K}_{\mathrm{Id}} \mathrm{C}$ by the relation :

$$
\mathbf{K}_{I d}{ }^{C}=c_{0} \sqrt{2 \pi}
$$

Assuming that the coating strains are equal to the specimen strains and that there is a negligible strain gradient through the coating thickness, it can be shown that stress intensity factor in steel, $\mathrm{K}_{I d^{S}}$, is related to the stress intensity factor in the coating, $\mathrm{K}_{\mathrm{Id}} \mathrm{C}$, by the relation [35]

$$
\mathbf{K}_{I d^{S}}=\left(E^{S} / E^{C}\right)\left\{(1+\nu C) /\left(1+\nu^{S}\right)\right\} \mathbf{K}_{I d^{C}} \quad \ldots(4.4)
$$

where

$$
\begin{aligned}
& E \text { is the modulus of elasticity } \\
& v \text { is the Poisson's ratio }
\end{aligned}
$$$$
\text { superscripts } C \text { and } S \text { refer to steel and }
$$ 


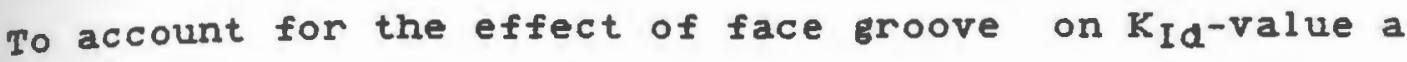
relation given by Kobayashi and Dally [7] is used

$$
\left(K_{I d^{S}}\right)^{G}=K_{I d^{S}} * F
$$

where

$$
F=\Gamma\left(B / B_{\mathbf{H}}\right)
$$

B is the specimen thickness

$B_{\mathbf{M}}$ is the net thickness

Q superscript identifying the $\mathrm{K}$ associated with

grooved specimen

Since $E^{C} / E^{S} \approx 0.013$ and $E C / E^{A} \approx 0.005$ the reinforcing effect is negligible. Therefore, reinforcing effect of the coating will be neglected in our calculations.

Substituting Eq. (4.3) and Eq. (4.4) in Eq. (4. 5) yields the final expression for the dynamic fracture toughness, $\left(\mathrm{I}_{\mathrm{Id}}\right)^{\mathrm{Q}}$ of steel as

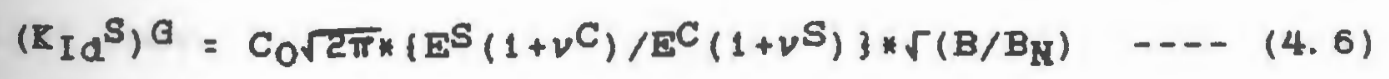

Siimplifying the notations, $\left(\mathrm{K}_{\mathrm{Id}^{S}}\right)^{G}$ will be denoted by $\mathrm{K}_{\text {Id } \text { in further references. }}$

Similarly, for aluminum 


$$
I_{1 d}=\cos 2 \pi *\left\{E^{A}(1+\nu C) / E^{C}(1+\nu A)\right\} * \sqrt{ }\left(B / B_{N}\right)
$$

YCE-GROOVES EFFECT

In order to control the crack path and to avoid failure in shear of the metal specimens, face grooves were made on the specimen with the included angle of 45 deg. The depth at the groove center to the nominal thickness of the specimen ratio, $\mathrm{B}_{\mathrm{H}} / \mathrm{B}$, was kept 0.75 . A series of experiments were conducted on Homalite 100 to study the face groove affected zone. This was of importance since strain gages are to be placed outside this groove influenced zone. The specimen geometry used for these experiments is shown in Fig.17. Five strips each having ten strain gages were placed on the model. The band saw cut notch was gradually extended in finite steps, the specimen was loaded to a predetermined $\mathrm{K}$-value, and strain data from all the strain gages recorded for several crack length to width ratio, a/w. Typical profiles of experimentally obtained strain per unit applied load as a function of helght above crack line for varying locations of the strain gage are shown in Fig. $18 \mathrm{a}, \mathrm{b}, \mathrm{c}$.

The theoretical strain profiles, $\epsilon^{T}$, are obtained using single parameter static strain field representation given by Dally and Sanford [11] 


$$
\begin{aligned}
2 \mu \epsilon^{T}= & A r^{-K}[K \cos (\theta / 2) \\
& -(K \sin \theta \sin (3 \theta / 2) \cos (2 \alpha) \\
& +K \sin \theta \cos (3 \theta / 2) \sin (2 \alpha)]
\end{aligned}
$$

where

$$
k=(1-v) /(1+v)
$$

and the coefficient $A$ is given by the relation

$$
A=K_{I s} / \sqrt{2 \pi} \text { where } K_{I s} \text { is the stress intensity }
$$

factor associated with the stationary crack, given by the standard relation for an edge crack problem as

$$
K_{I s}=\sigma_{\infty} \sqrt{\pi a} * f(a / w) * F
$$

where

$\sigma_{\infty}$ is the far field stress

a is the crack length

$W$ is the specimen width

$f(a / w)$ is the back surface correction factor [38]

$F$ is the correction factor for the groove

$F=\sqrt{\left(B / B_{K}\right)}$ as defined in eq. (4.5)

Using the location of the strain gage with respect to the crack tip, $r$, and $1 t^{\prime} s$ orientation, $a$, the theoretical strain, $\epsilon^{T}$, can be evaluated from eq. (4. 8 ). Theoretical strain profiles thus evaluated are shown in solid line in Figures $18 \mathrm{a}, \mathrm{b}, \mathrm{c}$.

It can be concluded from Figures $18 \mathrm{a}, \mathrm{b}, \mathrm{c}$ that for erooves with thickness at the groove center to thickness of 
the specimen ratio, $B_{\mathrm{H}} / \mathrm{B}$ equal to 0.75 , the influence of the groove dies out at distances larger than two third the plate thickness. It is assumed that this result will hold good for dynamic fracture also. Hence, the data acquisition region for face groove specimens is kept outside 2/3rd the plate thickness in both the photoelastic and strain gage experiments.

\section{MRAIN GAGE ANALYSIS}

Table 1 shows the angles, $\alpha$, which removes the contribution of $B_{0}$ term for 4340 steel which has a Poisson's ratio, $v$, of 0.3 is 118.7 deg. and for 7075 aluminum $v=1 / 3$, it is 120.0 deg. Accordingly, the strain gages were placed at orientation angle, $\alpha$, equal to 118.7 deg. and 120 deg. on steel and aluminum specimens respectively.

Theoretical strain at orientation, $a=118.7$ deg. for steel, $\epsilon_{G} S$, and $\alpha=120$ deg. for aluminum, $\varepsilon_{G}^{A}$, evaluated using eq. (3.6) are plotted as a function of the crack tip position, $x_{L}$, in Fig. 19. The plots show that the peak strain for these orientations for steel and aluminum occur when the crack tip is right below the strain gage, i.e., $x_{L}$ is equal to zero. Assuring, that the strain gage grid lies inside the $K_{I d}$ dominated zone, $K_{I d}$ can be evaluated from 
the peak strain recorded by a strain gage knowing that the crack tip is located right below the strain gage grid at that instant.

Rnowing peak strain from the strain profile, $\left(\epsilon_{\mathrm{ZG}}\right)^{P}$, the crack velocity, $c$, and measuring the gage orlentation, $\alpha$, and the gage helght, $H$, provides necessary data to evaluate $K_{I d}$ from equation (3.8).

To account for the face grooves KId-value is multiplied by the factor $F$ as given in eq. (11), i.e.

$$
\left(K_{I d}\right)^{G}=K_{I d} * F
$$

where $\quad F=r\left(B / B_{K}\right)$

\section{3 EXPERIMEKTAL PROCEDURE, RESULTS AKD DISCUSSIOH}

Dynamic experiments were conducted on heat-treated 4340-steel and 7075-T6 aluminum specimens using both the techniques. The single edge notch model geometry were used. The dimensions of the specimen used for steel and aluminum are shown in Fig.20 and Fig.21 respectively. Steel specimens were machined out of $1 / 4^{n}$ thick hot-rolled $4340-$ steel. They were given the following heat-treatment: 20 min. at $1550 \cdot F$, o1l quenched to $150 \cdot F$, air cooled to room temperature, and tempered at $650 . \mathrm{F}$ for $1 \mathrm{~K} \mathrm{hr}$ followed by straightening on a screw press and sand blasting. The hardness thus achleved was close to $R_{c} 49$. The initial crack 
was a vertical mill cut sharpened by a broaching tool, with crack length to width ratio of 0.25 . Aluminum specimens were cut out from 1/4" thick 7075-T6 aluminum sheet. The initial crack was a band saw cut with crack length to width ratio of 0.25 . In order to control the crack path and to avoid fallure in shear, face grooves were made on the specimens with the included angle of $45 \mathrm{deg}$. The depth at the groove center to the nominal thickness of the specimen ratio, $B_{N} / B$, was kept 0.75 . Four strain gages were mounted on each model. Details of the experiments conducted with photoelastic coatings and strain gages are given below.

PHOTOELASTIC EXPERIMENTS : The schematic of the experimental set up used for steel as well as aluminum models is shown in Fig. 22. The high speed recording system employed was a Cranz Schardin camera in reflection mode, which has twenty light sources in a matrix of $4 \times 5$ and has the capability of taking twenty frames at a speed of upto one million frames per second. Focused light was used to record these twenty different frames, each of size $2^{\prime \prime} \times 2^{n}$, on a static $8^{n} \times 10^{n}$ film. Light field polariscope arrangement was used with the same polarizer and quarter wave plate being used in the incident 11 ght path as well as the reflected light path. To focus the diverging light after reflection from the coating, a concave mirror (diameter equal to $12^{\prime \prime}$ ) of focal length 100" was employed. 
The coating used was $0.087 \pm .002$ inch thick sheet of polycarbonate (PS-11), with a mirror like reflective backing made by vacuum deposition of \#801 UV Aluminum², on the back surface. The reflective backing has an average reflectance greater than 87 percent in the 200-700nm 11 ght band. The coating was mounted on the specimen with PC-1 cement 1 and cured at room temperature for 12 hours. This provided adhesion required for the transmission of shear stresses from the steel surface to the coating. Electricity powered hydraulic pump and hydraulic cylinder were employed to load the model. Since focused 1 lght was being used and the optical path was lonf $\left(52^{\prime}\right)$, slight change in the angle of incidence on the model, of the order of 0.2 deg., due to resetting of the model under loading, lead to deflection of the image by $2^{*}$. Therefore, the model was loaded in two steps, in the first step it was loaded to 60 percent of the expected fracture load and optical arrangement adjusted to account for any tilt in the model due to loading, in the second step the load was gradually increased until the model fractured. In the photoelastic experiments on steel the crack started moving at a load of $119 \mathrm{kH}$. As the crack started moving it initiated delay generater circuit which in turn initiated the pulsing circuit of the spark gaps. As

1 Photoelastic Divilsion, Measurements Group, Raleigh, North Carolina.

2 Evaporated Coatings Inc., 798 Welsh Rd., Huntingdon Valley, PA 19006. 
the sparks took place the photodiode picked up the light intensity. The output of the photodiode was recorded on the oscilloscope as a function of time. Isochromatic fringe patterns of blue light $(\lambda=492 \mathrm{~nm})$ were obtained from the white spark light by employing proper light filters in the light path as shown in Fig.23. Fig.24 and Fig.25 show typical fringe patterns obtained from steel and aluminum models respectively. The crack tip location in these pictures is given by the point were the fringe loops close. The forward lean of the fringe loops shows the presense of the stress parallel to the crack propagation path. This means thath atleast a two parameter model is required to analyse these fringe loops. The increasing number of fringes as the crack propagates show an increasing stress intensity around the crack tip. In the fringe patterns obtained from aluminum models, the effect of the pproaching front boundry can be clearly seen.

The crack length to width ratio, a/w, as a function of time is plotted in Fig. 24 for the steel model. From the slope of the straight line the average crack velocity observed is $630 \mathrm{~m} / \mathrm{s}$. Post mortem analysis of the model confirmed that the specimen failed in brittle fracture with the crack faces perpendicular to the model faces and marked with shallow ridges along the model width. No indication of crack front curving in the specimen thickness direction was found. Dynamic fracture toughness, $\mathrm{K}_{I d}$, obtained are 
plotted as a function of crack length to width ratio in Fig. 26. The curve shows an increasing trend as expected for from a single edge notch geometry. Superimposed on the

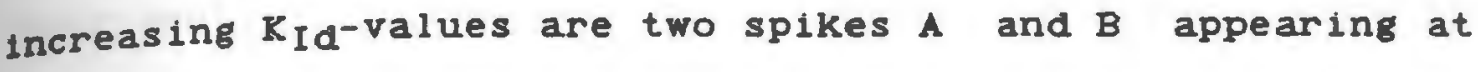
45 and 75 micro seconds respectively. Simple calculations show that these sharp rise in $\mathbf{K}_{\mathbf{I}}$-values can be attributed to the unloading waves reflected from the loading pins which originate at the crack tip at crack initiation. These raves comprise of $p$-wave and s-wave. The p-wave has a compressive front which becomes a tensile front after reflection from the free boundary of the loading pin hole. This tensile wave front is expected at 45 micro seconds after the crack initiation which is coincident with the spike A. The s-wave is expected back as a pressure wave at 70 micro seconds after crack initiation which corresponds closely with the spike $B$ seen at 75 micro seconds. The effect of the interaction of reflected unloading waves with the crack tip motion could not be seen in full detail due to lack of data points on the crack velocity curve Fig. 26 , though sharp increase in crack velocity can be observed at $45 \mathrm{Hs}$ and at 70 Hs. Such a phenomenon has been earlier reported by Freund [36], and Rosakis [37] where the authors have used MCT specimen geometry and method of caustics for investigation.

In the photoelastic experiments on 7075-T6 aluminum the crack started moving at a load of $84 \mathrm{kK}$. The crack 
average velocity obtained was $1075 \mathrm{~m} / \mathrm{s}$. The crack length to width ratio, $a / W$, as a function of time is shown in Fig. 28. Dynamic fracture toughness, $K_{I d}$, obtained from these experiments is plotted as a function of crack length to width ratio, a/W in Fig. 29. Again an increasing trend in $\mathrm{B}_{\text {Id }}$-value is observed as expected. Superimposed on this increasing $\mathrm{K}_{I d}$-value is spike A. Simple calculations show that reflected P-wave can be expected at 48 micro seconds and the reflected $s$-wave at 101 micro seconds after the crack initiation. Spike $A$ in $K_{I d}$-value, obtained at 52 micro seconds after crack initiation is therefore attributed to the reflected unloading $p$-wave. Since the model was narrow the reflected s-wave could not come back by the time the model fractured completely. Due to lack of a frame at 48 micro seconds the effect of p-wave on $\mathrm{K}_{\mathrm{Id}^{-}}$ value could not be captured in full intensity.

Since the polycarbonate coating (PS-1) has a strain limit of 10 percent, which is higher than the strain limit of the steel as well as the aluminum, a rough estimate of the plastic zone width in fractured steel and aluminum specimens could be made by observing the residual stresses in the coatings upon fracture. On observation of the fractured models half order fringe was found along the crack propagation path. The width of the residual stress zone to specimen thickness ratio was 0.65 and 0.75 in steel and aluminum specimens, respectively. Data acquisition zone 
in photoelastic experiments and the strain gage location in strain gage experiments were kept outside this zone.

STRAIN GAGE EXPERIMENTS : The strain gage circuit schematic is shown in Fig. 11. Four strain gages were mounted on each model as shown in Fig. 30 and Fig. 31. Strain gages were connected to dynamic amplifiers with frequency response of $200 \mathrm{kHz}$, and the output was recorded on a digital oscilloscope every 500 ns. Oscilloscopes were set to trigger simultaneously at 50 percent of the maximum expected strain value and on the positive slope of the strain profile from the first strain gage with a pretrigger setting of 100 micro seconds. Gages used in this work were EA-13-031DE-350 from Micro-measurements Group. These strain gages have a grid size of $0.79 \times 0.81 \mathrm{~mm}^{2}$. The averaging effect on strain of the strain gage grid is less than 0.5 percent [18]. The model was gradually loaded until the crack initiated. The load recorded by the load cell at initlation was $126 \mathrm{kN}$ and $83.8 \mathrm{kN}$ for steel and aluminum specimen respectively. Typlcal strain profiles obtained from an aluminum specimen are shown in Fig. 32. The crack tip locations corresponding to the peak strains were taken to be right below the strain gage i.e., $\theta=90$ deg. [18]. Instantaneous stress intensity factor were calculated from the peak strain using eq. (3.8). The results obtained are shown in Fig. 27 and Fig. 29 for steel and aluminum 
respectively, together with the results obtained from the method of photoelasticity. It can be seen the KId-values obtained using strain gages are in good agreement with the values obtained from the photoelastic coatings.

\section{4 SUMMARY}

This study illustrates the successful use of method strain gages and split photoelastic coating on 4340 steel and 7075-T6 aluminum. Use of mirror like coating, made by vacuum deposition of aluminum on the back surface of polycarbonate sheet (PS-1) yielded clear isochromatic fringe pattern with focused light. The problem encountered with focused light was resetting of the model while loading which called for readjustment and checking of the optical path. It should be pointed out that this problem was aggravated due to the long optical path. To shorten the optical path a condenser lens or shorter focal length mirror can be employed. The instantaneous stress intensity factor value was found to be greatiy affected by the reflected unloading waves generated at crack initiation. The results from strain gages and the photoelastic coatings showed good agreement. 


\section{Chapter - 5}

\section{COICLUSIOI}

This thesis presents an analytical and experimental study of dynamic fracture in brittle polyester material Homalite 100, and structural metals 4340 steel and 7075-T6 aluminum. Method of strain gages and photoelastic coatings are employed to measure the intensity of crack tip strain and stress fields. It can be concluded that

1. The present investigation extends the use of resistance gages to dynamic fracture which was so far limited to static fracture studies. It was shown that due to the small size of the strain gages the averaging effect over the gage grid area under steep strain gradients in vicinity of the crack tip are negligible. With proper orientation and location of the strain gages at least two parameter dynamic strain field equation can be solved for the computation of instantaneous stress intensity factor $K$.

2. Results obtained from the method of strain gages and method of photoelasticity (coatings) were in good arreement when the methods were applied to fracture study on brittle materials viz. Homalite 100, neat-treated 4340 steel $\left(R_{C}=49\right)$ and $7075-T 6$ aluminum. 
3.

Mirror like reflective coating is the key to obtalning clear isochromatic fringe patterns under focused 11ght. These coatings were successfully employed on structural steel and aluminum for the evaluation of instantaneous stress intensity factor $\mathbf{K}$.

4. The influence of the face groove with included angle 90 deg. and net thickness at the groove to the thickness of the model ratio, $B_{K} / B$ equal to 0.75 dies out at distances $2 / 3$ d the model thickness. 


\section{FUTURE WORT}

The applicability of the method of strain gages in

dynamic fracture was successfully demonstrated, also suitable photoelastic coatings were used in conjunction with focused light. These methods have their advantages specially when applied to opaque materials. As an extension of the present study some suggestion are as follows.

1. Use of the method of strain gages for dynamic stress intensity evaluation of materials like ceramics and rocks. This method has an edge over photoelastic coatings method when applied to these materials since they have high crack velocities and small strains associated with the running crack tip. Both these factors lead to increase in coating thickness thereby decreasing its frequency response which is critical in the interpretation of the recorded fringe patterns. Also the method of caustics can not be used since highly reflective specimen surface can not be obtained on these materials.

2. J - Integral can be evaluated for elastic plastic materials using photoelastic coatings and the method of strain gages. 
3.

a-K curve can be obtained for different materials using photoelastic coatings and the method of strain gages. It must be pointed out that the method of strain gages will need many strain gages on the model for accurate crack velocity measurements.

4. Coefficient of higher order terms in the series representation of strain can be evaluated using the method of strain gages by mounting more than one strain gage. At least one strain gage should be at an angle alpha for which the contribution of the second term goes to zero. This gage will identify the crack tip position. A set of simultaneous equations will be obtained to be solved for the evaluation of the coefficients in the series. 


\section{REETERET:CES}

1. Dally, J.W. "Dymamic Photoelastic Studies of Fracture," Experimental Mechanics, Vol.19, Lo. 10, Pp. 349-61, october 1979.

2. Lobayashi, A. S., Wade, B. G. and Bradley, W. B. , "Fracture Dynamics of Homalite 100," Deformation and Fracture of High Polymers, eds. H. H. Kausch, J.A.Hassell, and R. I. Jaffee, Plenum Press, KY, pp. 487-500, 1973.

3. Theocaris, P.S. and Gdoutos, E. "An Optical Hethod for Determining Opening-Mode and Edge sliding-Mode StressIntensity Factors," J. Appl. Mechanics, Vol. 39, Ho. 1, March 1972, pp. $91-97$.

4. Kalthoff,J.F. and et al, "Experimental Analysis of Dynamic Effects in Different Crack Arrest Test Specimens," ASTM STP711 - Crack Arrest Methodology and Applications, American. Society for Testing and Haterials, Philadelphia, USA, 1980, pp. 109-127.

5. Ravi-chander, $\mathbf{R}$. and Kanauss, W. G. , "An experimental investigation into Dynamic Fracture: I Crack Initiation and Arrest," International Journal of Fracture, Vol.25, 1984, pp. 247-262.

6. Rosakis, A.J., "Experimental Determination of the Fracture Initiation and Dynamic Crack Propagation Resistance of Structural steels by the Optical Method of Caustics," PhD Thesis, Brown University, June 1982.

7. Kobayashi, T. and Dally, J.W., "Dynamic Photoelastic Determination of the a-K Relation for 4340 Alloy Steel," Crack Arrest MethodologY and Applications, ASTM STP 711 , 1980, pp. 189-210.

8. Irw1n, G. R., "Series Representation of the Stress Field Around Constant Speed Cracks," Univ. of Haryland Lecture Lotes, 1980.

9. Irwin, G. R., "Constant Speed Semi-Infinite Tensile Crack Opened by a Line Fotce, $P$, at a Distance, $b$, from the Leading Edge," Leigh Univ. Kotes.

10. Irwin, G.R., "Analysis of stresses and Strains Near the End of a Crack Traversing a Plate," J. Appl. Hechanics, Vol.24, No. 3, 1957.

11. Dally,J.W. and Sanford, R.J.,"strain Gage Methods 
forleasuring the opening mode Stress Intensity Factor," SEM Spring Conference Proceedings 1985, Las Vegas, pp. $851-60$.

12. Shukla, A. and $\mathrm{Nigam}, \mathrm{H}$. "A note on the Stress Intensity Factor and Crack Velocity Relationship for Homalite 100," Engineering Fracture Mechanics, 1986, Vol.25, Mo. 1, pp. 91-102.

13. Hetcalf,J.T. and Kobayashi, T., "Comparison of Crack Behavior in Homalite 100 and Araldite B, "Crack Arrest Hethodology and Applications, ASTM STP 711, 1980, pp. $128-145$.

14. Rosakis, A. J. and Ravi-chander, K. "On Crack Tip Stress State: An Experimental Evaluation of Three-Dimensional Effects," California Institute of Technology Report, SM 84-2, March 1984.

15. Manog8, P., "Investigation of the rupture of a Plexiglas Plate by means of an Optical Method Involving High-speed Filming of the Shadows Originating Around Holes Drilling in the Plate," International Journal of Fracture Mechanics, 2, 1966, pp. 604-613.

16. Theocaris,P.S. "Caustics for the Determination of Singularities in Cracked Plates," Proceedings of IUT Symposium on Optical Methods in Mechanics of Solids, Univ. of Poitires, (1979).

17. Beinert, J. and Kalthoff, J.F., "Experimental determination of dynamic stress intensity factors by shadow patterns," Mechanics of Fracture, vol. VII, G.C.Sih, ed., Noordhoff Int. Publishing, London, The Letherlands, 1981.

18. Rosakis, A. J., Ma, C. C. and Freund, L. B., "Analysis of the Optical Shadow Spot Method for a Tensile Crack in a Power-Law Hardenine Material," Journal of Applied Mechanics, vol. 105. December 1983, pp. 777-782.

19. Dally, J.W., "Dynamic Photoelastic studies of Fracture," Experimental Mechanics, vol. 19, No. 10, October 1979. pp. 349-361.

20. Etheridge, J.M. and Dally, J.W., "A Simplified Three Parameter Method For Determining stress Intensity Factor," Mechanics Research Communication, vol. 5(1), 1978, pp. 21-26.

21. Etheridge,J.M. and Dally, J.W., "A Three Parameter Method 
for Determining Stress Intensity Factor from Isochromatic Fringe Loops," Journal Strain Analysis, $13(2), 1978$, pp. $91-94$.

22. Sanford, R.J. and Dally, J.W., "A General Method for Determining Mixed-mode stress Intensity Factor from Isochromatic Fringe Patterns, Journal of Engineering Fracture Mechanics, 11, 1979, pp. 621-633.

23. Kobayashi, Takao and Dally, J.W., "Dynamic Photoelastic Determination of the $\mathbf{a}-\boldsymbol{K}$ Relation for 4340 Alloy Steel," Crack Arrest Methodology and Applications, ASTM STP 711, G. T. Hann and M. F. Kanninen, Eds., American Society forTesting Materials, 1980, pp. 189-210.

24. Der, V.K., Barker, D. B., and Holloway, D. C., "A Split Birefringent Coating Technique to Determine Dynamic Stress Intensity Factors," Mech. Res. Comm., Vol. 5(6), 1978, pp. 313-18.

25. Mesnager, M. : Sur la determination optique des tensions interieures dans les solides a trois dimensions, C. R. (Paris), vol. 190, Pp. $1249,1930$.

26. Oppel, G. : Das polarrisationsoptische Schicchtverfahren zur Messung der Oberflachenspannung ambeaspruchten Bautell ohne Modell, Z. Ver. Dtsch. Ing., vol. 81, pp. 803-804, 1937.

27. Fleury, R., and F. Zandman: Jauge d'efforts photoelastique, C. R. (Paris), vol. 238, pp. $1559,1954$.

28. D'Agostino, J., D. C. Drucker, C. K. Liu, and C. MYlonas: An Analysis of Plastic Beharior of Hetals with Bonded Birefringent Plastic, Proc. SESA, vol. XII, No. 2 , pp. 115-122, 1955.

29. Kawata, K. : Analysis of Elastoplastic Behavior of Metals by Means of Photoelastic Coatings Method, J. Sc1. Res. Instrum, Tokyo, Vol. 52, pp. 17-40, 1958.

30. Van Elst, H. C. "DYnamic Crack Propagation," G. C. Sih, Ed. Hoordhoff International Publishing, Leyden, The Netherlands, 1972, pp. 283-332.

31. Daniel, I. $M$. and Rowlands, R. E. "Experimental Mechanics," Vol. 15, Dec. 1975, pp. 449-457.

32. Der, v. K. , Barker, D. B., and Holloway, D. C., "A split Birefringent Coating Technique to Determine Dynamic Stress Intensity Factors," Mech. Res. Comm., Vol. 5(6), 1978, pp. $313-18$. 
33. Kawata, R. , Takeda, K., and Hashimoto, S., "Photoelast1ccoating Analysis of Dynamic stress Concentration in Composite Strips," Expt. Mech., vol. 24, No. 4, Dec. 1984, Pp. $316-327$.

34. Chona, R., Irwin, G. R., and Sanford, R. J., "Influence of Specimen Size and Shape on the Singularity Dominated Zone," Fracture Hechanics: Fourteenth Symposium - Vol I: Theory and Analysis, ASTM STP 791, Lewis and Sines, Eds. Amer. Soc. for Testing and Materials, 1983, pp. I3-I-23.

35. Zandman, F., Redner, S., and Dally, J. W., "Photoelastic Coatings," Society for Experimental stress Analysis Monograph No. 3, Iowa State University Press, Ames, Iowa, 1977.

36. Freund, L. B. " "Influence of the Reflected Raleigh Wave on a Propagating Edge Crack," International Journal of Fracture, vol. 17, 1981, pp. 83-86.

37. Rosakis, A. J., "Experimental Determinetion of the Fracture Initiation and Dynamic Crack Propagation Resistance of Structural Steels by the Optical Hethod of Caustics," Ph. D. Thesis, Brown University, 1982.

38. Tada, Irwin, G. R. and Paris, "The Stress Analysis of Cracks Handbook," Del Research Corporation, 1973. 
APPEADIX 


\section{APPLICATION OF PHOTOELASTICITY TO THE OYMAMIC EQUATIONS}

The stress optic law, which relates the optical properties of the material to its stress state, is given by

$$
2 \tau_{m}=\frac{N f_{a}}{h}
$$

where $\tau_{M}$ is the maximum for plane shear stress, $f_{0}$ the material fringe value, $n$ the thickness of the model and $N$ the order of the fringe in consideration.

It is known that

$$
\begin{aligned}
\left(2 \tau_{m}\right)^{2} & =\left(\sigma_{y}-\sigma_{x}\right)^{2}+4 \tau_{x y}^{2} \\
\tau_{m}^{2} & =\left(\frac{\sigma_{y}-\sigma_{x}}{2}\right)^{2}+\tau_{x y}^{2}
\end{aligned}
$$

Combining equations (E.73) and (E.74), we get

$$
\left(\frac{N f_{g}}{2 h}\right)^{2}=\left(\frac{\sigma_{y}-\sigma_{x}}{2}\right)^{2}+\tau_{x y}^{2}
$$


The expressions for $(0 x-O y) / 2$ and $\operatorname{TXY}_{\mathrm{X}}\left(\mathrm{E}_{-}\right)$to $\left(\mathrm{E}_{-}\right)$) can be substituted into equation (E.81) to obtain an equation connecting the series constants, the fringe order, the material fringe value, and the polar coordinates $r$ and $\bullet$. The function

$$
\left(\frac{N f_{\alpha}}{2 h}\right)^{2}-\left(\frac{\sigma_{y}-\sigma_{x}}{2}\right)^{2}-\tau_{x y}^{2}
$$

is denoted by $G_{K}$ and $\left(O_{X}-O_{Y}\right) / 2$, and $\tau_{X Y}$ are denoted by $D$ and $T$ respectively.

$$
G_{k}=\left(\frac{N f_{\sigma}}{2 h}\right)^{2}-\Delta^{2}-T_{0}^{2}
$$

taken at the $k^{\text {th }}$ data point.

A combination of least squares and Newton-Raphson techniques is applied to this function as follows.

\section{THE OVERDETERMINISTIC METHOD}

The approach used is that suggested by Sanford and Dally [8]. The series constants must be determined to make $6_{k}=0$. Though equation (E.76) can be solved in closed form, the algebra becomes quite involved and a simpler numerical method based on the Newton-Raphson technique is employed. 
In the overdeterministic method, the function is evaluated at a large number of data points in the stress field. If initial estimates are given for the series constants in equation (E.76), $G_{K} \neq 0$, since the initial estimates will usually be in error. To correct the estimates, a series of iterative equations based on a Taylor series expansion of GK are written as

$$
\left(G_{k}\right)_{i+1}=\left(G_{k}\right)_{i}+\left[\frac{\partial G_{k}}{\partial A_{0}}\right] \Delta A_{0}+\left[\frac{\partial G_{k}}{\partial A_{1}}\right] \Delta A_{1}+\cdots
$$

where the subscript $i$ refers to the $i$ th iteration step and $\Delta A_{0}$, $\Delta A_{1}$, etc. are corrections for the previous estimates of $A_{0}, A_{1}$, etc.

The corrections are determined in order that $\left(G_{K}\right)(i+1)$ and thus equation (E.77) gives

$$
\left[\frac{\partial G_{k}}{\partial A_{0}}\right] \Delta A_{0}+\left[\frac{\partial G_{k}}{\partial A_{1}}\right] \Delta A_{1}+\cdots=-\left(G_{k}\right)_{i}
$$

The method of least squares involves the determination of the series coefficients so that equation (E.76) is fitted to a large number of data points in the isochromatic field. 
Equation (E.78) in the matrix form gives

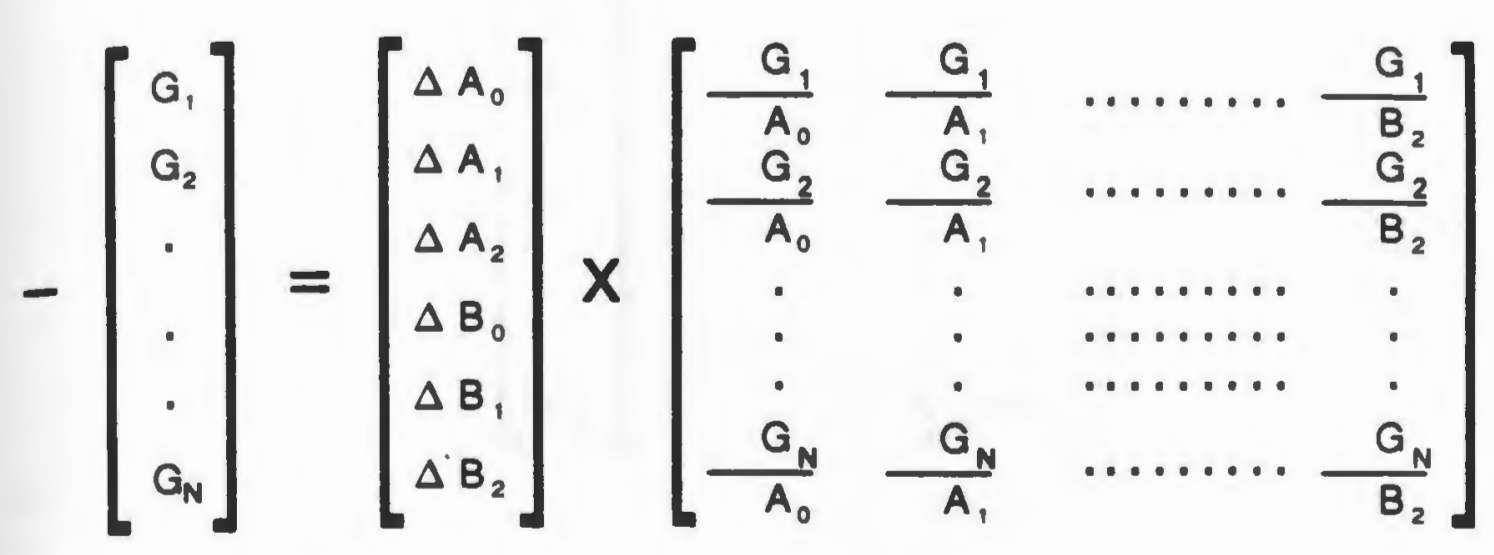

where $N$ is the total number of data points considered. The above equation can be put in the form of

$$
G=[a][\Delta A]
$$


where

$$
G=\left[\begin{array}{c}
G_{1} \\
G_{2} \\
\cdot \\
\cdot \\
\cdot \\
G_{N}
\end{array}\right] \quad \Delta A=\left[\begin{array}{c}
\Delta A_{0} \\
\Delta A_{1} \\
\cdot \\
\cdot \\
\cdot \\
\Delta B_{2}
\end{array}\right]
$$

and

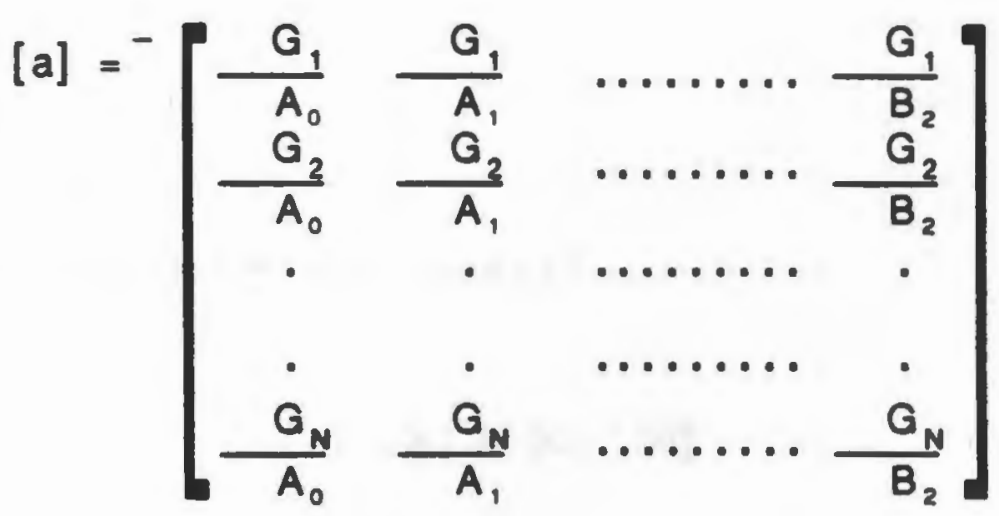


Premultiplying by at (transposition of a),

$$
[a]^{\top} G=[a]^{\top}[a][\Delta A]
$$

or

$$
[d]=[c][\Delta A]
$$

where

$$
[d]=[a]^{\top} G
$$

and

$$
[c]=[a]^{\top}[a]
$$

The correction factors are given by

$$
[\Delta A]=[c]^{-1}[d]
$$


The solution of equation (E.80) gives $\Delta A_{j}$ and $\Delta B_{j}(i=0,1,2)$

which are used to correct the initial estimates of $A_{j}$ and $B_{i} ;$ i.e.,

$$
\begin{aligned}
& \left(A_{0}\right)_{i+1}=\left(A_{0}\right)_{i}+\Delta A_{0} \\
& \left(A_{1}\right)_{i+1}=\left(A_{1}\right)_{i}+\Delta A_{1} \\
& \left(B_{0}\right)_{i+1}=\left(B_{0}\right)_{i}+\dot{\Delta} B_{0}
\end{aligned}
$$

This procedure fits the function $G_{K}\left(A_{i}, B_{i}\right)$ to the $K$ data points in the determination. The convergence of the method is rapid and usually five to ten iterations are sufficient for obtaining precise values. The number of data points used depends upon the fringe pattern being analyzed. If several fringes exist at the crack tip, 20 data points should be employed with $r$ and - measured from four different fringe loops; i.e., two above and two below the crack. 
The whole iteration process has been set up in a computer program written in BASIC. The data points from the isochromatic field are put into the computer with the help of a Calcomp 9000 digitizer. The HP9845A microprocessor is used for computing the series constants iteration after iteration. Appendix $C$ contains a listing of this program.

It is possible to then check the fit of $G_{k}$ to the input data by using the results for $A_{0}, A_{1}, A_{2}, B_{0}, B_{1}, B_{2}$ in equation (E.78) and to plot the analytically determined isochromatic-fringe pattern. If the input data are then superposed on this fringe pattern, the adequacy of the fit between the solution and the data can be determined. 


\section{IELIOCRAPHT}

Beinert, J. and determination of dynamic stress intensity factors by shadow patterns," Mechanics of Fracture, vol. VII, c. C. Sih, ed., Noordhoff Int. Publishing, London, The Ketherlands, 1981.

2. Chona, R., Irwin, G. R., and Sanford, R. J., "Influence of Specimen Size and Shape on the Singularity Dominated zone," Fracture Mechanics: Fourteenth Symposium - Vol I: Theory and Analysis, ASTM STP 791, Lewis and Sines, Eds., Amer. Soc. for Testing and Materials, 1983, Pp. I3-I - 23.

3. Cole, A. A., Quinlan, J. F., and Zandman, F., "The Use of High Speed Photography and Photoelastic Coatings for the Determination of Dynamic Strains," Proc. 5 th Int 1 . Cong. High-Speed Photography, 250-261 (1962).

4. D'Agostino, J., D.C. Drucker, C.K.Liu, and C. MYlonas: An Analysis of Plastic Behavior of Metals with Bonded Birefringent Plastic, Proc. SESA, vol. XII, No. 2 , pp. $115-122,1955$.

5. Dally,J.W., Reley, W. F., and Durel1i, A. J., "A Photoelastic Approach to Transient Stress Problems Employing Low Modulus Materials," J. Appl. Mech., 81, $613-620$ (1959).

6. Dally,J.W., "Dynamic Photoelastic studies of Fracture," Experimental Mechanics, vol. 19, No. 10, October 1979. pp. 349-361.

7. Dally,J.W. and Sanford, R.J.,"strain Gage Methods forMeasuring the opening mode Stress Intensity Factor," SEM Spring Conference Proceedings 1985, Las Vegas, pp. $851-60$.

8. Daniel, I. M. and Rowlands, R. E., "Experimental Mechanics, Vol. 15, Dec. 1975, pp. 449-457.

9. Der, V. R., Barker, D. B., and Holloway, D. C., "A Split Birefringent Coating Technique to Determine Dynamic Stress Intensity Factors," Mech. Res. Comm., Vol. $5(6)$, 1978, pp. 313-18.

10. Etheridge, J.M. and Dally, J.W., "A Three Parameter Method for Determining Stress Intensity Factor from Isochromatic Fringe Loops," Journal Strain Analysis, 
13(2), 1978, pp. 91-94.

11. Etherldge, J. M. and Dally, J.W. "A Simplified Three Parameter Method For Determining Stress Intensity Factor," Mechanics Research Communication, vol. 5(1), 1978, pp. 21-26.

12. Fleury, R., and F. Zandman: Jauge d'efforts photoelastique, C.R. (Paris), vol. 238, pp. 1559, 1954.

13. Freund, L. B. "Influence of the Reflected Ralelgh Wave on a Propagating Edge Crack, " International Journal of Fracture, vol. 17, 1981, pp. 83-86.

14. Irwin, G. R., "Constant Speed Semi-Infinite Tensile Crack opened by a Line Fotce, $P$, at a Distance, $b$, from the Leading Edge," Leigh Univ. Hotes.

15. Irwin, G. R., "Series Representation of the Stress Field Around Constant Speed Cracks," Univ. of Maryland Lecture Hotes, 1980.

16. Irwin, G. R. " Analysis of stresses and Strains Near the End of a Crack Traversing a Plate," J. Appl. Mechanics, Vol. 24, No. 3, 1957.

17. Kalthoff, J.F. and et al, "Experimental Analysis of Dynamic Effects in Different Crack Arrest Test Specimens," ASTM STP711 - Crack Arrest Methodology and Applications, American Society for Testing and Materials, Philadelphia, USA, 1980, Pp. 109-127.

18. Kawata, K. : Analysis of Elastoplastic Behavior of Metals by Means of Photoelastic Coatings Method, J. Sci. Res. Instrun. Tokyo, Vol. 52, pp. 17-40, 1958.

19. Kawata, K. , Takeda, N., and Hashimoto, S. " Photoelasticcoating Analysis of Dynamic stress Concentration in Composite Strips," Expt. Mech., vol. 24, Mo. 4, Dec. 1984, pp. 316-327.

20. Kobayashi, Takao and Dally, J.W. "Dynamic Photoelastic Determination of the a-K Relation for 4340 Alloy Steel," Crack Arrest MethodologY and Applications, ASTM STP 711, G. T. Hahn and M.F. Kanninen, Eds., American Society forTesting Materials, 1980, pp. 189-210.

21. Kobayashi, A.S., Wade, B. G. and Bradley, W. B. , "Fracture Dynamics of Homalite 100," Deformation and Fracture of High Polymers, eds. H. H. Kausch, J. A. Hassell, and R. I. Jaffee, Plenum Press, KY, PP. 487-500, 1973. 
22. Lobayashi, T. and Dally, J.W., "Dynamic Photoelastic Determination of the $\mathbf{A}-\mathrm{K}$ Relation for 4340 Alloy Steel," Crack Arrest Methodology and Applications, ASTM STP 711 , 1980, pp. 189-210.

23. Manog8, P. " "Investigation of the rupture of a Plexiglas Plate by means of an Optical Method Involving High-speed Filming of the Shadows Originating Around Holes Drilling in the Plate," International Journal of Fracture Mechanics, 2, 1966, pp. 604-613.

24. Mesnager, M.: Sur la determination optique des tensions interieures dans les solides a trois dimensions, C.R. (Paris), vol. 190, pp. 1249, 1930.

25. Metcalf, J.T. and Kobayashi, T., "Comparison of Crack Behavior in Homalite 100 and Araldite B, "Crack Arrest Hethodology and Applications, ASTH STP 711, 1980, pp. $128-145$.

26. Oppe1, G. : Das polarrisationsoptische Schicchtverfahren zur Hessung der Oberflachenspannung ambeaspruchten Bauteil ohne Modell, Z. Ver. Dtsch. Ing., vol. 81, pp. 803-804, 1937.

27. Ravi-chander, $\mathbf{K}$. and Kanauss, W. G., "An experimental investigation into Dynamic Fracture: I Crack Initiation and Arrest," International Journal of Fracture, Vol.25, 1984, pp. 247-262.

28. Rosakis, A. J., "Experimental Determinetion of the Fracture Initiation and Dynamic Crack Propagation Resistance of Structural steels by the Optical Method of Caustics," Ph. D. Thesis, Brown University, 1982.

29. Rosakis, A. J., Ma, C. C. and Freund, L. B., "Analysis of the Optical Shadow Spot Method for a Tensile Crack in a Power-Law Hardening Material," Journal of Applied Mechanics, vol. 105, December 1983, pp. 777-782.

30. Rosakis, A.J. and Rav1-chander, K., "On Crack Tip Stress State: An Experimental Evaluation of Three-Dimensional Effects," California Institute of Technology Report, SM 84-2, Harch 1984.

31. Rosakis, A. J., "Experimental Determination of the Fracture Initiation and Dynamic Crack Propagation Resistance of Structural Steels by the Optical Method of Caustics," PhD Thesis, Brown University, June 1982.

32. Sanford,R.J. and Dally, J.W., "A General Method for Determining Mixed-mode stress Intensity Factor from 
Isochromatic Fringe Patterns, Journal of Engineering Fracture Mechanics, 11, 1979, pp. 621-633.

33. Shukla, A. and Migam, H. "A note on the Stress Intensity Factor and Crack Velocity Relationship for Homalite 100," Engineering Fracture Mechanics, 1986, Vol.25, No. 1, pp. 91-102.

34. Tada, Irwin, G. R. and Paris, "The Stress Analysis of Cracks Handbook," Del Research Corporation, 1973.

35. Theocaris,P.S., "Caustics for the Determination of Singularities in Cracked Plates," Proceedings of IUT Symposium on Optical Methods in Mechanics of Solids, Univ. of Poitires, (1979).

36. Theocaris, P.S. and Gdoutos, E., "An Optical Method for Determining Opening-Mode and Edge Sliding-Mode StressIntensity Factors," J. Appl. Mechanics, Vol. 39, No.1, Harch 1972, Pp. 91-97.

37. Van Elst, H. C., "Dynamic Crack Propagation," G. C. Sih, Ed. Noordhoff International Publishing, Leyden, The Metherlands, 1972, pp. 283-332.

38. Zandman, F., Redner, S., and Dally, J. W. , "Photoelastic Coatings," Society for Experimental Stress Analysis Monograph No. 3, Iowa State University Press, Ames, Iowa, 1977. 
TABLE 1

Orientation, $\alpha$ as a function of Poisson's ratio, $v$

\begin{tabular}{|c|c|c|c|}
\hline Poisson's ratio, $v$ & \multicolumn{3}{|c|}{ Orientation, $\alpha$ (deg) } \\
\hline 0.30 & -61.29 & 61.29 & 118.71 \\
\hline 0.33 & -60.00 & 60.00 & 120.00 \\
\hline 0.35 & -59.39 & 59.39 & 120.60 \\
\hline
\end{tabular}


TABLE 2

Mechanical Properties

\begin{tabular}{|c|c|c|c|c|}
\hline PROPERTY & UNITS & HOMALITE 100 & 4340 STEEL & $\begin{array}{r}7075-T 6 \\
\text { ALUMI NUM }\end{array}$ \\
\hline Polsson's ratio & $v$ & 0.35 & 0.30 & 0.33 \\
\hline Density & $p\left(\mathrm{~kg} / \mathrm{m}^{3}\right)$ & 1220 & 7800 & 2700 \\
\hline $\begin{array}{l}\text { Modulus of Elasticity: } \\
\text { Static } \\
\text { Wave propagation } \\
\text { Crack propagation }\end{array}$ & $\begin{array}{ll}\mathrm{E}^{\mathrm{S}} & (\mathrm{MPa}) \\
\mathrm{E}^{\mathrm{S}} & (\mathrm{MPa}) \\
\mathrm{E}^{\mathrm{W}} & (\mathrm{MPa}) \\
\mathrm{C} & \\
\end{array}$ & $\begin{array}{l}3860 \\
4820 \\
4380\end{array}$ & $\begin{array}{l}201,000 \\
210,000 \\
210,000\end{array}$ & $\begin{array}{l}70,000 \\
70,000 \\
70,000\end{array}$ \\
\hline $\begin{array}{l}\text { Wave speed: } \\
\text { Raleigh wave } \\
\text { Pressure wave } \\
\text { Shear wave }\end{array}$ & $\begin{array}{ll}c & (m / s) \\
c^{r} & (m / s) \\
c^{1} & (m / s)\end{array}$ & $\begin{array}{l}1120 \\
2135 \\
1219\end{array}$ & $\begin{array}{l}3720 \\
6201 \\
3217\end{array}$ & $\begin{array}{l}3741 \\
6236 \\
2788\end{array}$ \\
\hline
\end{tabular}


TABLE 3

Properties of Photoelastic coating (PS-1)

\begin{tabular}{|c|c|c|c|c|c|}
\hline POISSON'S, v & \multicolumn{2}{|c|}{ MODULUS, E } & SENSITIVITY, K & STRAIN LIMIT & $f_{\varepsilon}$ \\
\hline \hline$\#$ & ksi & MPa & \# & $\%$ & m/fringes \\
\hline 0.36 & 360 & 2,500 & 0.15 & 10 & 3.906 \\
\hline
\end{tabular}




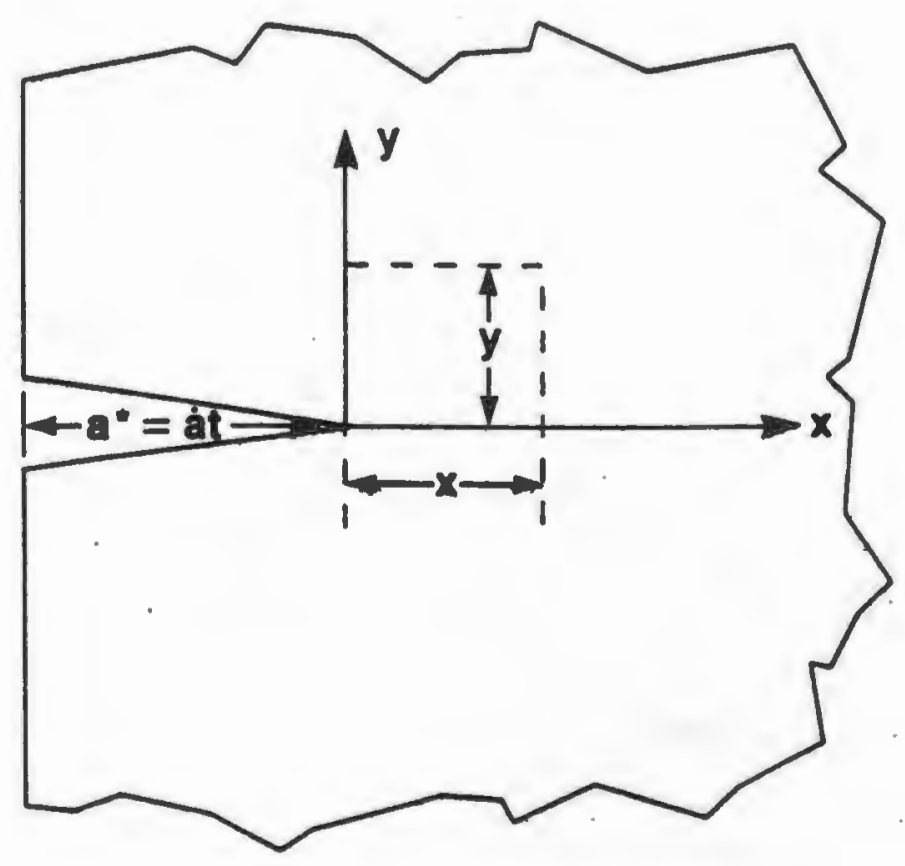

Figure: 1. Coordinate System

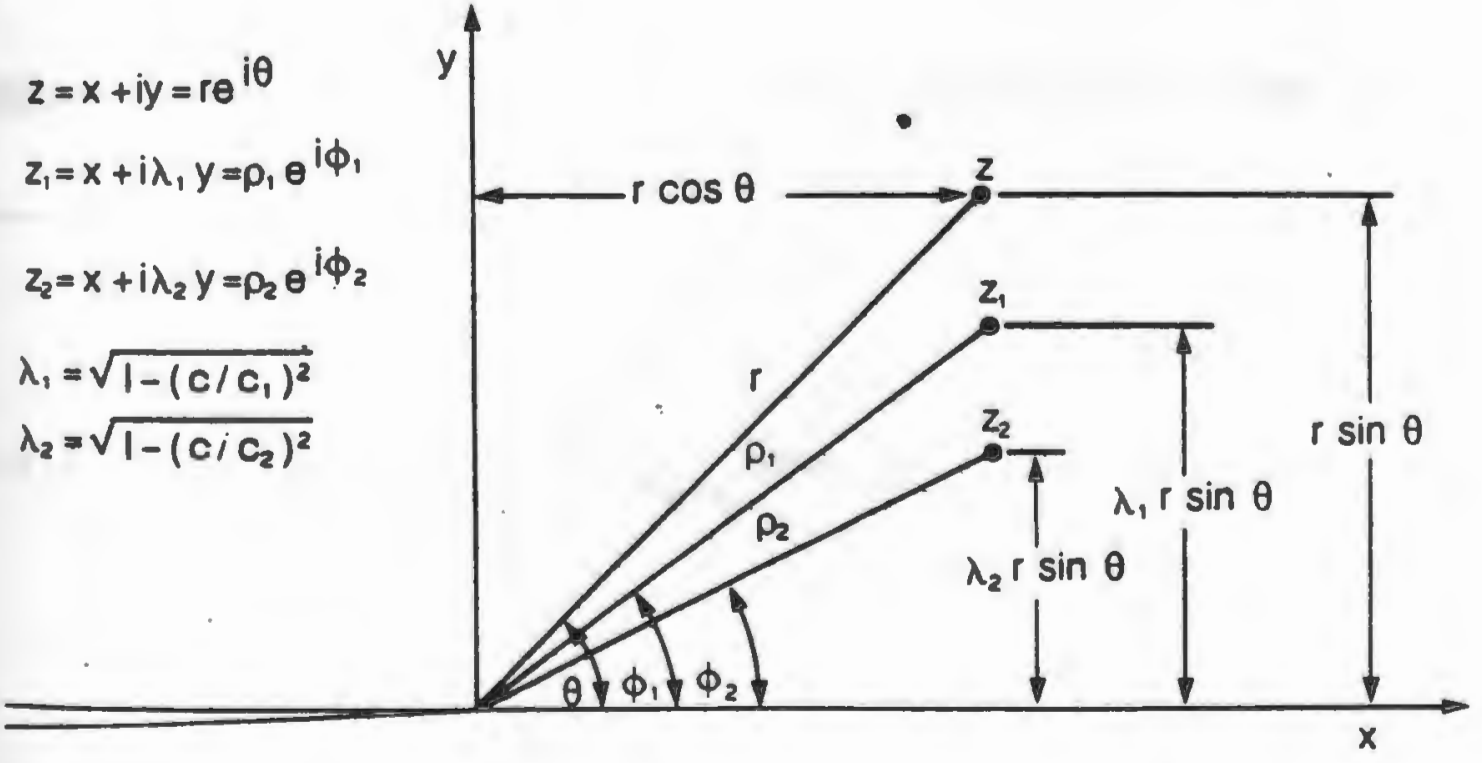

Figure -2 Relationship of the Radif of Complex Variables of the Stress Functions 


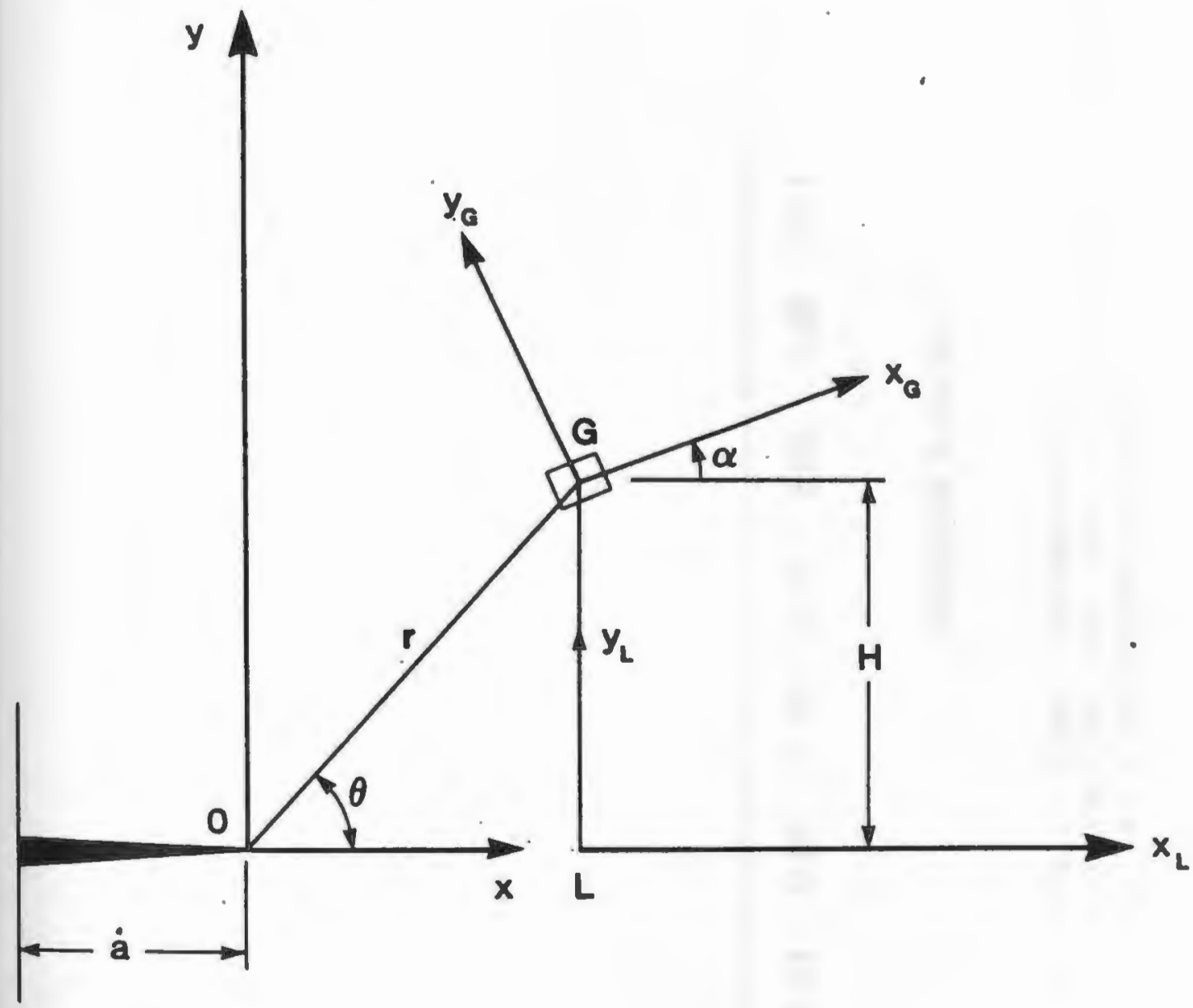

Fig.3 Coordinate system $G_{X_{G} Y_{G}}$ and $L_{X_{L} Y_{L}}$ for strain gage analyses. 


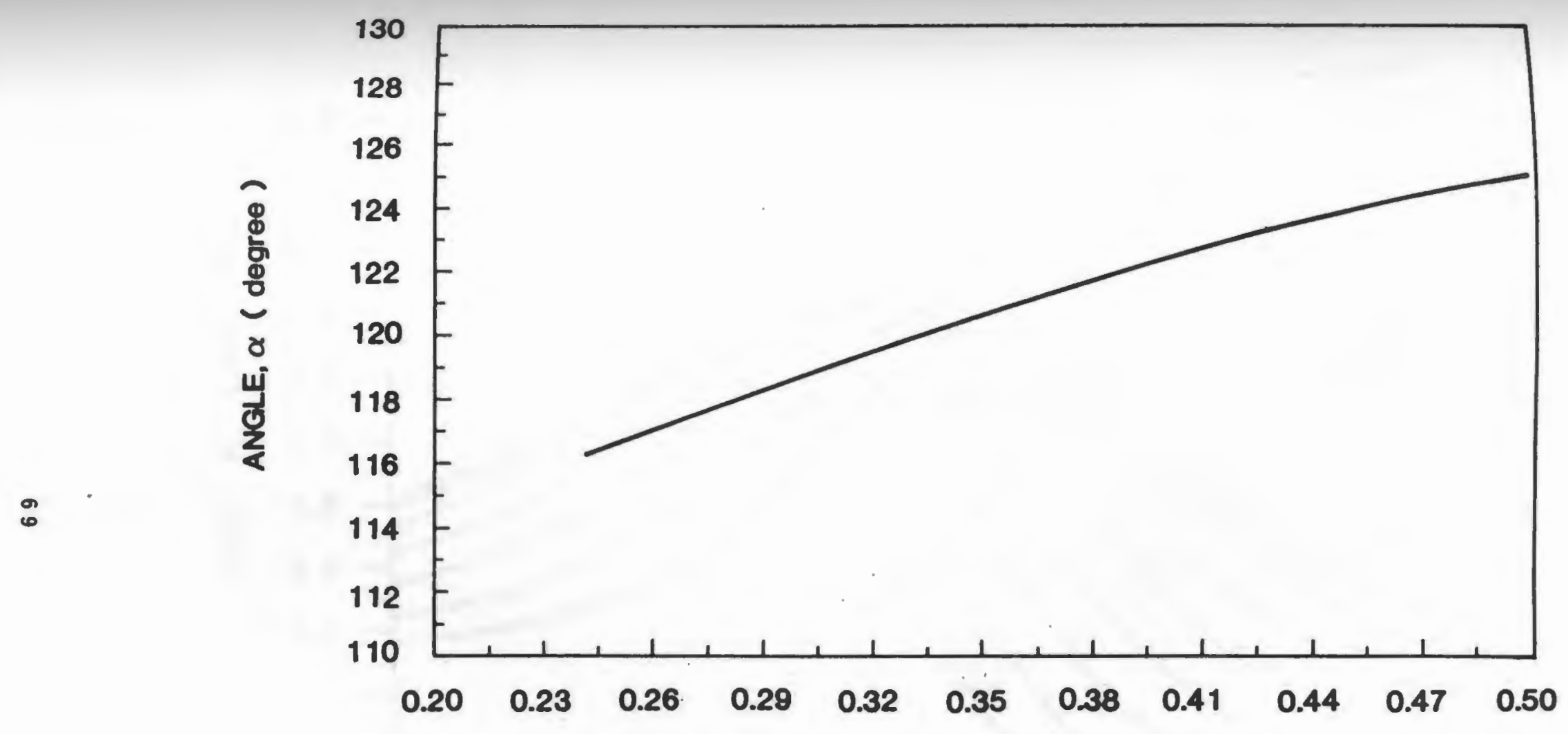

POISSON'S RATIO, $v$

FIG. 4. Strain gage orientation, $\alpha$, for which the contribution of the first nonsingular term drops out, as a function of Poisson's ratio, $v$ 


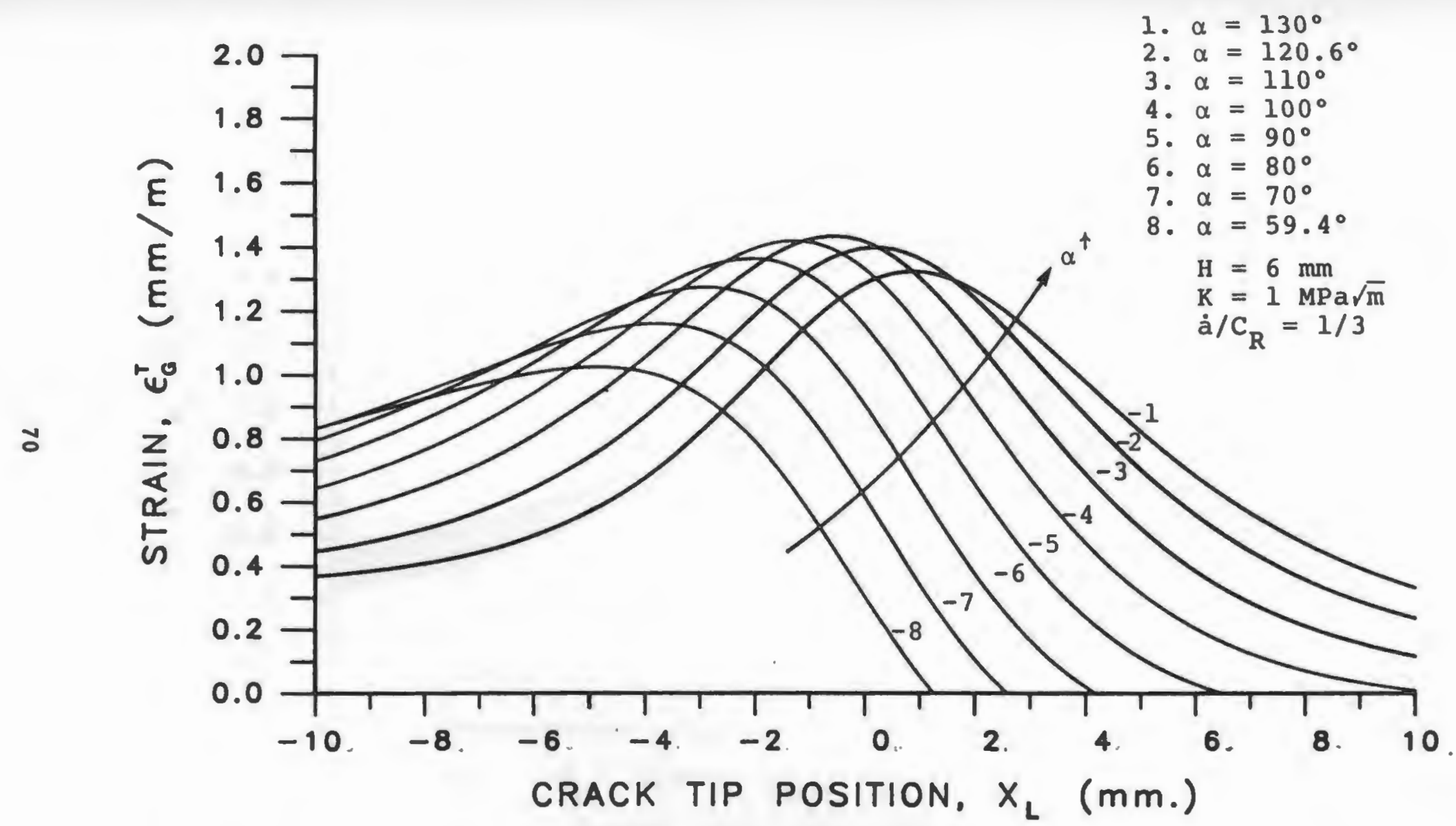

Fig. 5.: Theoretical strain $\varepsilon_{G}^{T}$ as a function of crack tip position, $x_{L}$ for various strain gage orientation angles $\alpha$ at a distance of $6 \mathrm{~mm}$ from the crack propagation path. 


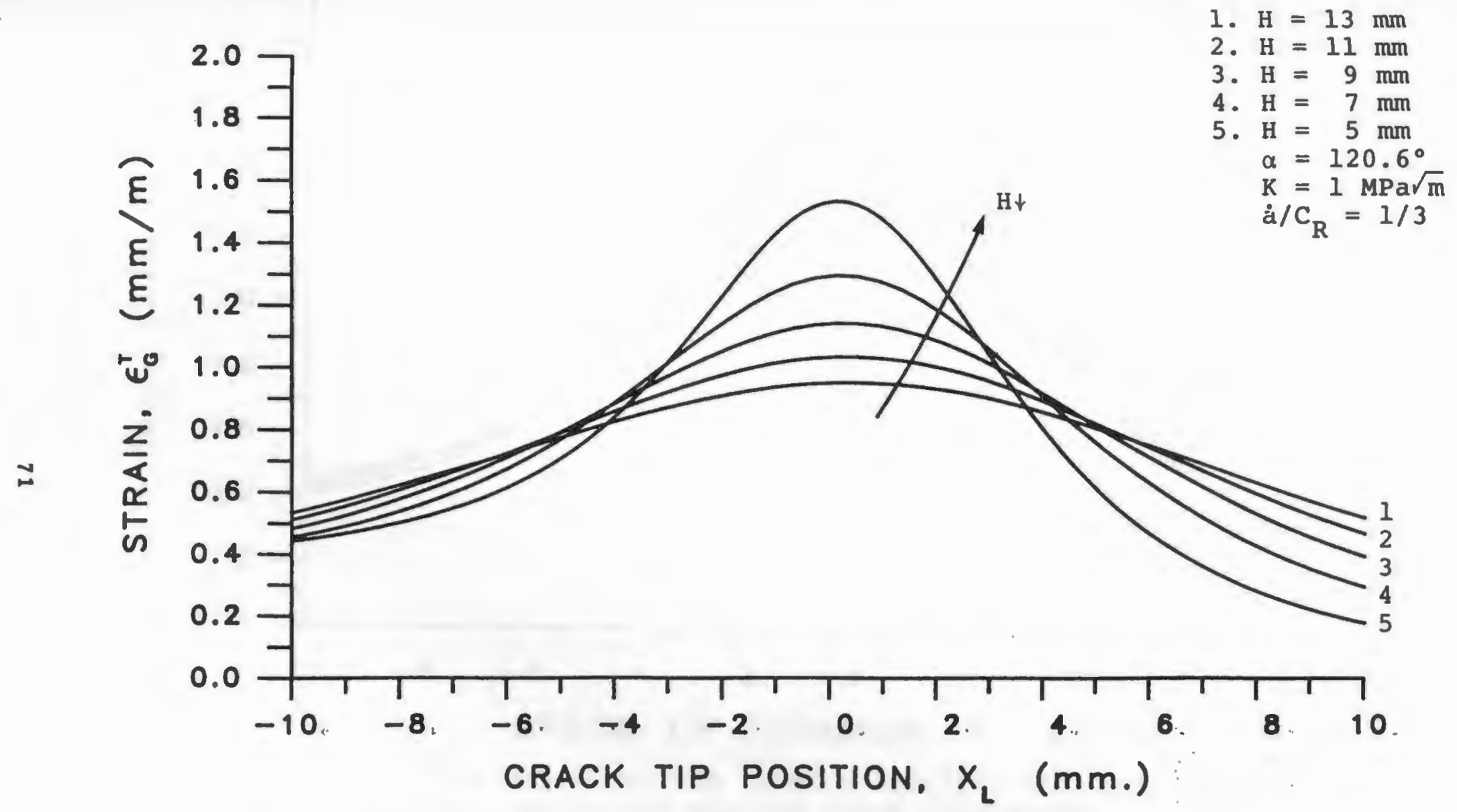

Fig.6 Theoretical strain $\varepsilon_{G}^{T}$ as a function of crack tip position $\mathrm{x}_{L}$ for various strain gage distance $\mathrm{H}$ above the crack propagation path. 


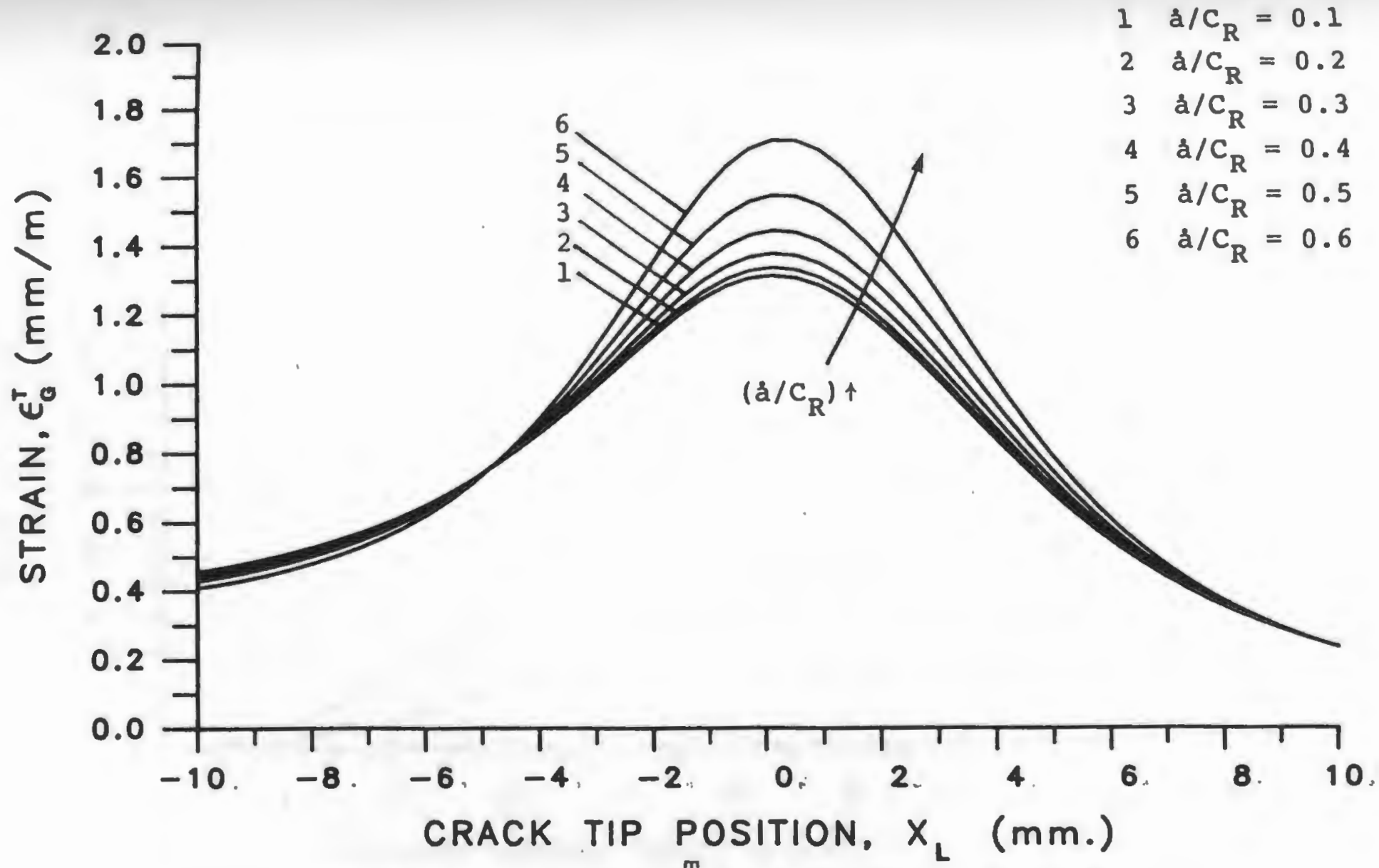

Fig. 7 Theoretical strain $\varepsilon_{G}^{T}$ as a function of crack tip position $x_{L}$ for various crack velocities. 


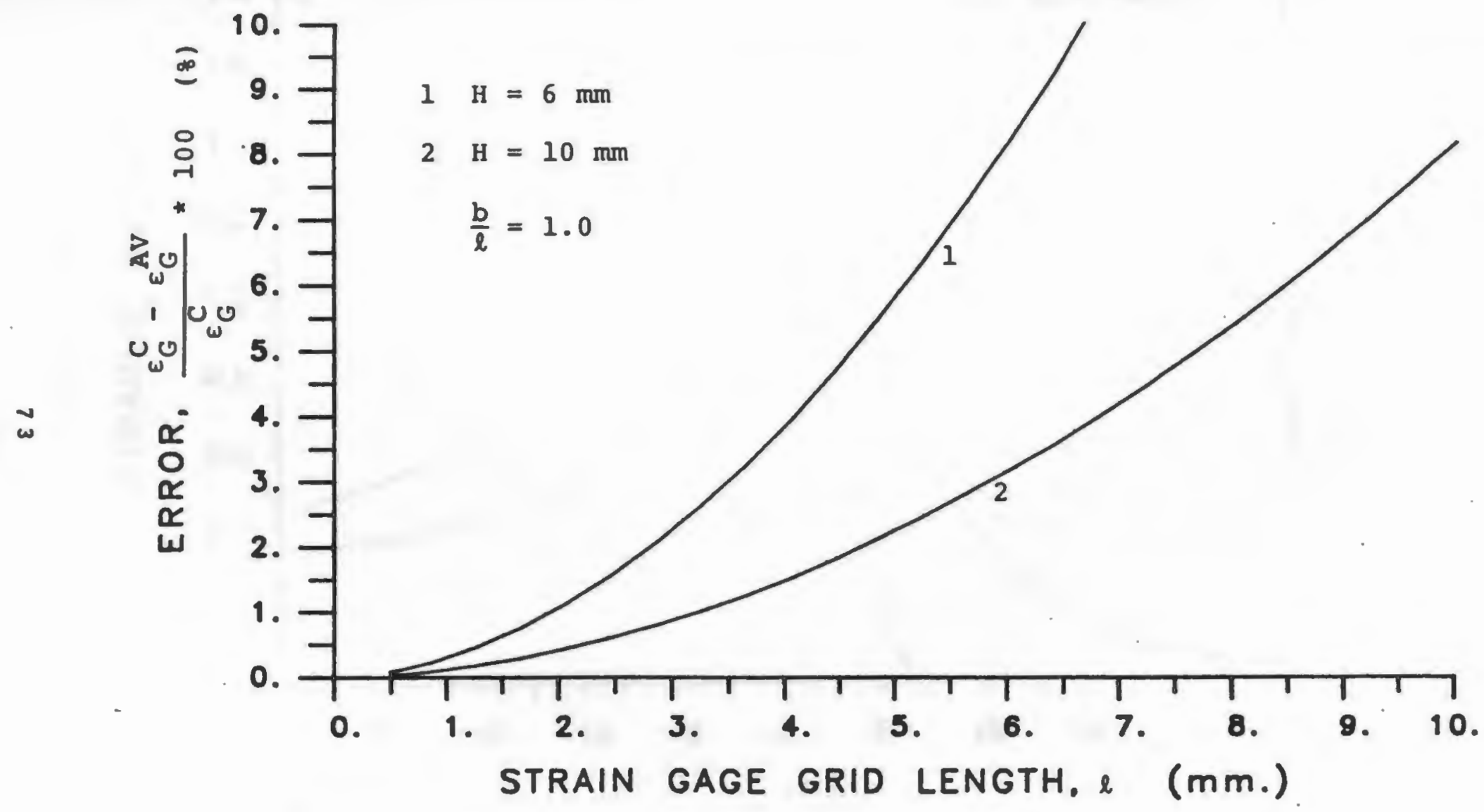

Fig.8. Error in evaluating peak strain $\varepsilon_{G}^{T}$ at the strain gage grid center as a function of strain gage grid length, $\ell$. 


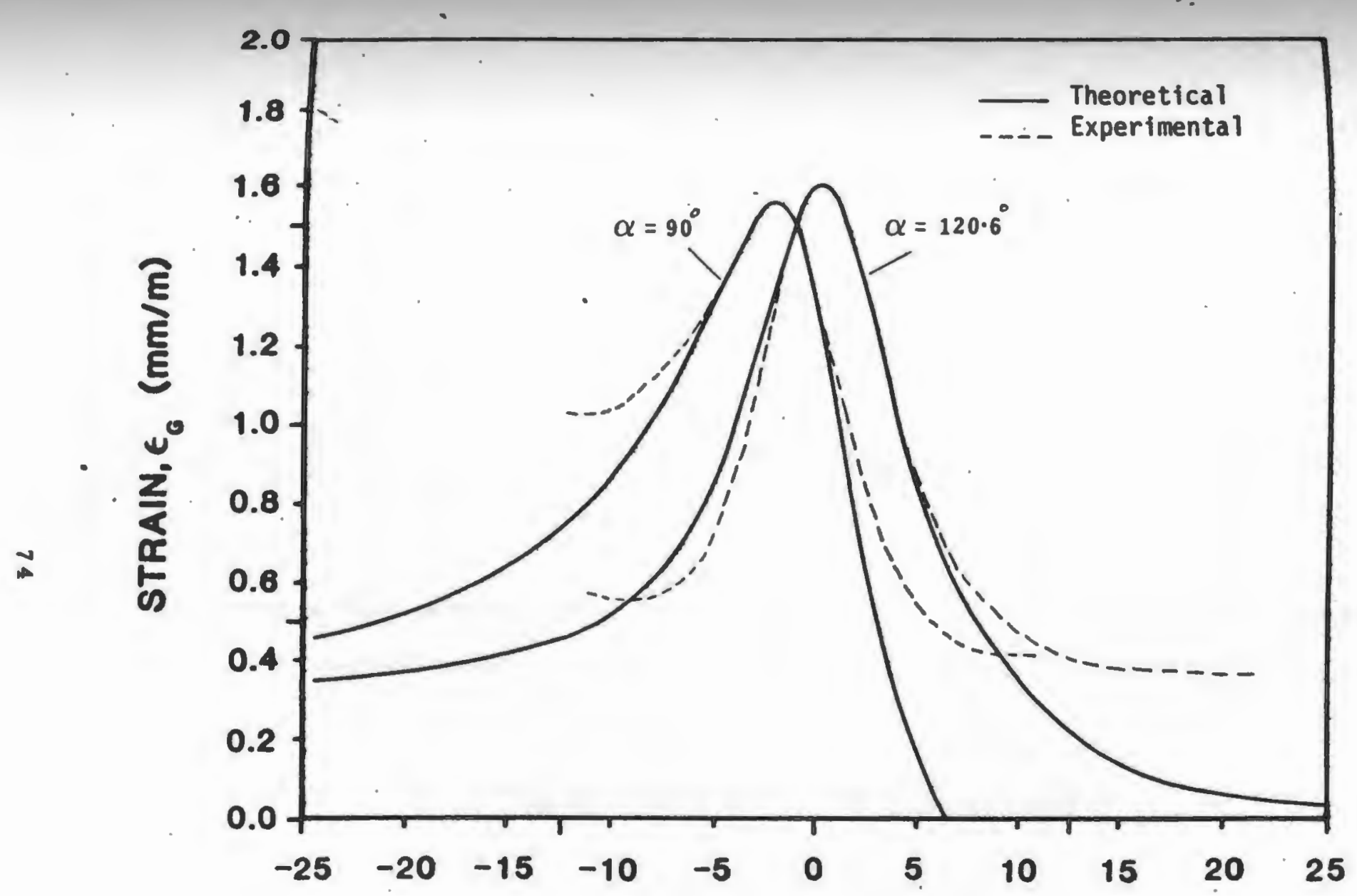

CRACK TIP POSITION, $x_{L}(\mathrm{~mm})$

Fig. 9. Theoretical and experimental strain for strain gage orientation, $\alpha=90$. and 120.6 . on Homalite 100. 

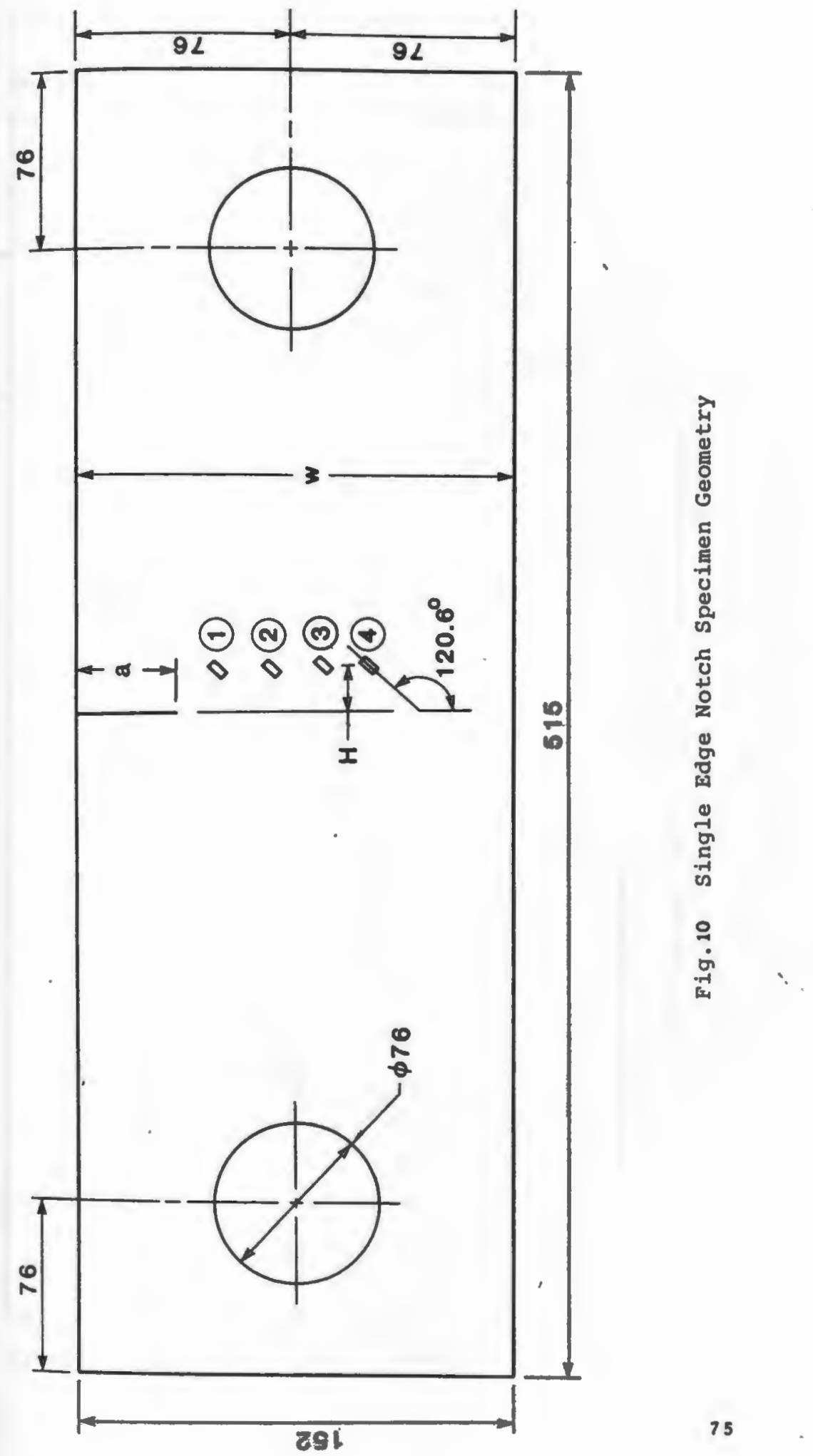


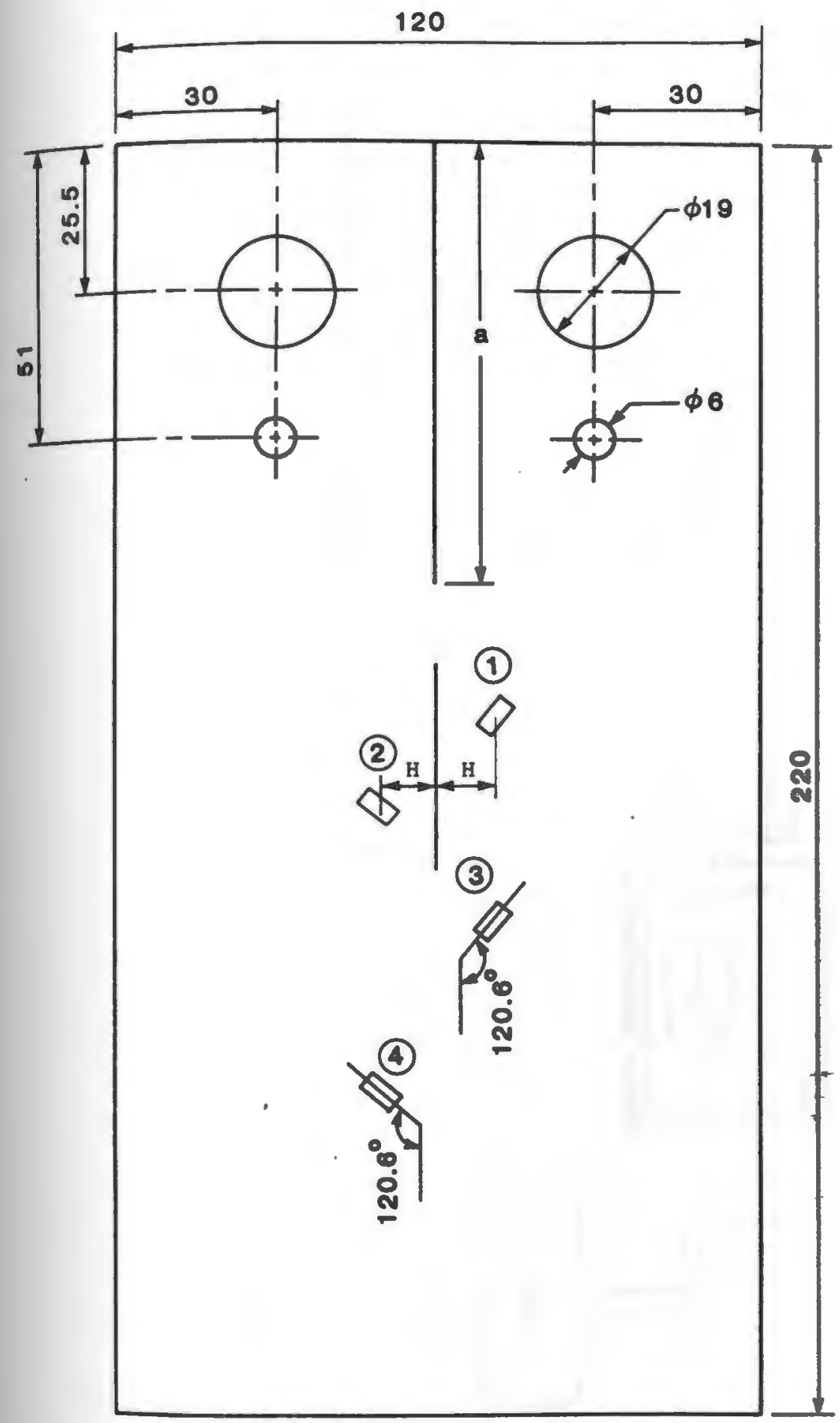

Fig.11 Double Cantilever Beam Specimen Geometry 


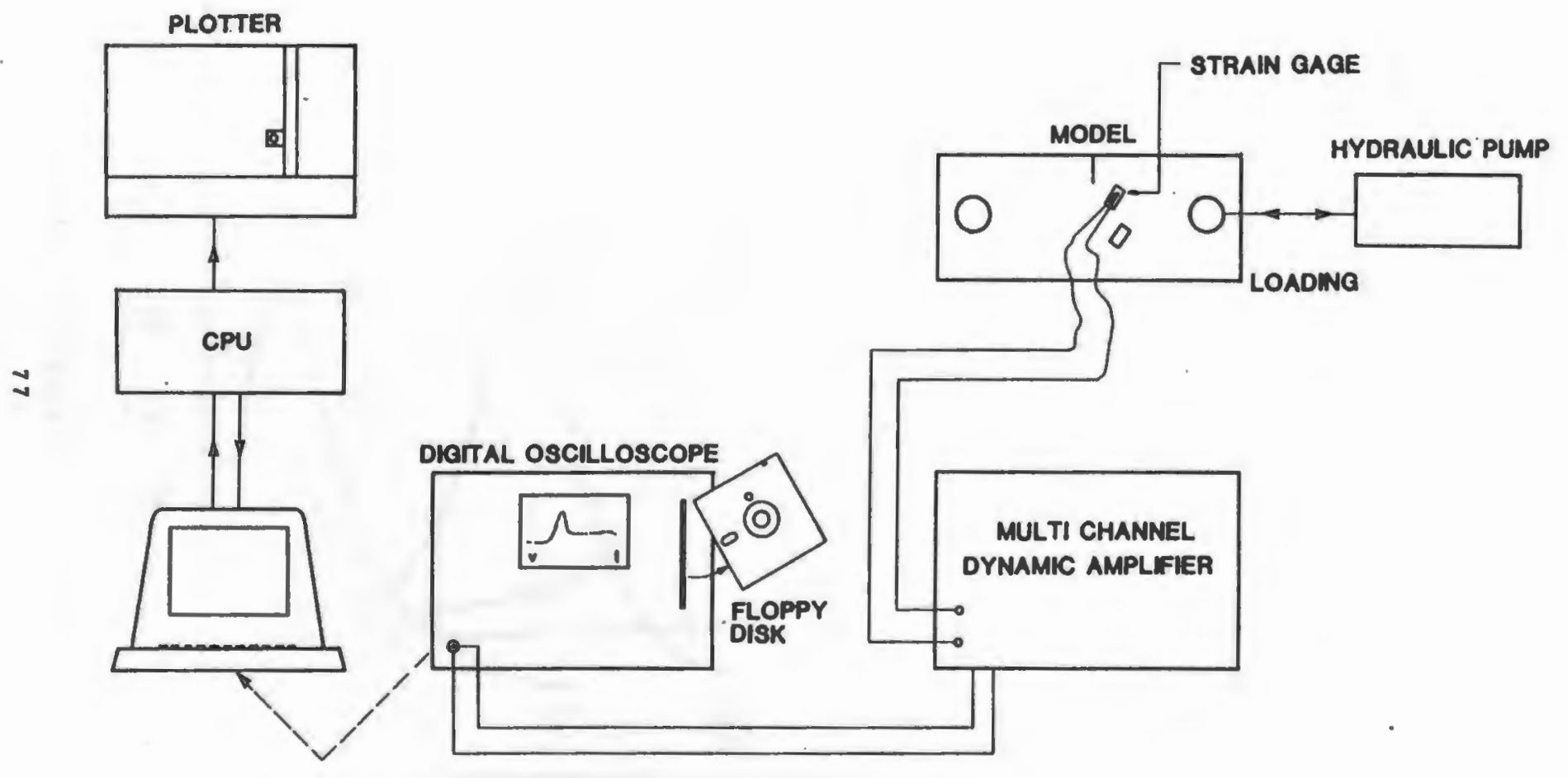

Fig. 12. Schematic for the Strain Gage circuit. 


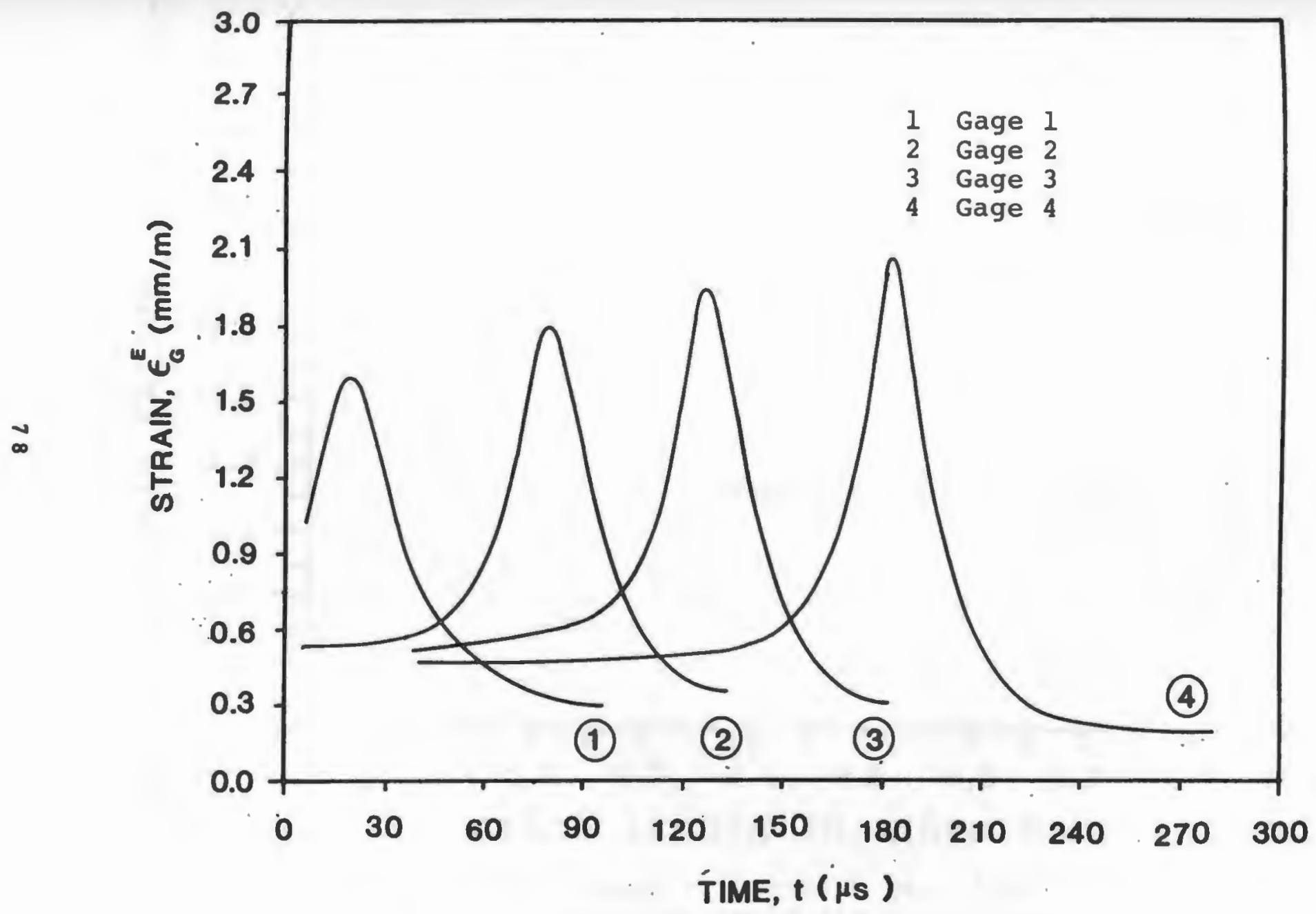

Fig. 13 Typical strain profiles" as a function of time from four strain gages mounted on SEN model. 


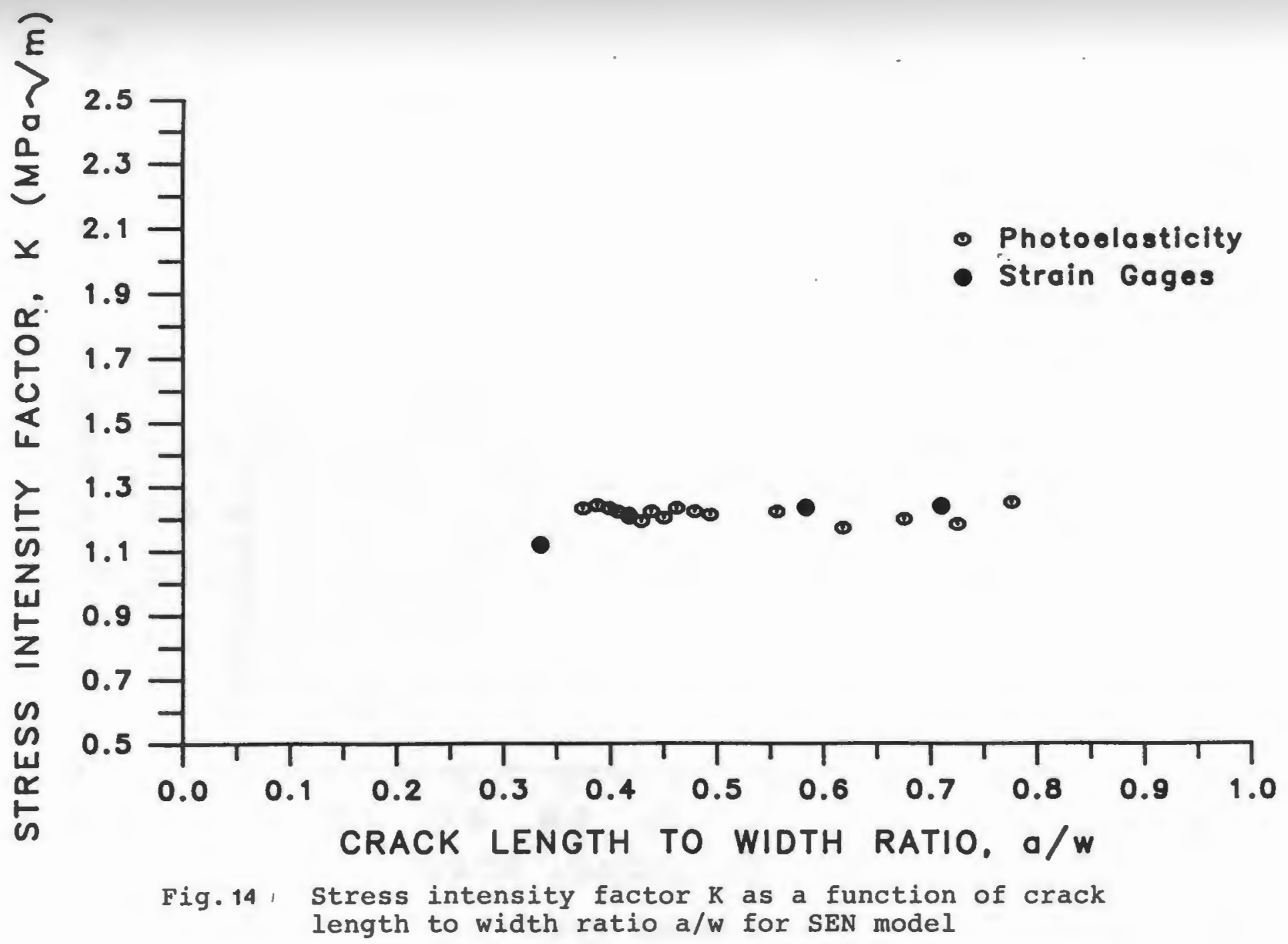




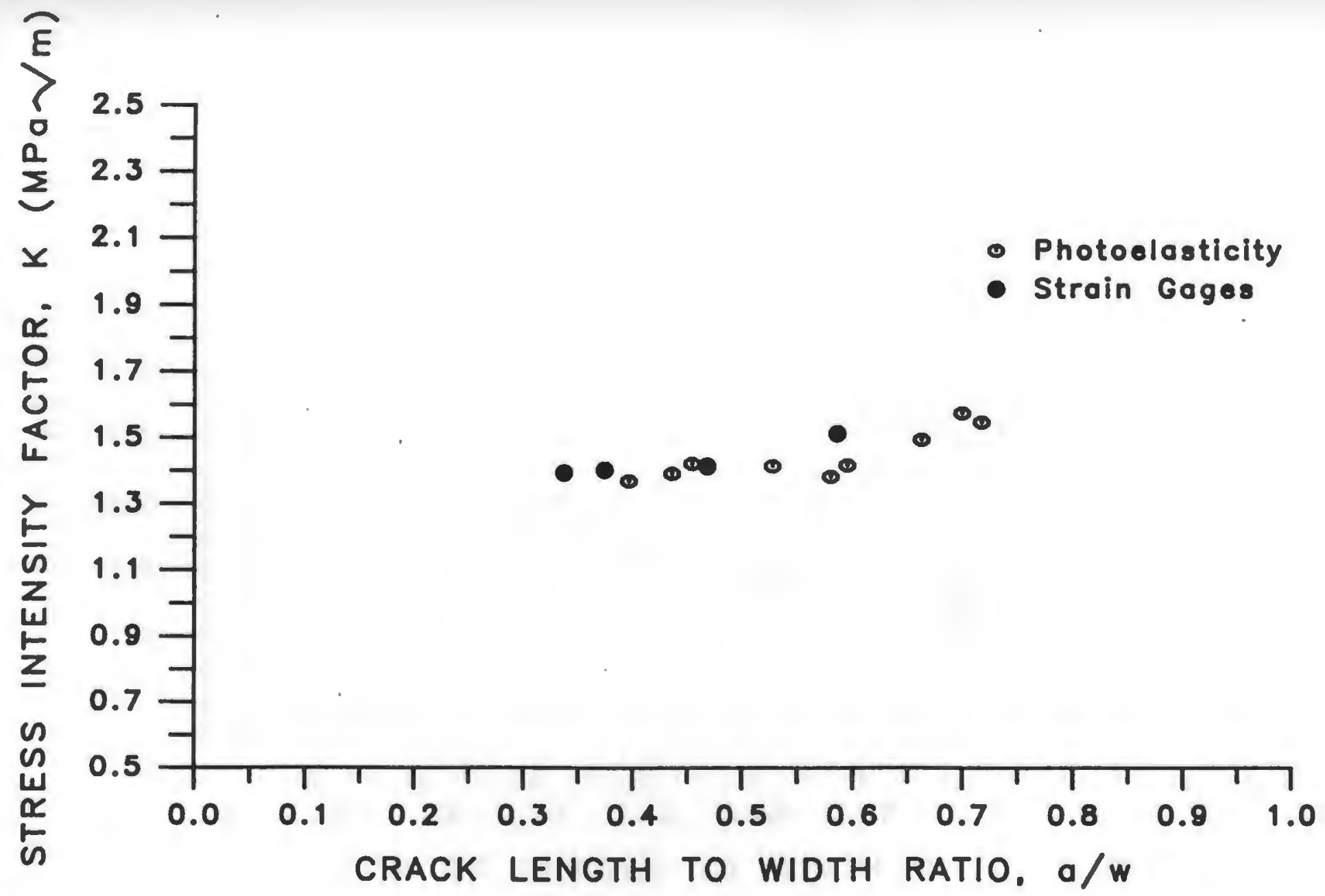

Fig. 15 Stress intensity factor $\mathrm{K}$ as a function of crack length to width ratio a/w for SEN model 


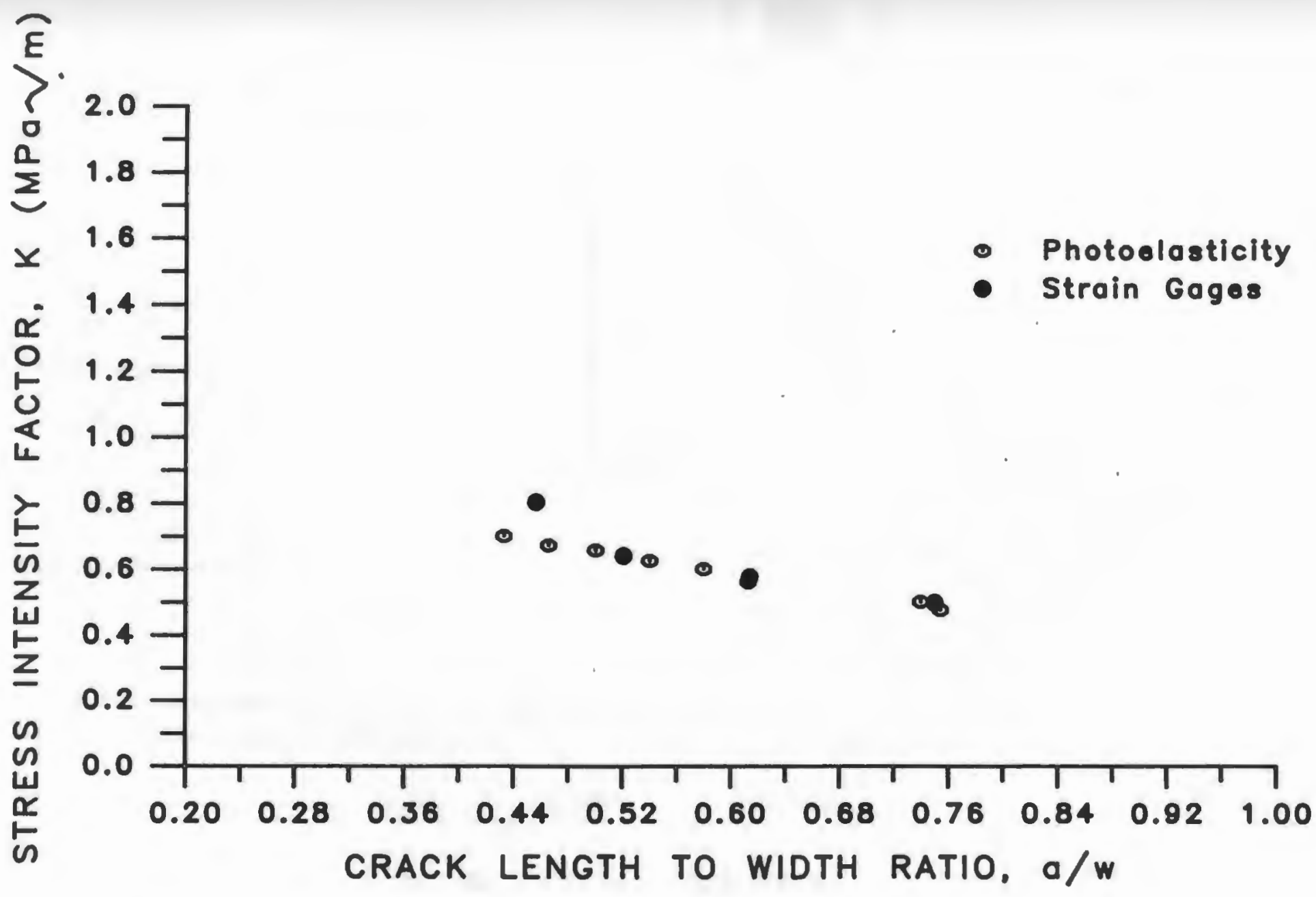

Fig.16 - Stress intensity factor $\mathrm{K}$ as a function of crack length to width ratio $\mathrm{a} / \mathrm{w}$ for the DCB model. 


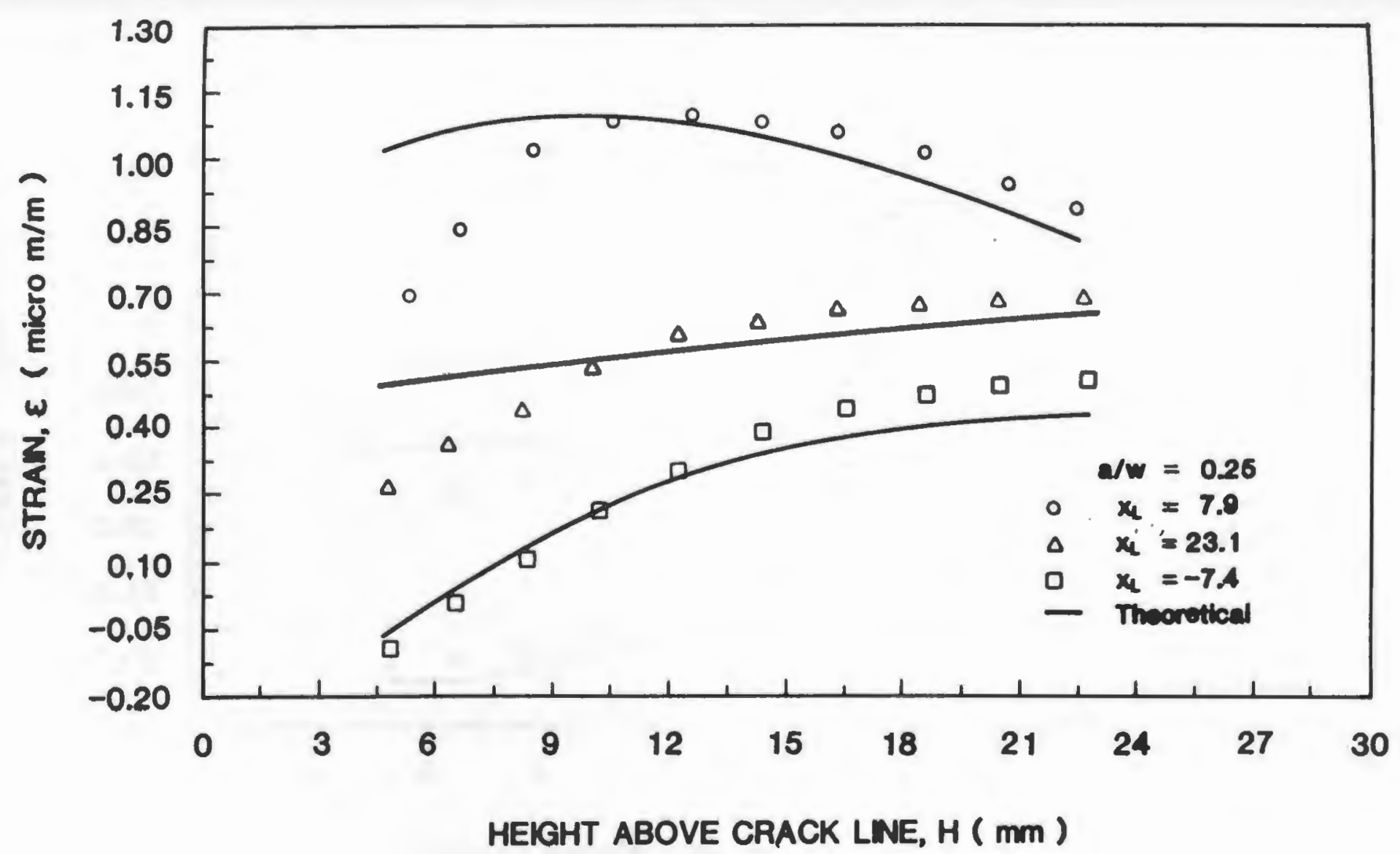

Fig. 18 axperimental and theoretical strain per pound load in vicinlty of the face grooves as a function of the height of the strain gage above the crack line, $H$, for crack length to widh ratio, $a / W=0.25$. 


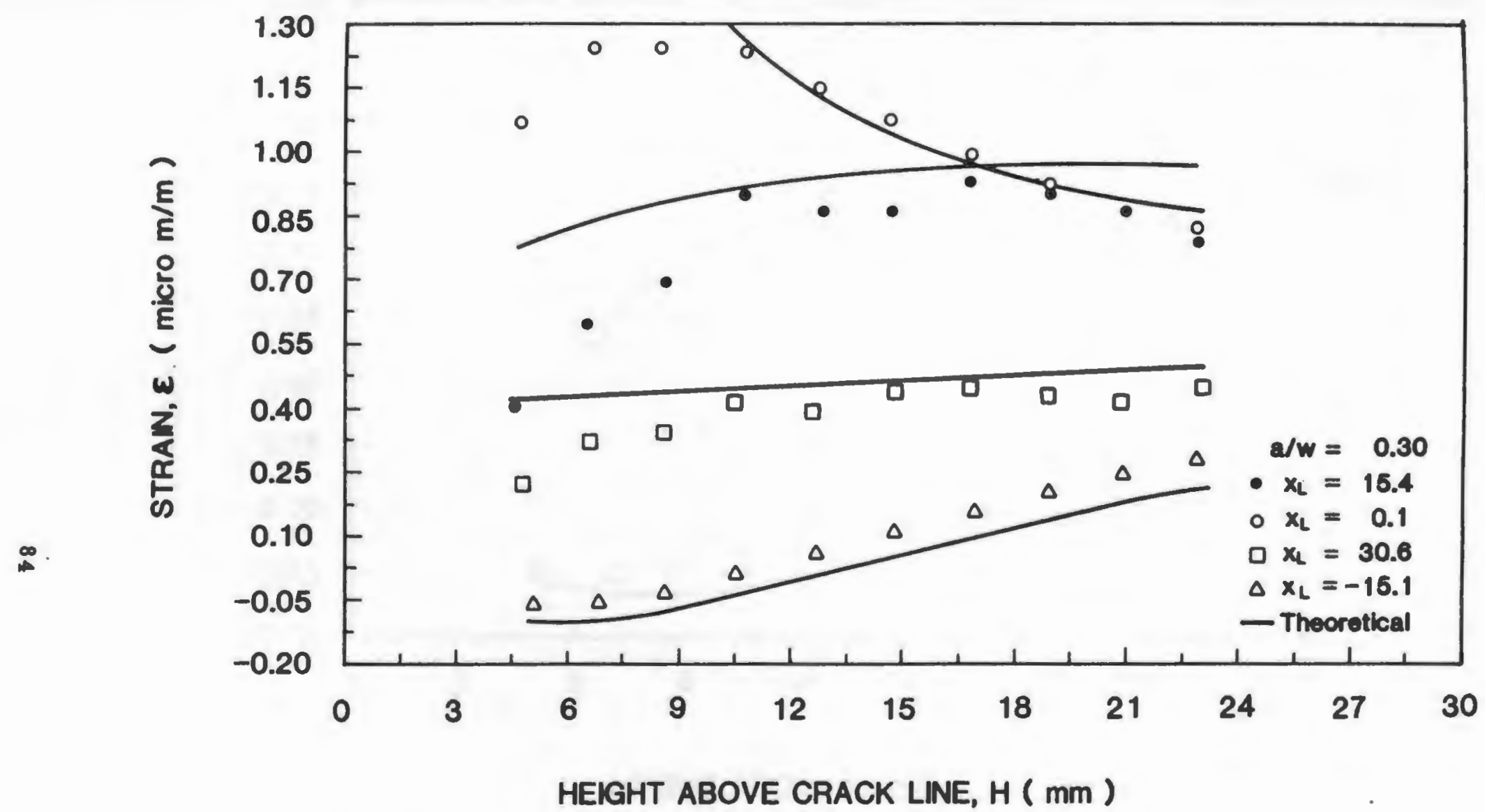

Fig. $18 \mathrm{~b}$ Experimental and theoretical strain per pound load in vicinity of the face grooves as a function of the height of the strain gage above the crack line, $H$, for crack length to width ratio, $a / W=0.30$. 


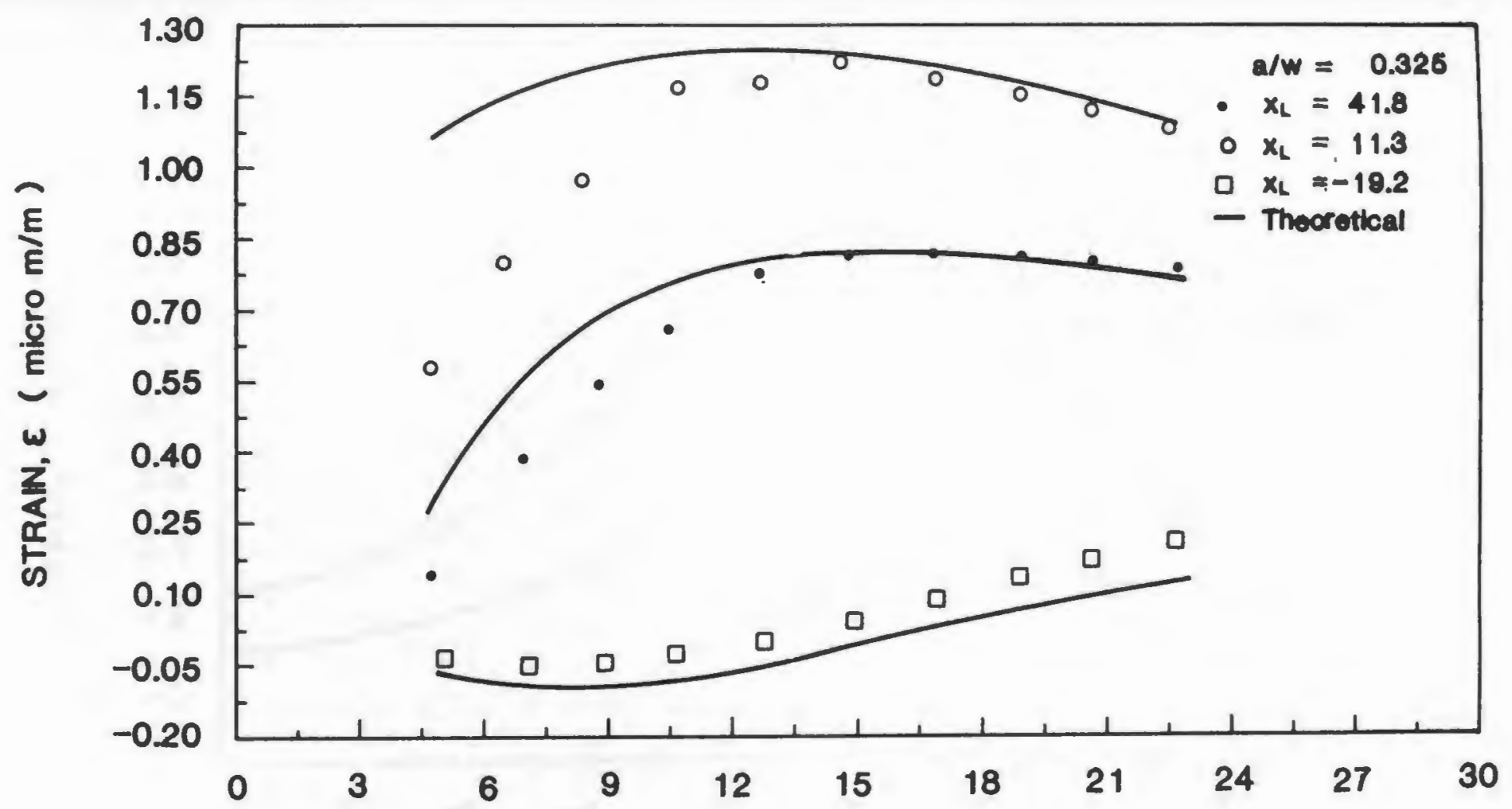

HEIGHT ABOVE CRACK LINE, H ( mm )

Fig. $18 \mathrm{C}$ Experimental and theoretical strain per pound load in vicinity of the face grooves as a function of the height of the strain gage above the crack line, $H$, for crack length to width ratio, $a / w=0.325$. 


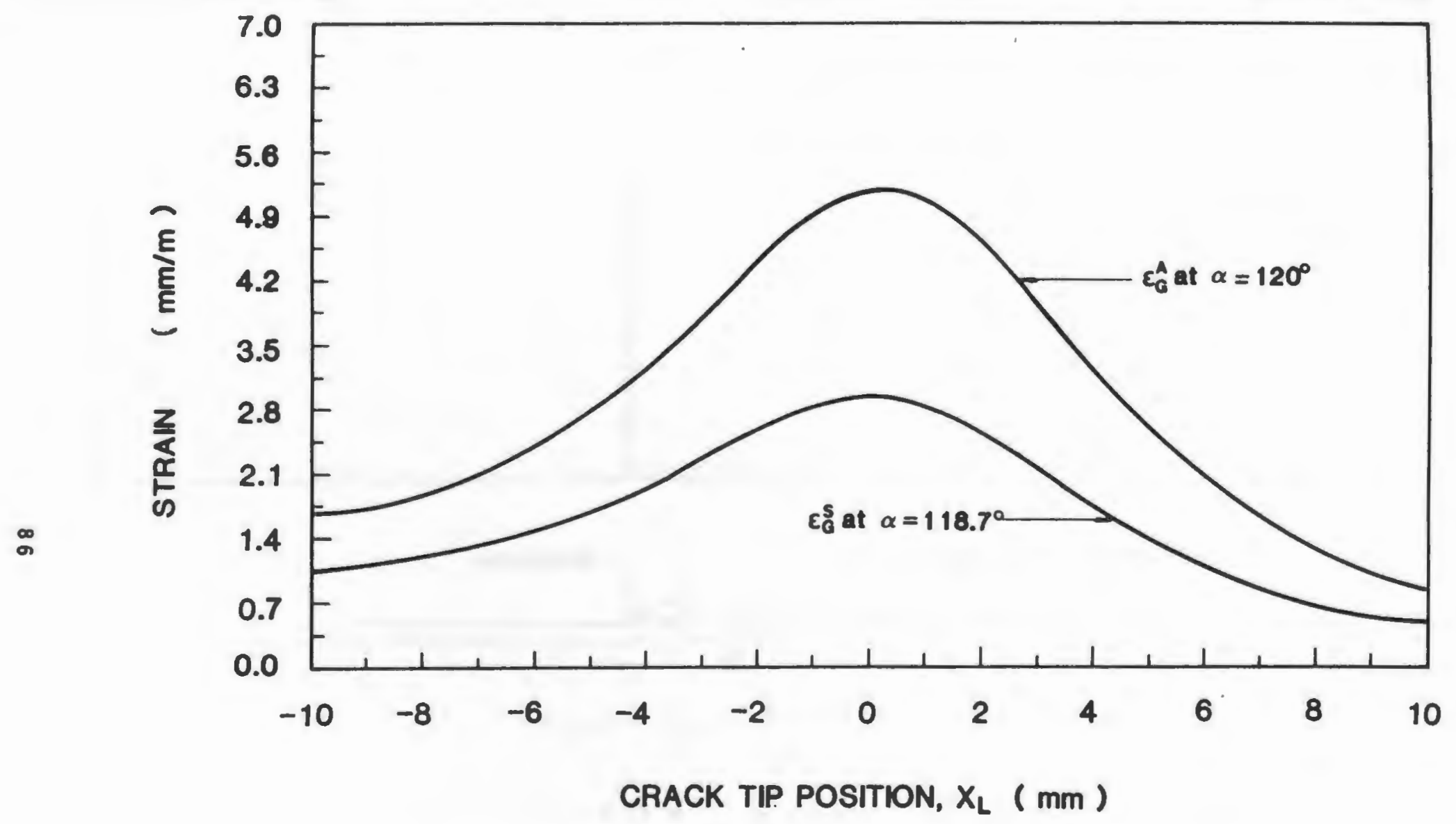

Fig. 19. Theoretical strain for steel, $\epsilon_{G} S$, and for aluminum, $\epsilon_{G^{A}}$, as a function of crack tip position, $\mathbf{x}_{L}$. 

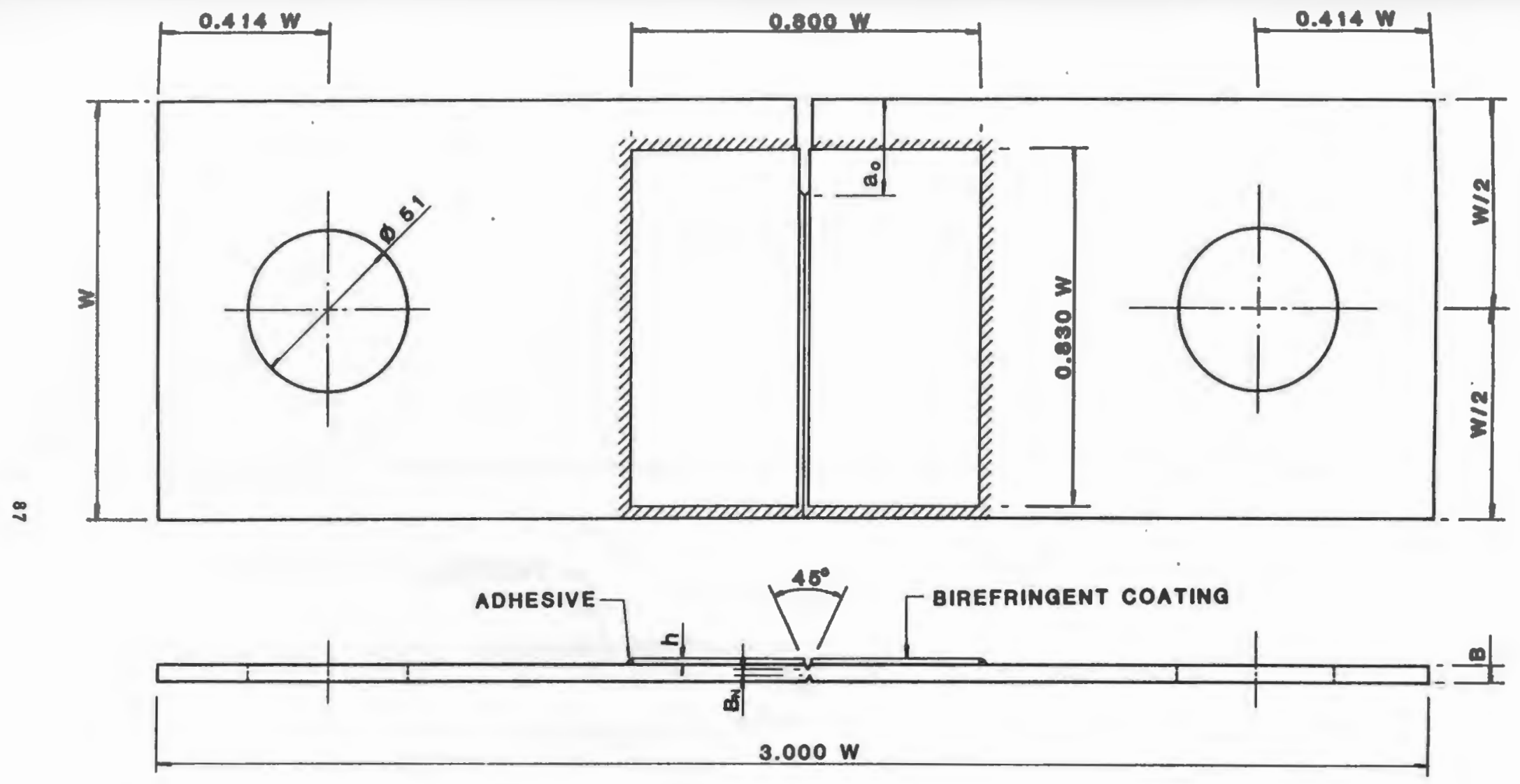

$w=162.0 \quad a_{0}=0.26 w \quad B=6.36 \quad B_{w} / B=0.76 . \quad h=2.032$

Fig. 20. Photoelastic Coating on SEN 4340 steel specimen. 

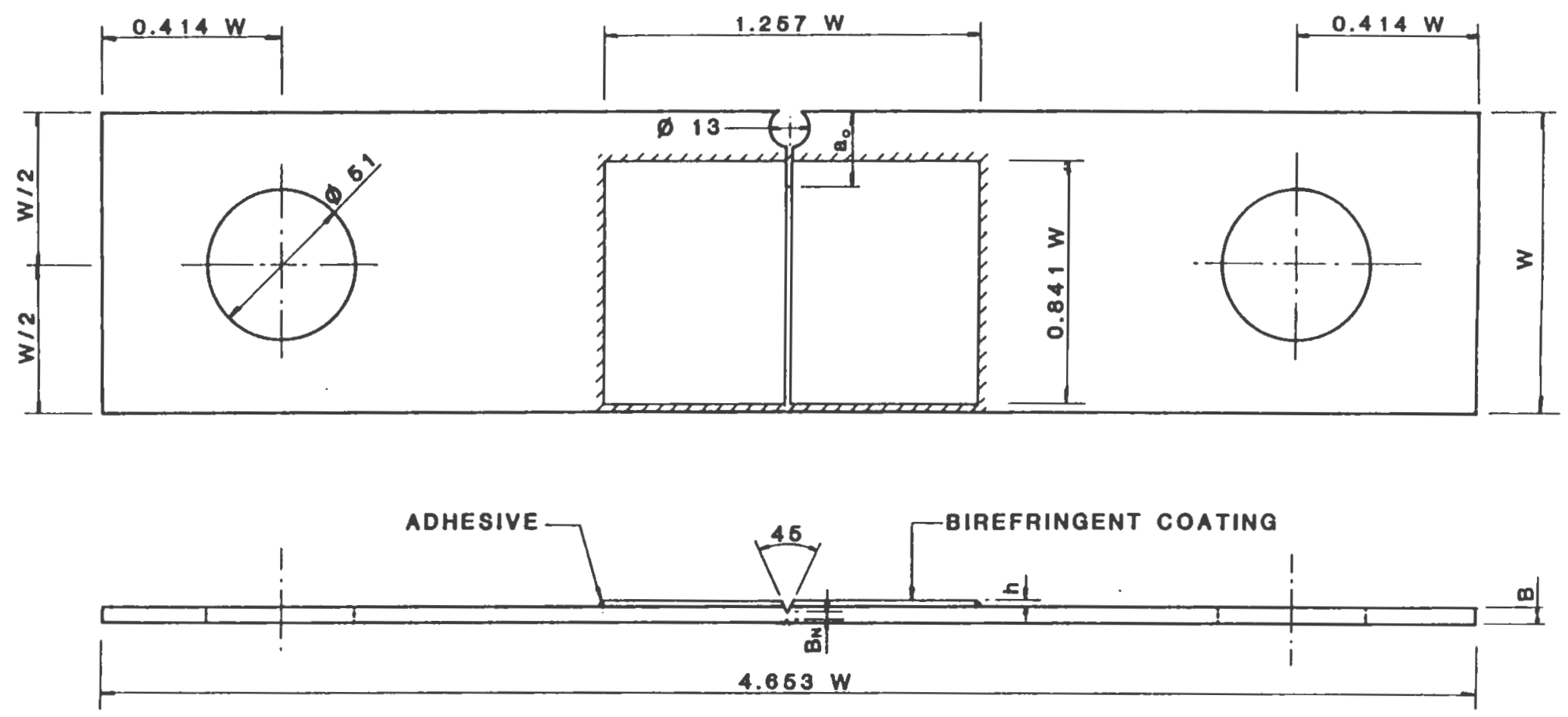

$W=101.0 \quad B=6.376 \quad B_{N} / B=0.76 \quad h=2.184 \quad a_{0}=22$

Fig.21. Photoelastic Coating on SEN 7075-T6 aluminum
specimen. 


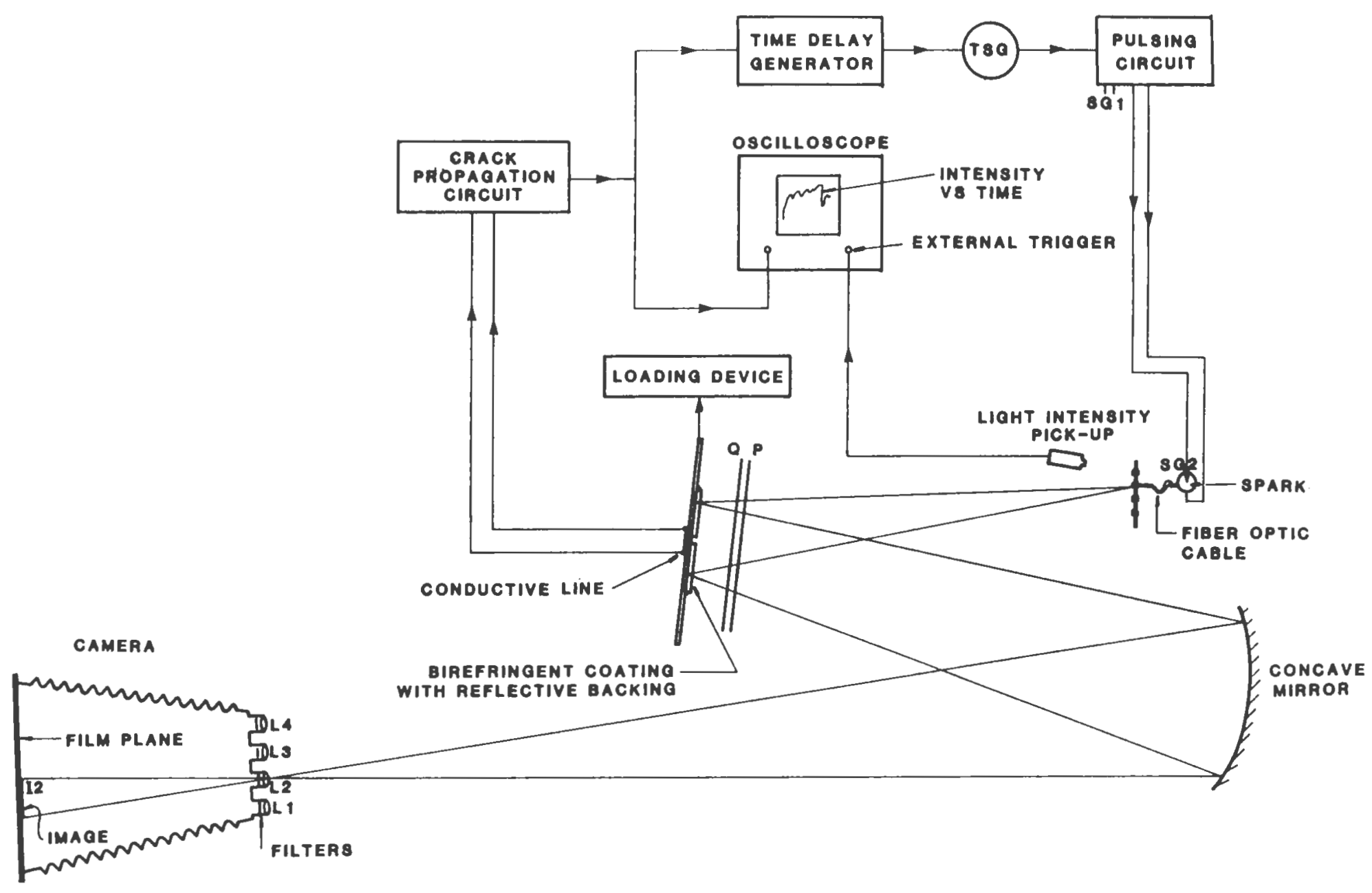

Fig. 22. Diagram showing optical arrangement and synchronization circuit. 
SPARK GAP

(WHITE LIOHT)

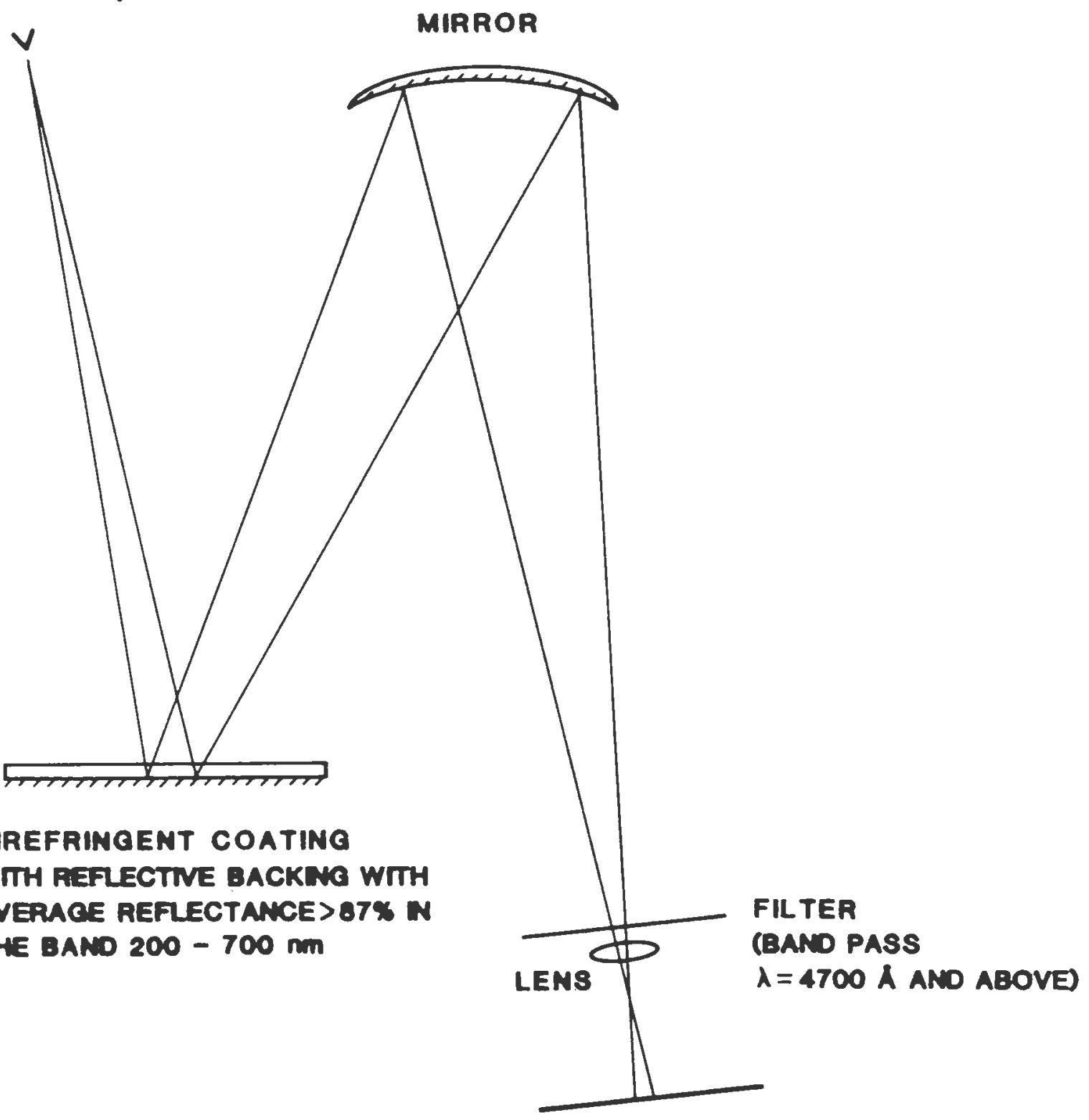

FILM

(SENSTTNE FOR LIOHT BAND $\lambda=3600$ to 5000 A)

Fig. 23. Diagram showing various stages of light filtering to obtain isochromatic fringes. 


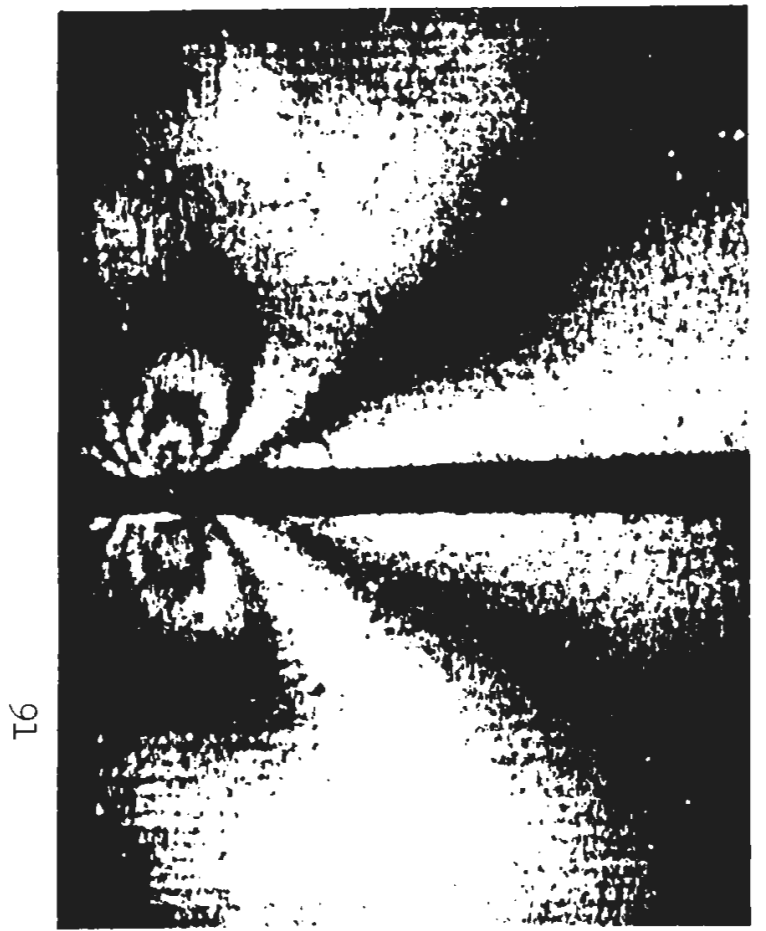

FRAME $8, a / W=0.40$

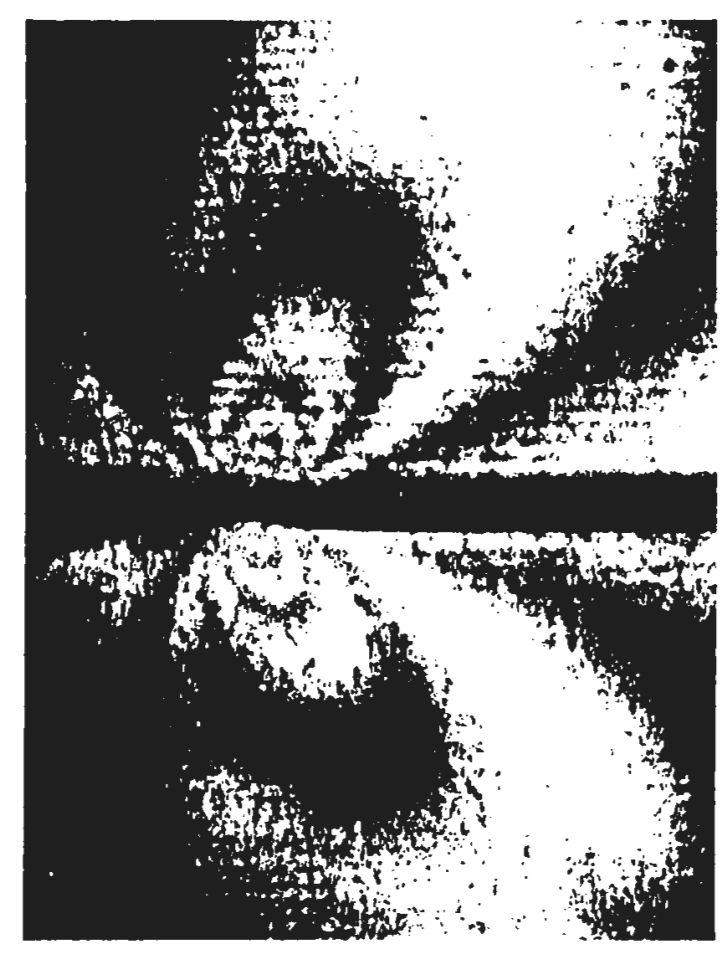

FRAME 15, a / W $=0.59$

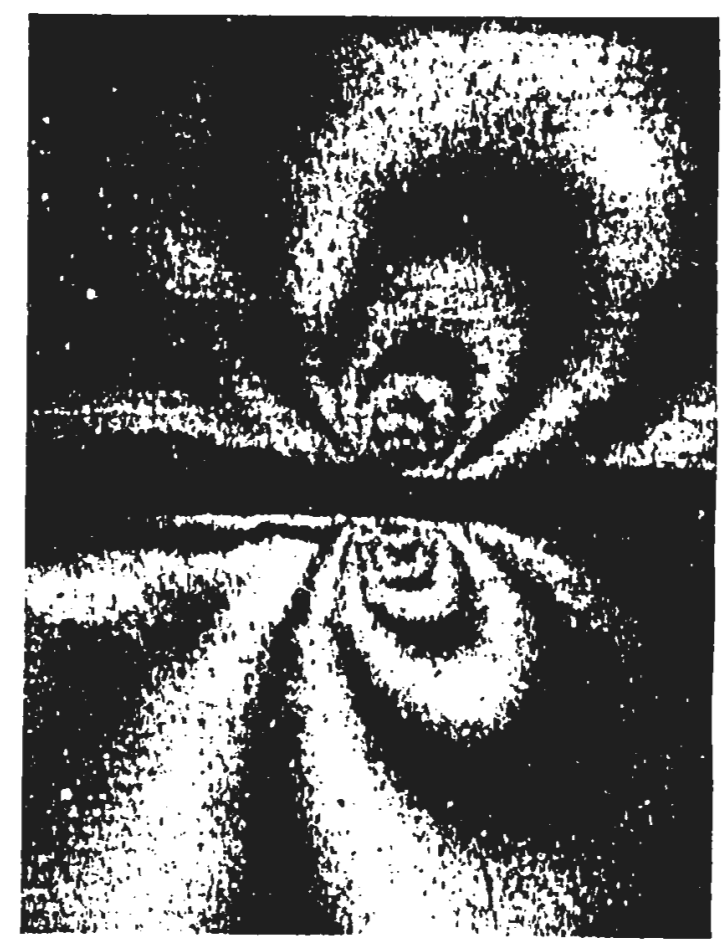

FRAME $20, a / W=0.77$

Fig. 24. Isochromatic fringe loops obtained with the photoelastic coatings on 4340 steel specimen. 


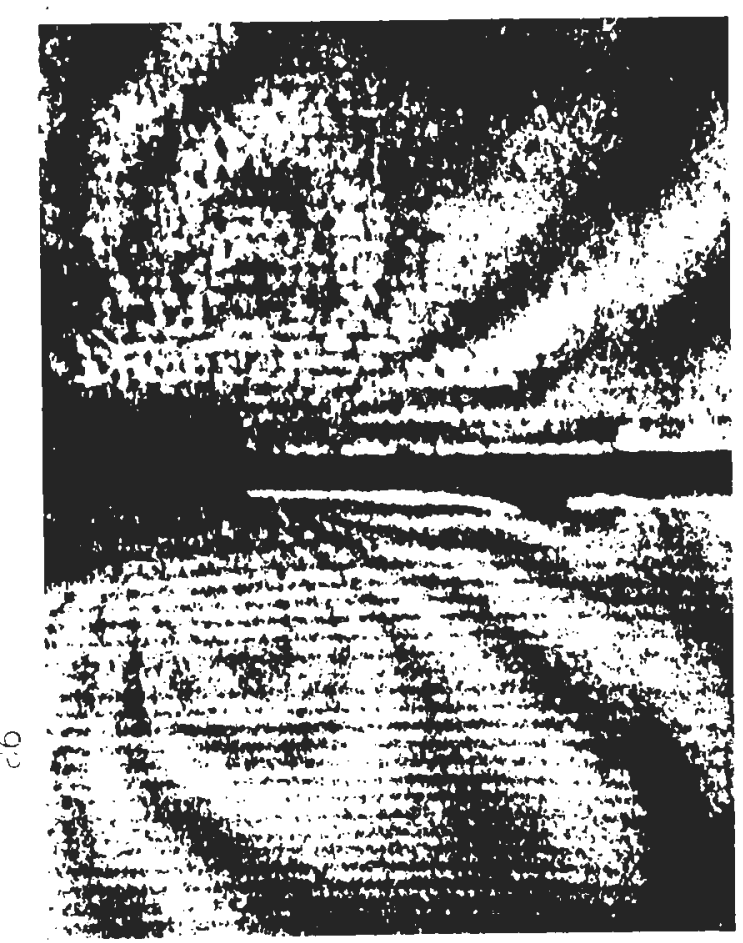

FRAME 2, a / W $=0.53$

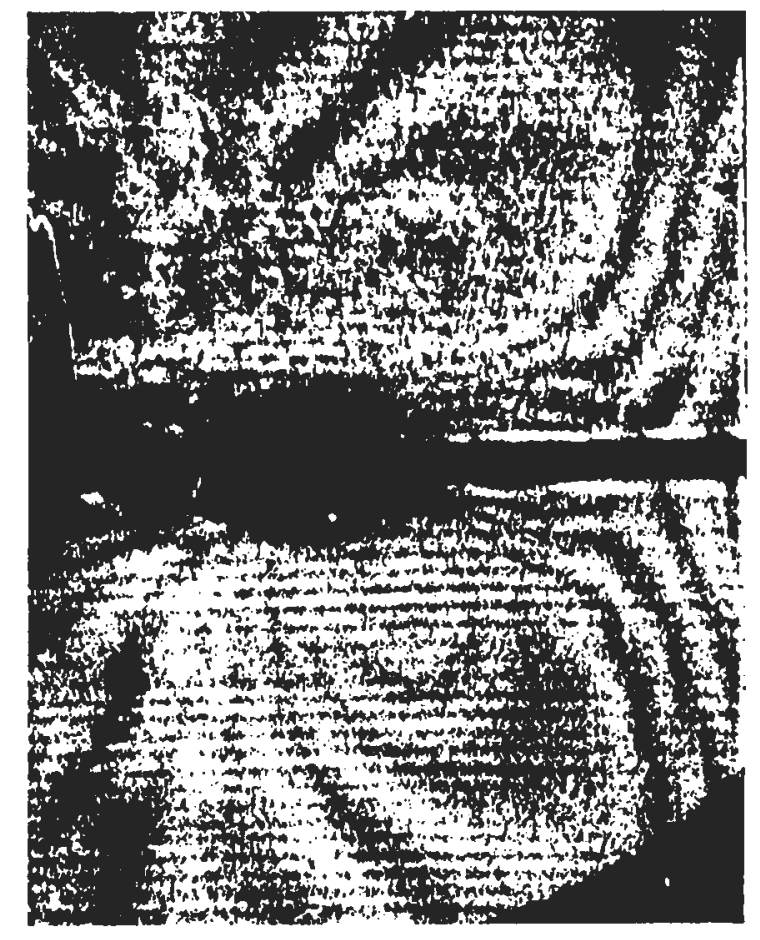

FRAME 5, a $/ W=0.66$

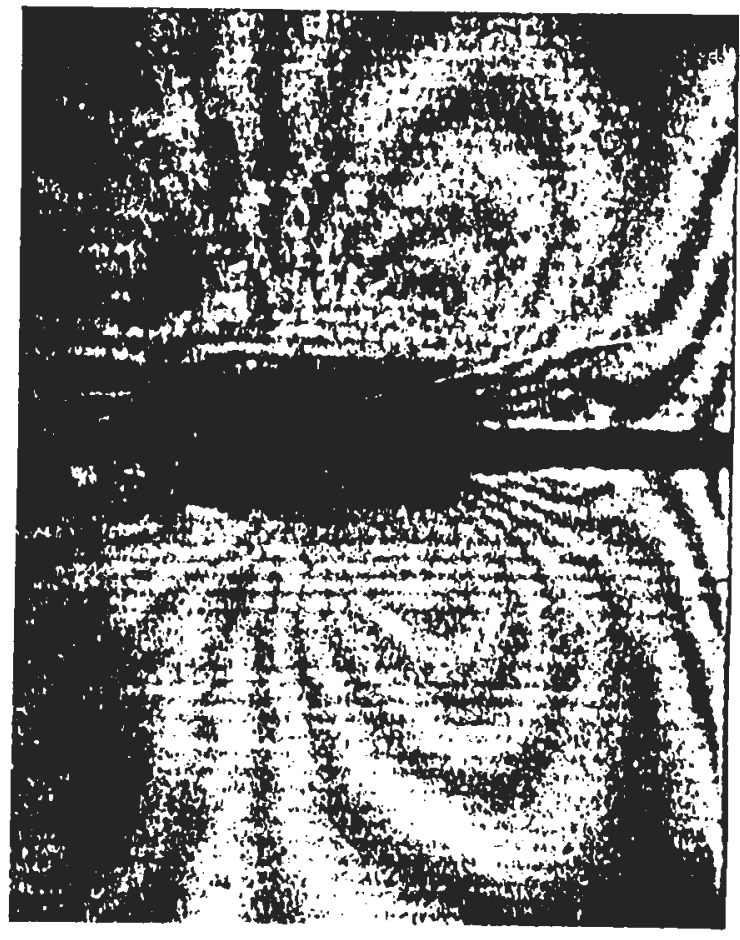

FRAME 6, a / W $=0.70$

Fig. 25. Isochromatic fringe loops obtained with the photoelastic coatings on 7075-T6 aluminum specimen. 


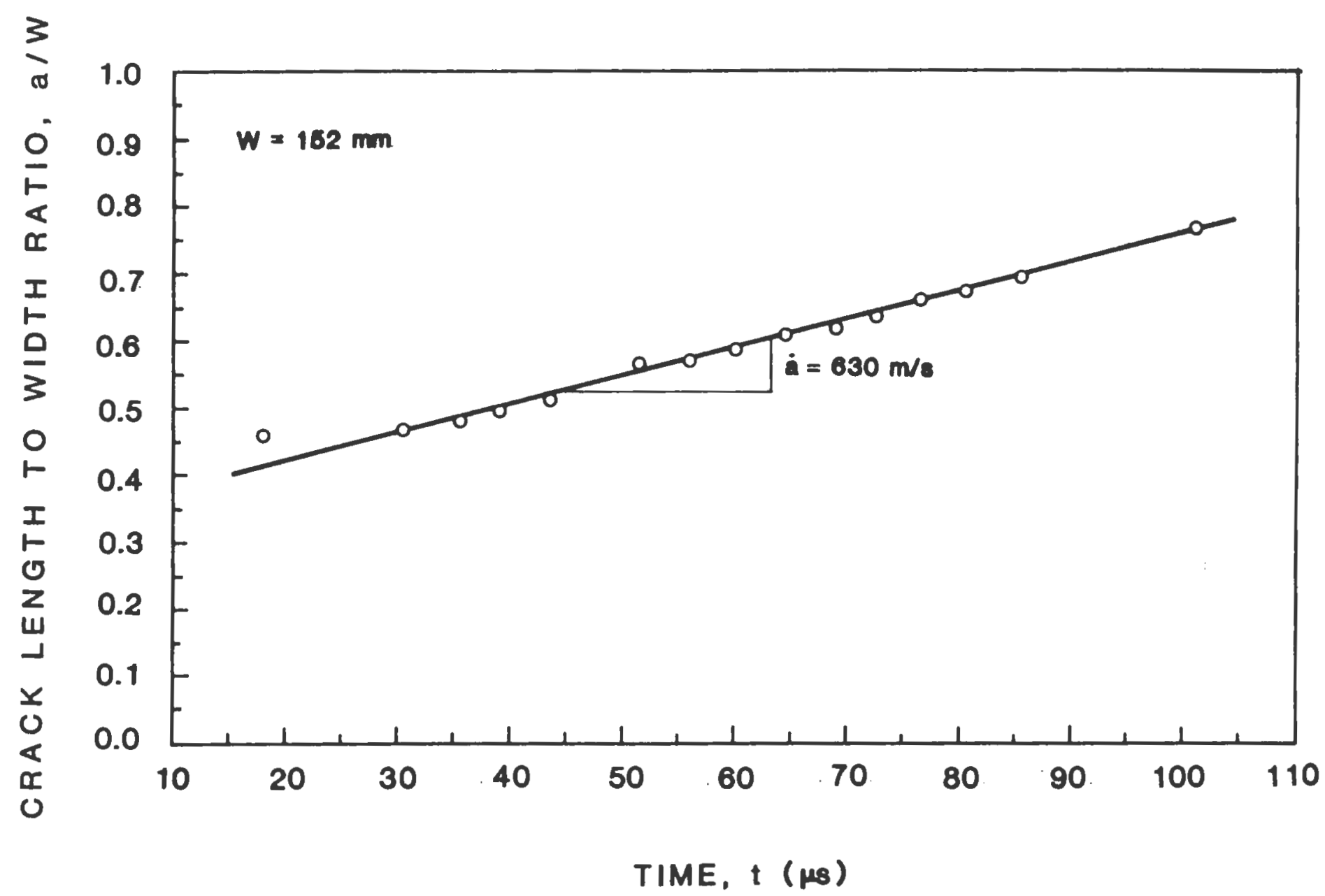

Fig. 26. Crack length, a/w, as a function of time, $t$, for 4340 steel specimen. 
TIME, $t$ ( $\mu s$ )

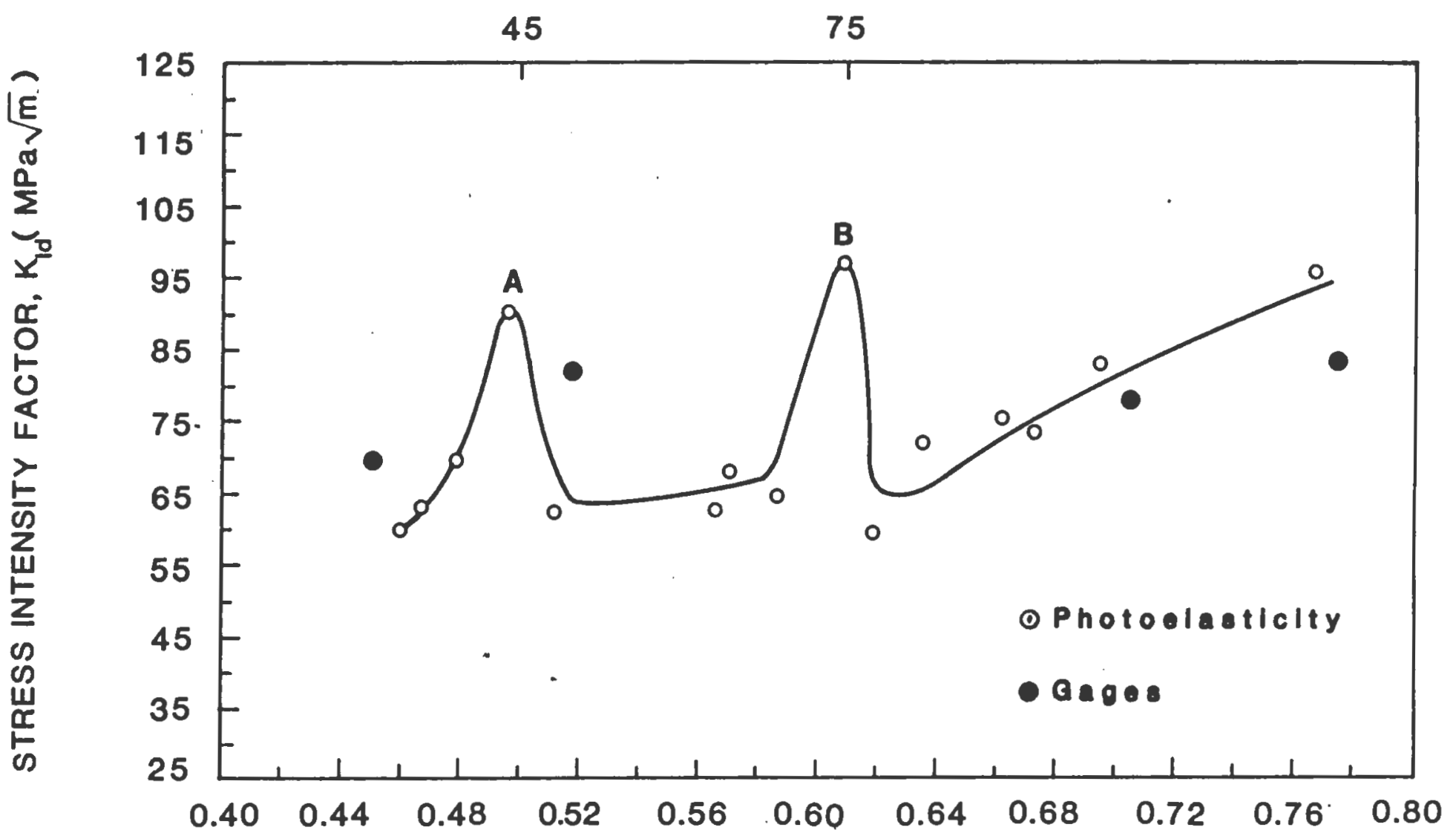

CRACK LENGTH TO WIDTH RATIO, a/W

Fig. 27. Stress intensity factor $\mathrm{F}_{\mathrm{Id}}$ as a function of crack length to width ratio, $a / w$ and $t i m e, t$ for 4340 steel specimen. 


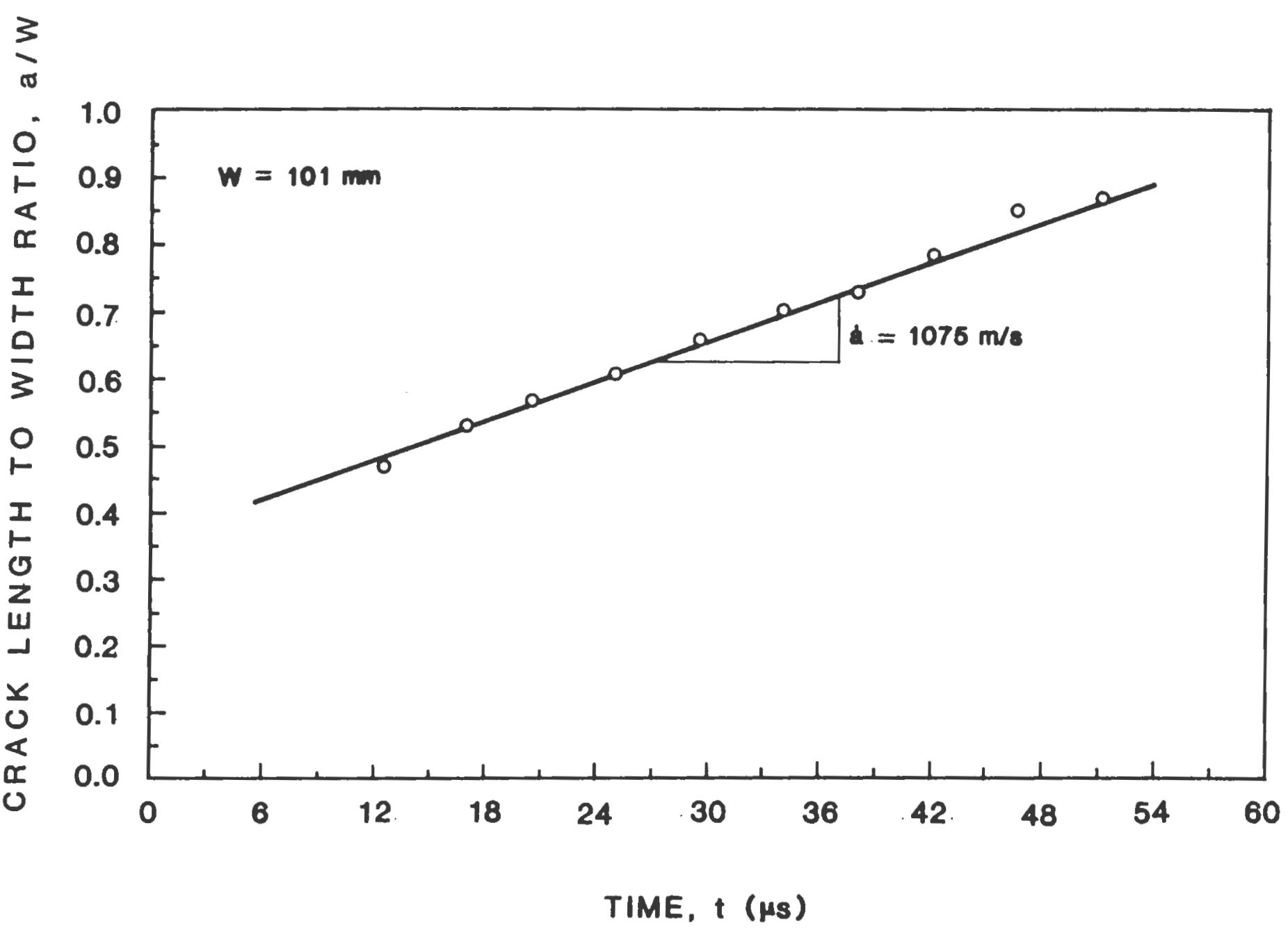

Fig. 28. Crack length, $a / w$, as a function of time, $t$, for 7075-T6 aluminum specimen. 
TIME, $t(\mu s)$

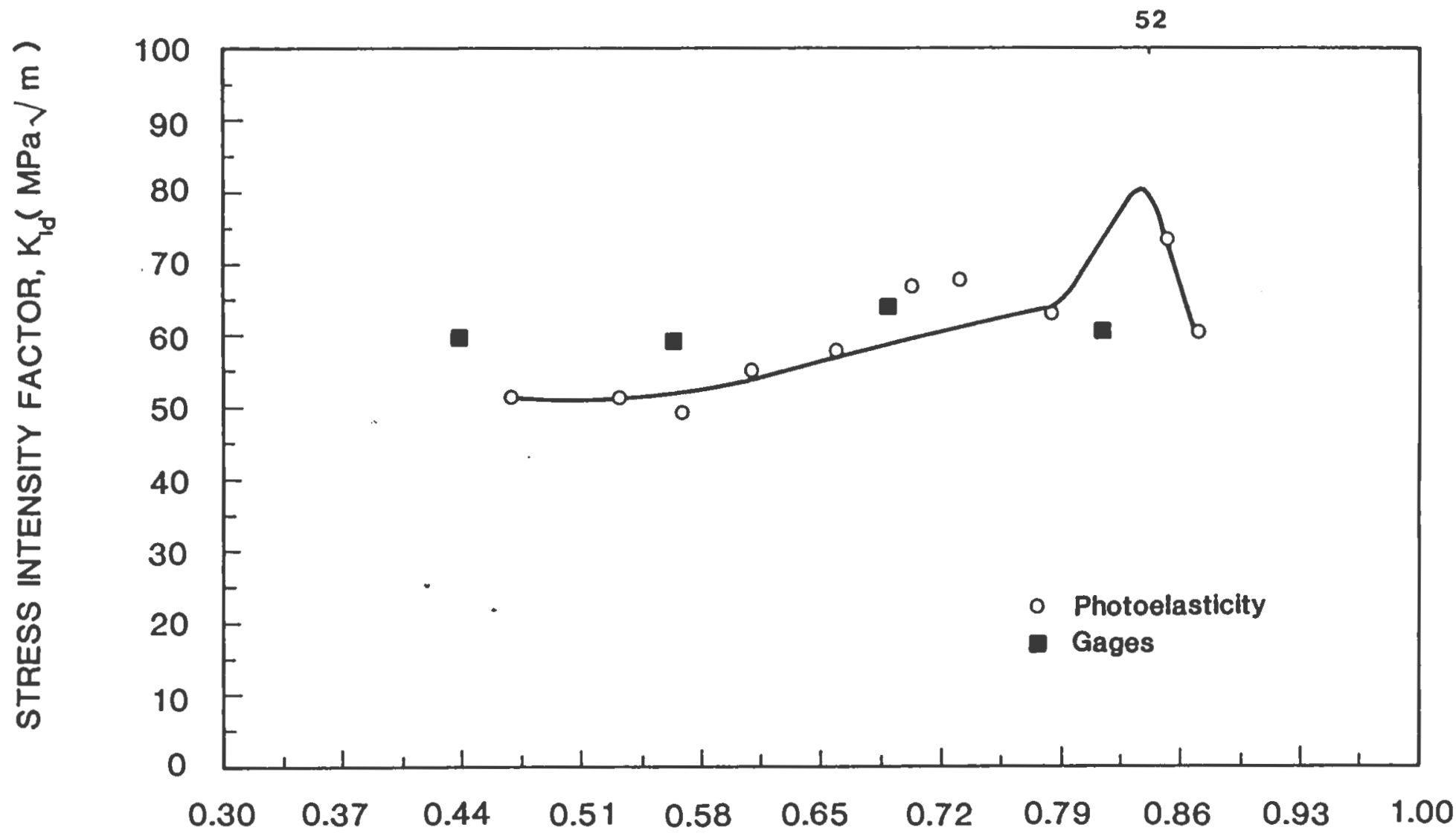

CRACK LENGTH TO WIDTH RATIO, a/w

Fig. 29. Stress intensity factor $\mathrm{K}_{\mathrm{Id}}$ as a function of crack length to width ratio, $a / w$ and $t$ ime, $t$ for 7075-T6 aluminum specimen. 

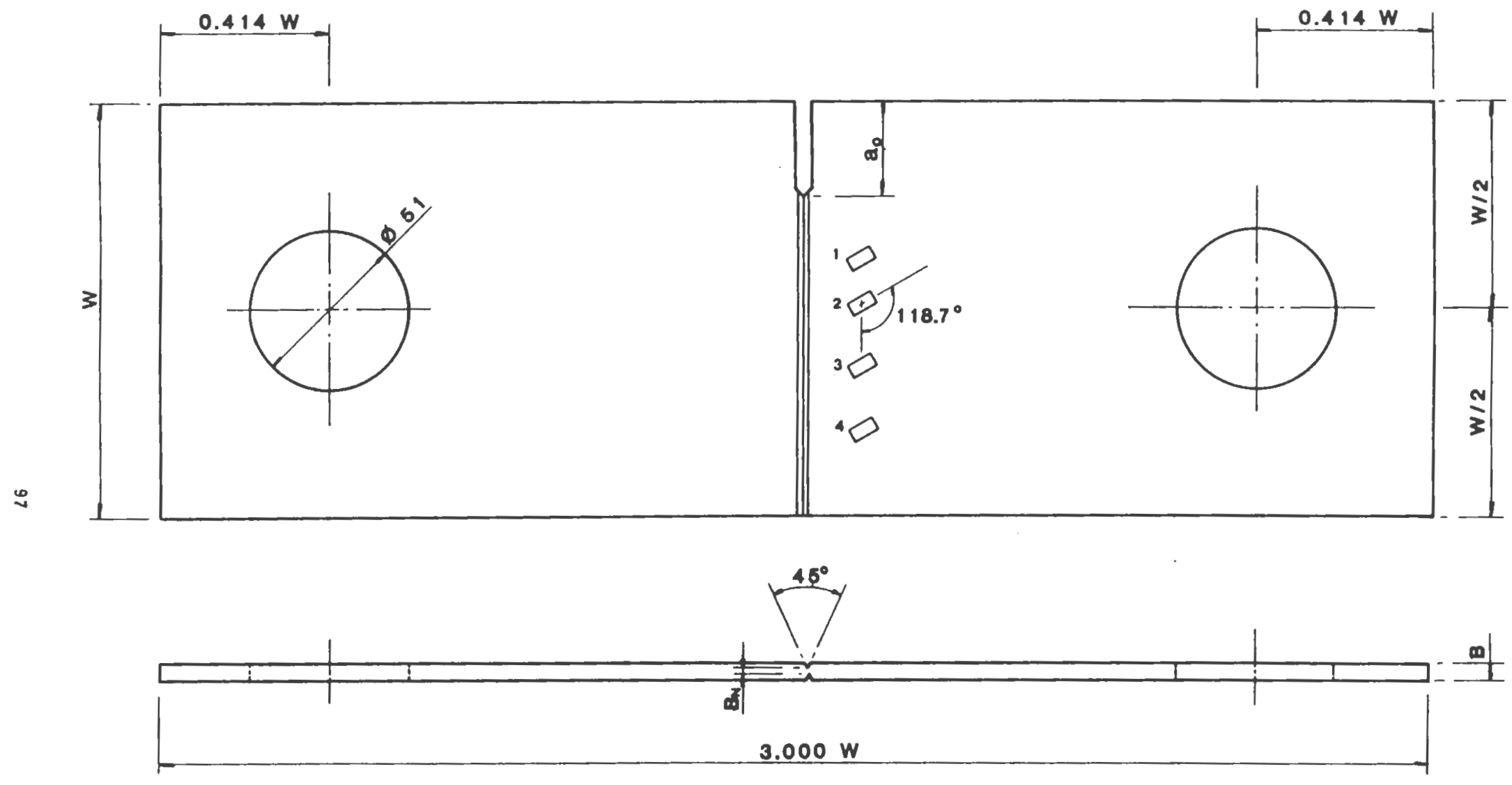

$w=162.0 \quad a_{0}=0.26 W \quad B=6.36 \quad a_{w} / B=0.76$

Fig. 30. Strain Gages on SEK 4340 steel specimen. 


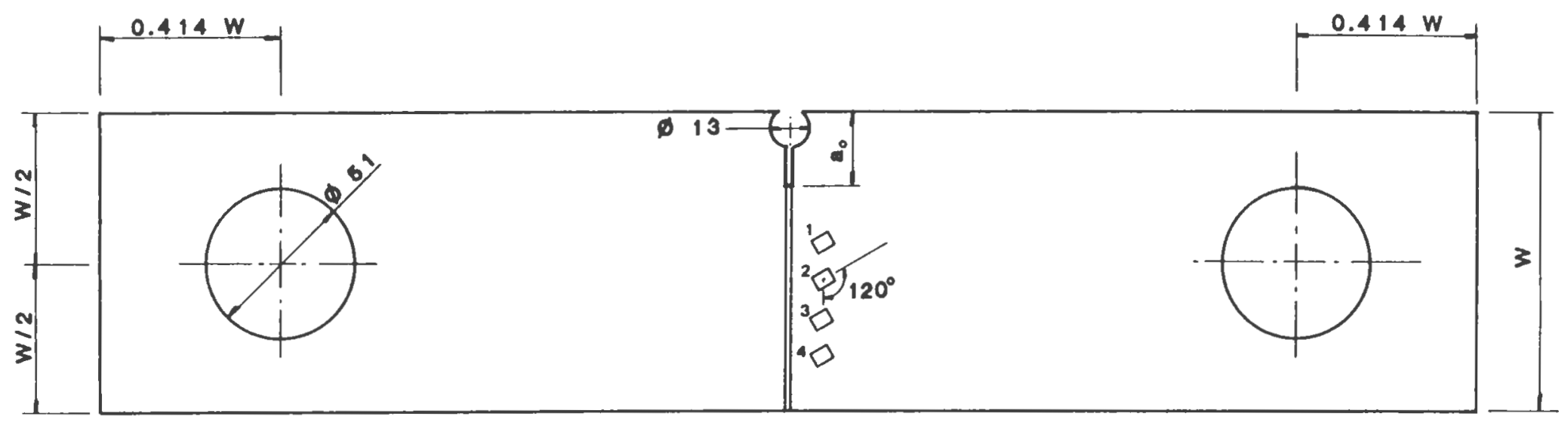

$\stackrel{\infty}{\infty}$

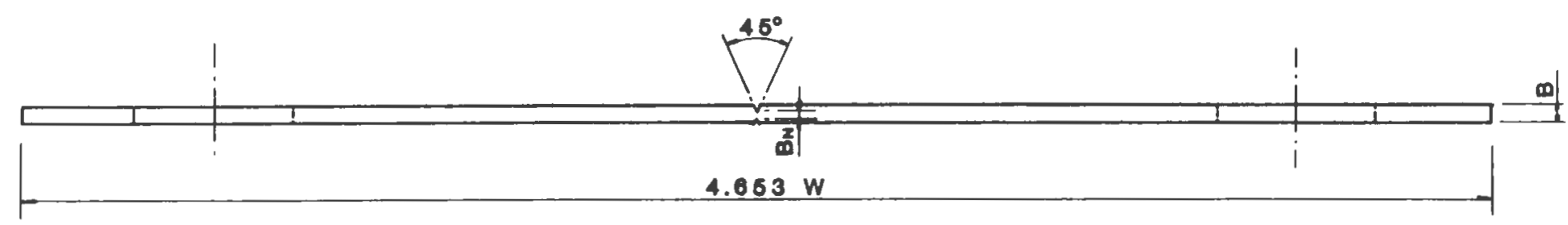

$$
W=101.0 \quad B=6.376 \quad B_{N} / B=0.76 \quad a_{0}=22
$$

Fig. 31. Strain Gages on SEM 7075-T6 aluminum specimen. 


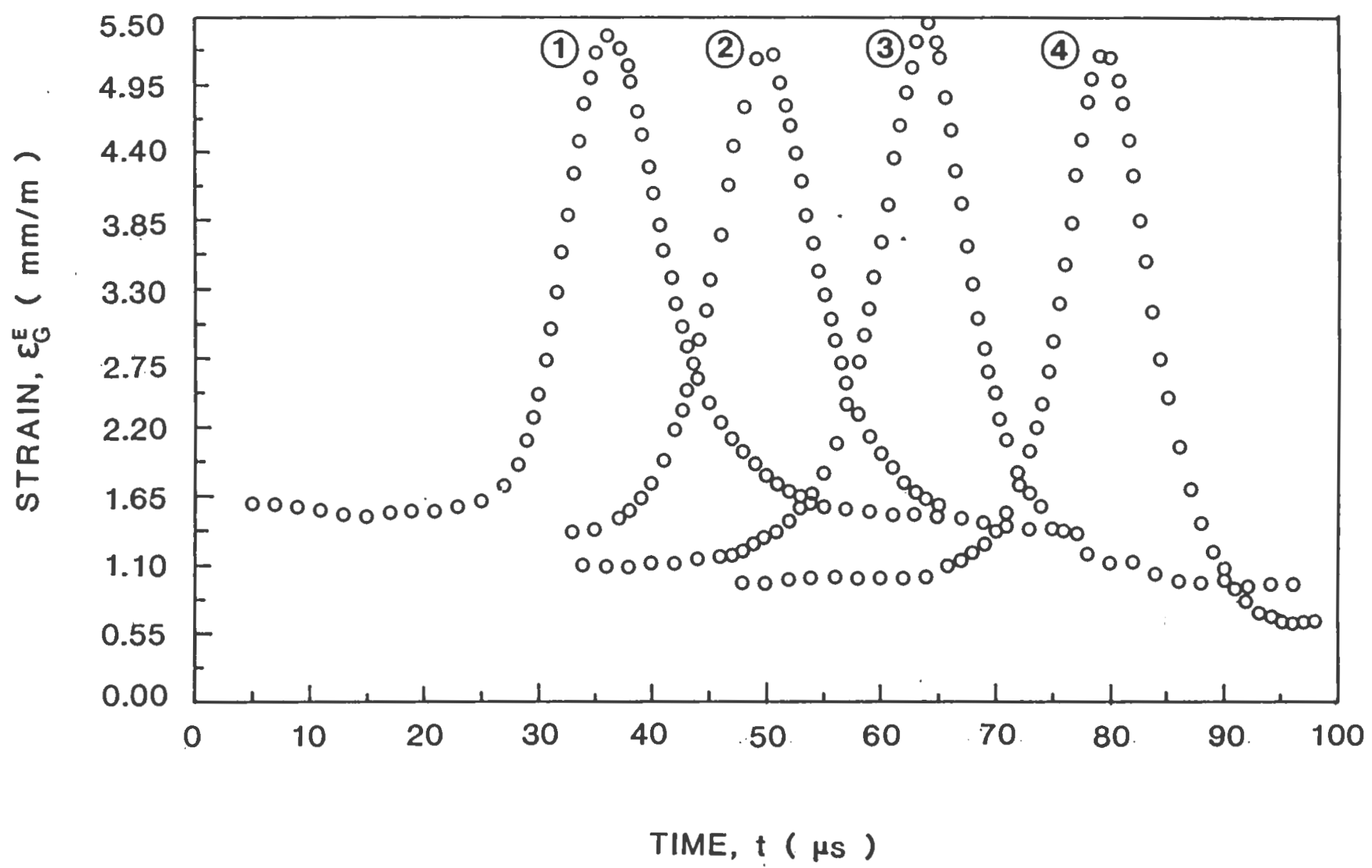

Fig. 32. Typical strain profiles obtained from the strain gages mounted on the aluminum specimen. 